\title{
Red, hot and scared? : inquiries into fear of blushing
}

Citation for published version (APA):

Mulkens, S. (2000). Red, hot and scared? : inquiries into fear of blushing. [Doctoral Thesis, Maastricht University]. Datawyse / Universitaire Pers Maastricht. https://doi.org/10.26481/dis.20001103sm

Document status and date:

Published: 01/01/2000

DOI:

10.26481/dis.20001103sm

Document Version:

Publisher's PDF, also known as Version of record

\section{Please check the document version of this publication:}

- A submitted manuscript is the version of the article upon submission and before peer-review. There can be important differences between the submitted version and the official published version of record.

People interested in the research are advised to contact the author for the final version of the publication, or visit the DOI to the publisher's website.

- The final author version and the galley proof are versions of the publication after peer review.

- The final published version features the final layout of the paper including the volume, issue and page numbers.

Link to publication

\footnotetext{
General rights rights.

- You may freely distribute the URL identifying the publication in the public portal. please follow below link for the End User Agreement:

www.umlib.nl/taverne-license

Take down policy

If you believe that this document breaches copyright please contact us at:

repository@maastrichtuniversity.nl

providing details and we will investigate your claim.
}

Copyright and moral rights for the publications made accessible in the public portal are retained by the authors and/or other copyright owners and it is a condition of accessing publications that users recognise and abide by the legal requirements associated with these

- Users may download and print one copy of any publication from the public portal for the purpose of private study or research.

- You may not further distribute the material or use it for any profit-making activity or commercial gain

If the publication is distributed under the terms of Article $25 \mathrm{fa}$ of the Dutch Copyright Act, indicated by the "Taverne" license above, 


\section{Red, Hot, and Scared?}

Inquiries into Fear of Blushing 


\section{Cover design}

Maya Schiffers

Druk

Datawyse / Universitaire Pers Maastricht

ISBN 90-9014146-4

(C) S. Mulkens, Maastricht 2000 


\section{Red, Hot, and Scared?}

\section{Inquiries into Fear of Blushing}

\section{PROEFSCHRIFT}

ter verkrijging van de graad van doctor

aan de Universiteit Maastricht,

op gezag van de Rector Magnificus,

Prof. Dr. A.C. Nieuwenhuijzen Kruseman, volgens het besluit van het College van Decanen,

in het openbaar te verdedigen op

vrijdag 3 november 2000 om 16.00 uur

door

Alexandra Anne Nicole Mulkens 


\section{Promotor:}

Prof. Dr. M.A. van den Hout

\section{Co-promotores:}

Dr. S.M. Bögels

Dr. P.J. de Jong

\section{Beoordelingscommissie:}

Prof. Dr. A.T.M. Jansen (voorzitter)

Dr. A. Arntz

Prof. Dr. M. Maes

Prof. Dr. H.T. van der Molen (Open Universiteit Nederland)

Dr. H.A. Scholing (Universiteit van Amsterdam)

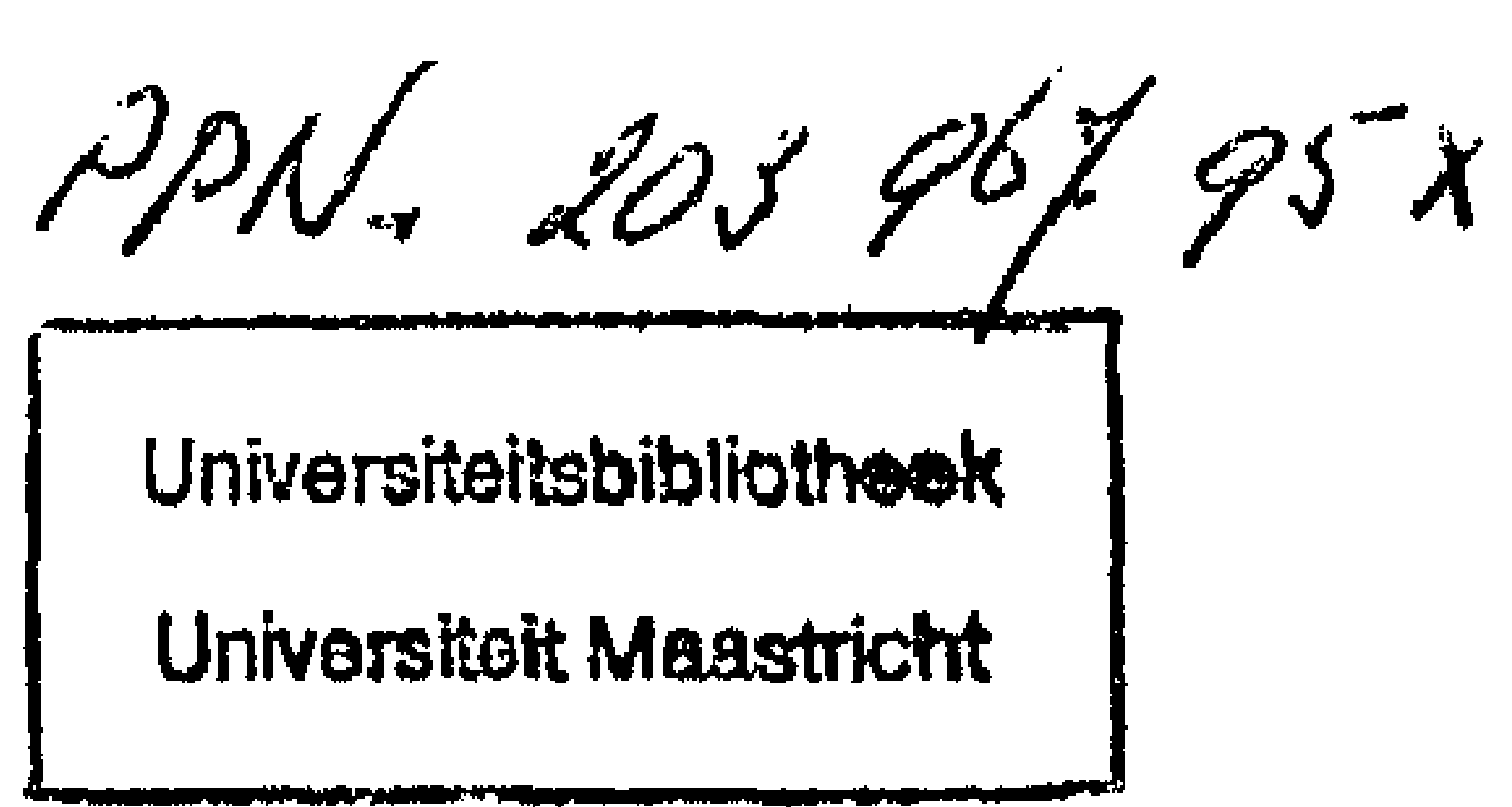




\section{Contents}

1 Blushing 9

1.1 Introduction 9

$\begin{array}{lr}1.2 \text { Physiology of blushing } & 10\end{array}$

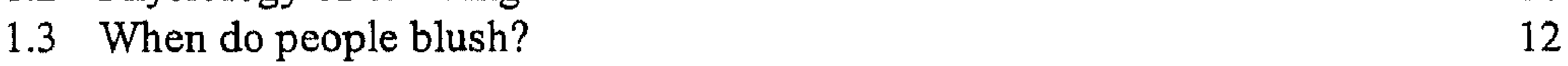

1.4 Why do people blush? 14

$2 \quad$ Fear of blushing and social phobia 19

2.1 Evolution of the concept fear of blushing: Brief historical consideration 19

2.2 Diagnostic criteria: From DSM-III to DSM-IV 21

2.3 Epidemiology of social phobia and fear of blushing 23

2.4 Comorbidity and consequences 25

2.5 Etiology and maintenance of fear of blushing 26

2.6 Therapeutical interventions 33

3 Outline of this thesis 41

4 Empirical studies 45

4.1 High blushing propensity: Fearful preoccupation or facial colouration? 47

4.2 Fear of blushing: Fearful preoccupation irrespective of facial colouration $\quad 59$

4.3 Learning history 69

4.4 How irrational are blushing phobics' beliefs about blushing? 79

4.5 Attentional focus and fear of blushing: A case study 89

4.6 Effects of Task Concentration Training versus Exposure in Vivo on fear 101 and physiology

\section{General discussion}

5.1 No evidence for differences in objective blushing 119

5.2 Learning experiences and fear of blushing 122

5.3 Normal individuals have predominantly negative beliefs about blushing $\quad 124$

5.4 Fear of blushing can be successfully treated with Task Concentration 125 Training

$\begin{array}{ll}\text { 5.5 The model revisited } & 126\end{array}$

$\begin{array}{ll}5.6 \text { Directions for future research } & 128\end{array}$ 
References

Summary

Samenvatting

Dankwoord

Curriculum Vitae 


\section{Blushing}

\subsection{Introduction}

'Blushing' refers to 'the spontaneous reddening or darkening of the face, the ears, the neck and the upper chest that occurs in response to perceived social scrutiny or evaluation' (Leary, Britt, Cutlip, \& Templeton, 1992). Blushing occurs when the small blood vessels of this so-called blush region of the body dilate, increasing the blood volume in this area (Leary et al., 1992). Blushing is usually accompanied by a feeling of warmth in the affected area (Edelmann, 1987; Leary \& Meadows, 1991), but it is also possible to blush without being aware of it (Leary et al., 1992). The red blotches that may appear on people's upper chest and neck, for example when they are speaking before an audience, are called 'creeping blush', a specific type of blushing (Leary et al., 1992).

Blushing is not a modern, Western phenomenon. It is already discussed in ancient, Oriental texts such as the Bible. Blushing, for example, occurred in the Old Testamental story about Jacob's sons and their brother Joseph who had been sold as a slave in Egypt, and later became a powerful man. Charles Brim (1936; in Crissey \& Parish, 1993), a student in biblical medicine, described the situation: "When Joseph saw his brother Benjamin after an absence of twenty-two years he became nervous and fidgety, vaymahar, and, trying to conceal his emotional reaction, he blushed, nichm 'roo rachmov - his emotions heated up his skin; he felt like crying y'vakesh livkoss. So he retired to an antechamber and sobbed there."

Karch (1971) notes that symbolic meanings are often attributed to blushing, but. that the nature of the symbolic meanings varies. In the Bible, so he says, blushing is related to shame. For example in Jeremiah VI, 15, "Nay, they were not at all ashamed, neither could they blush", or in Ezra IX, 6, "Oh, my God! I am ashamed, and blush to lift up my head to thee, my God." (Note, though, that the word 'blush' was translated from the original text, leaving unclear whether this was really implied; cf. Mitchell (1905), page 140). However, as Karch states, in Shakespeare's Romeo and Juliet, the symbolic seems to be not shame, but a complex of embarrassment and sexual arousal elements: "Thou know'st the mask of night is on my face/ Else would a maiden blush bepaint my cheek/ For what which thou hast heard me speak tonight."

Although blushing throughout the ages frequently appeared in various types of texts, little attention has been paid to its psychophysiological determinants since Darwin's observations in 1872 (Darwin, 1965/1872). Darwin described his findings in a chapter of his book The expression of emotions in man and animals, starting with the

\footnotetext{
'Chapter one is an adjusted and translated version of the Dutch article: Mulkens, S. (1995). Waarom blozen mensen eigenlijk? De Psycholoog, 30, 490-495. This article was awarded the 'Publicatieprijs voor aankomende auteurs $1995^{\prime}$ by the journal De Psycholoog.
} 
famous and frequently cited phrase "Blushing is the most peculiar and most human of all expressions". Darwin's observations concern the fact that young people blush more often than the elderly, but not during their infancy. It appeared to him that the mental capacities of young children had not yet been fully developed for them to be able to blush. He based this temporary judgment on the fact that the mentally handicapped seldom blush. The mental capacities, supposed to be needed in order to be able to blush, are later circumscribed as the awareness of the self as a social object (e.g. Wicklund, 1975; Buss, 1980).

Other observations of Darwin concerned, for instance, sex (women blush more than men), heredity (blushing runs in the family), populations (all races blush), location of the blush (the blush region), accompanying behaviours (averted eyes and body) and eliciting factors (praise, remarks about personal appearance, and ridicule). Furthermore, Darwin established that the blind also blush.

\subsection{Physiology of blushing}

Social blushing may be distinguished from reddening in general (flushing) in terms of the nature of the eliciting situation (Shearn, Bergman, Hill, Abel, \& Hinds, 1990). Both phenomena entail epithelial vasodilatation, but blushing is induced by social stimulation, whereas flushing is induced by physiological or pharmacological stimulation (Mulley, 1978; Wilkin, 1993). For instance, flushing can be caused by sexual arousal, physical exertion, menopausal 'hot flushes', particular dermatologic disorders, and exogenic chemicals (Mulley, 1978). Blushing is considered uniquely human because it is not seen in animals, although most vertebrates do possess the capillaries and associated cardiovascular apparatus with which to blush (Shearn et al., 1990). Darwin (1965/1872) said: "Monkeys redden with passion, but it would require an overwhelming amount of evidence to make us believe that any animal could blush."

In physiological respect, blushing is a temporary vasodilatation of the small blood vessels at the skin surface (Jawad, 1982). In most people, blushing is limited to the blush region (Wilkin, 1993; Shields, Mallory, \& Simon, 1990), although there are individual differences in the localisation of the blush: some people go red in the entire blush region, others get red cheeks only (Mulley, 1978). Wilkin (1988) suggested three possible explanations for the fact that blushing is limited to the blush region: (1) the facial cutaneous vasculature may be different from the vasculature elsewhere in the body; (2) the neural control of the facial cutaneous vasculature may be different from that of other - cutaneous sites; (3) the vascular system in the skin of the blush region is more visible.

To investigate the tenability of each of these possibilities, Wilkin (1988) studied two types of flushing challenges in normal volunteers: the ingestion of nicotinic acid and the ingestion of hot water. Nicotinic acid provokes flushing through a direct action of vasodilator prostaglandins on vascular smooth muscle. The flushing reaction provoked by oral thermal challenge is mediated via neural mechanisms. Vascular response to each challenge was assessed and the erythrocyte flux was monitored continuously at two sites 
during each challenge: the malar site and the volar forearm site. It appeared that the proportional increase of the erythrocyte flux was roughly the same in both sites, but that the redness was more visible in the face, which would indicate support for the third explanation. Wilkin concluded that the facial cutaneous vasculature has a higher capacitance for erythrocytes than other parts of the body, such as the forearm. Furthermore, there are more capillary loops per square millimetre in the face than at other sites, and the subpapillary plexus is nearer to the surface in the facial skin than in other areas of the body because the upper dermis is thinner (Ryan, 1973).

Taken together, Wilkin (1988) argued that, although there is evidence for a greater capacitance in the facial cutaneous vasculature, flushing is in part an optical phenomenon, because vessels that have a greater capacity to dilate lie in a more visible orientation just beneath the epidermis; therefore, increased capacity and greater visibility can account for the limited distribution of flushing (Wilkin, 1988).

Although the vasculature of the face may well differ from that of other parts of the body in ways that make flushing more apparent in the face than elsewhere, evidence based on flushing may not apply to blushing (Cutlip \& Leary, 1993). Specifically, research measuring the facial and the peripheral blood flow (e.g. in the forearm) during embarrassing situations, indicated that the peripheral temperature remained constant or decreased at the same time that facial temperature increased (e.g. Ginsburg \& O'Reilly, 1987; Templeton \& Leary, 1991). Consequently, there seems to be a specific response in the blush region as well, which supports the first explanation.

Another explanation for the fact that blushing is limited to the face was postulated by Mellander, Andersson, Afzelius, and Hellstrand (1982), who discovered that certain veins in the face possess $\alpha$ - and $\beta$-adrenergic receptors, and even have a tonus. Generally, only human arteries possess a tonus, causing a continuous tension. As this tonus decreases, the arteries are filled with more blood. In veins, however, there is no such tonus as a rule. In the smooth muscular tissue inside artery walls, $\alpha$ - and $\beta$-adrenergic receptors are situated; the $\alpha$-adrenergic receptors are sensitive for the contraction (vasoconstriction), the $\beta$-adrenergic receptors for the relaxation (vasodilatation) of the muscular tissue. As a general rule, these receptors are absent in veins. Thus, the results provided by Mellander et al. (1982) reasonably explain why vasodilatation does take place in facial tissue, but is impossible elsewhere in the body. Furthermore, they discovered that there are individual differences with respect to the ratio of $\alpha$ - and $\beta$ adrenergic receptors, which might explain why some people are more prone to blush than others. In addition, the facial veins' ability to relax decreases with age, which could help explain the curious phenomenon that the elderly blush less, or not at all anymore (Mellander et al., 1982).

Although the above explanations by Mellander et al. (1982) seem to explain the restricted distribution of blushing to some extent, Drummond (1997) found evidence against their hypothesis. In his study, the effect of adrenergic blockade on vascular responses in the forehead was assessed during three types of tasks (stressful mental arythmetic, singing, and moderate exercise) in frequent and infrequent blushers. Results indicated that, generally, the effects of $\alpha$ - and $\beta$-adrenergic blockade on vascular 
responses were similar in both groups, with one exception: during mental arythmetic, $\beta$-blockade prevented increases in blood flow in infrequent blushers but not in frequent blushers, indicating a minor participation of $\beta$-adrenoceptors in blushing. Bèta-adrenergic blockade partially inhibited vasodilatation during singing in both groups. Alpha blockade did not affect blushing but augmented vasodilatation during exercise. Drummond concluded that blushing propensity does not appear to be related to the density of $\alpha$ - or $\beta$-adrenoceptors in facial vessels, but may have another basis. Taken together, then, several explanations have been put forward to explain the limited distribution of blushing. However, since evidence has been found against each of these explanations, the issue remains largely unclear.

All in all, it seems justified to conclude that the limited distribution of blushing is due to a combination of factors. Firstly, the facial veins lie more at the surface than veins in other parts of the body, which facilitates the visibility of the facial blush response. Secondly, the composition of the vein system in the face seems to be different from that in the rest of the body, so that vasodilatation in the face may occur as a reaction to stimuli that cannot cause vasodilatation elsewhere in the body.

\subsection{When do people blush?}

The human face colours under a variety of circumstances and as a result of many different agents (Cutlip \& Leary, 1993). Darwin (1965/1872) linked blushing with shyness, shame and modesty, and stated that these emotions share the presence of selffocused attention, occurring as a result of the concern about other people's opinions about the blusher. Darwin's vision and the contemporary views with regard to blushing have in common that blushing is considered a purely social phenomenon, seldom occurring when one is alone. Still, Darwin did not explain how and why self-focused attention leads to an increased blood volume in the blush region (Leary \& Meadows, 1991).

Leary et al. (1992) distinguished four categories of situations in which people tend to blush: (1) threats to the public identity (e.g. being caught blundering; (2) praise and other forms of positive attention; (3) scrutiny; and (4) accusations of blushing. With respect to the first category, it can be stated that people are generally concerned about the way others might perceive and evaluate them. The situations most common to elicit a blush, therefore, are situations which form a direct threat to the public identity, such as breaking the rules in public, incompetence, or other shameful situations (Miller, 1986; Miller, 1992). For the sake of clarity, an emotional reaction evoked by a social predicament is labeled shame if one's infraction involves ethical or moral standards, or the failure to live up to central personal expectations or to those of significant others, and embarrassment if one violates social norms (Leary, 1983; Lindsay-Hartz, 1984). Recent research indeed empirically established that shame and embarrassment are distinct emotions, being reliably recognized as separate emotions, following their own particular antecedents and using their own specific displays (Keltner, 1995; Keltner \& Buswell, 
1996). Blushing might co-occur with both of these emotions, but is not a necessary or automatic response to shameful situations. People can be ashamed without displaying a blush, and, in turn, people can blush without feeling ashamed. Nevertheless, since the feeling of shame is one of the feelings that often accompany threats to the public identity, many authors consider blushing simply an expression of shame (Buss, 1980).

An explanation for the second category of blush-evoking stimuli (praise and other forms of positive attention) might be that receiving positive attention might at the same time induce worry about the impression one makes on other people. Another reason might be that, when one is praised, there is the fear of not being able to perform equally well in the future (Baumeister, Hamilton, \& Tice, 1985). Thirdly, one may be concerned that the observers think that the hope for receiving a compliment was the most important motivation for their behaviour or performance, which in turn may result in such a blush (De Jong, 1998a).

The third category of situations in which people tend to blush, concerns the fact that some people blush as soon as they are being stared at (Leary \& Meadows, 1991). Two processes might account for this phenomenon. Firstly, being stared at might give rise to the possibility that someone's behaviour is not approved of, and, as such, might form a threat to the public identity. Secondly, blushing might be a relatively automatic reaction to staring eyes, independent of potential social evaluation. Templeton and Leary (1991) carried out an experiment using a one-way screen, in order to investigate which interpretation best explained the relationship between blushing and staring. Test individuals were placed on one side of the screen, an audience of 6-9 individuals on the other, the latter being instructed to stare at the test individual during the experiment. Cheek and finger temperatures were assessed during the experiment. Two variables were manipulated: test individuals were either told that the audience could see them clearly, or that the audience could only see their silhouette. Furthermore, in one condition the audience wore dark sunglasses, through which their eyes were not visible. It appeared that blushing could only be elicited in the case that the test individual was able to see the (staring) eyes of the audience. This finding is in line with the idea that blushing is a relatively automatic reaction to staring eyes, irrespective of fear of negative evaluation.

Finally, the fourth category (being accused of blushing) indicates that blushing can be easily elicited, simply by telling people that they are blushing. Edelmann (1987, 1990a) suggested that people use their own expressive behaviours (like blushing) as clues to interpret their internal state. As a consequence, the conviction that one is blushing might lead to the thought that one is embarrassed, causing the actual blush. Although this interpretation seems reasonable, Leary and his colleagues (1992) suggest that other explanations are possible: (1) Being accused of blushing might, in itself, serve as a threat to the public identity, (2) In such situations, people are being stared at, making this a specific form of blushing in response to staring. 


\subsection{Why do people blush?}

Several theories have been developed to explain people's blushing behaviour. There are, for instance, several psychoanalytic explications, interpersonal or social attention theories, and accounts with respect to the remedial functions of blushing. A proper explanatory model should be able to predict the conditions under which people blush. In the following, some major theoretical considerations will be outlined, and critically judged with respect to the above rule.

\section{Psychoanalytic views}

Psychoanalytically oriented theorists have concentrated primarily on fear of blushing or 'erythrophobia'. This fear of blushing was in many instances considered neurotic (Karch, 1971). Although psychoanalytic explanations with regard to blushing are diverse, they have in common that the blush is considered an indirect manifestation of repressed libidinous (or aggressive) excitement.

One explanation departs from the idea that blushing is a symptom of conversion, a physical manifestation of an earlier emotional problem (Benedek, 1925). A related view considers blushing an expression of suppressed genital excitement, moving towards the head because of fear of castration (Feldman, 1962). According to Feldman, this is an alarming theme in men as well as in women: in men because of the castration fear, in women because they are not men. Furthermore, he notes that blushing is at least partly an exhibitionistic act in which genital excitement is shown. Thus, Feldman interprets blushing as a conversion symptom (Karch, 1971). Yet, there are also authors who interpret blushing in a different way. For example, Schnenk (1967) interprets blushing as a response to subconscious hostility. According to Karch (1971), a recent addition to psychoanalytic literature on blushing is that of Jule Miller (1965), who recognizes the wide disparity of opinion regarding the factors which have been considered important in blushing, and tries to correlate the structural factors and the relationship of the instinctual, characterological and social factors. Miller regards blushing as "...primarily a vasomotor response to affect discharge, and shame as the affect involved. In this view, the direct conversion of the cathexis of unconscious fantasies into blushing is considered a secondary phenomenon. Blushing is regarded as the physiological end result of a more or less intense 'affective spell', as defined by Fenichel" (1945, p. 20). Miller postulates that the blusher's sense of shame is derived from tension between the ego and the ego ideal, and that ego defensiveness and superego immaturity both increase the tendency to feel shame and, thus, the tendency to blush.

It should be noted that the extensiveness of theoretical considerations is in contrast with the absence of controlled research. At most, there is a small number of case studies concerning atypical forms of erythrophobia (e.g. Friedländer, 1900; Bechterew, 1897a, 1897b). Furthermore, it seems difficult to redefine all situations in which people tend to blush (see 1.3) to sexual situations (Edelmann, 1987; Karch, 1971). All in all, the psychoanalytic views do not provide a particularly convincing framework to explain people's blushing behaviour. 


\section{Blushing resulting from self-focused attention}

Poets and novelists viewed and still view blushing as a sign of shyness, timidity, and shame (Halberstadt \& Green, 1993). According to Halberstadt and Green (1993), the common, essential element in these affective states is self-attention, resulting from either the fear of being ridiculed or the fear of being praised. When one is ridiculed or praised, one is likely to become aware of oneself as a social object, in the midst of other people. In other words, one views oneself as if looking through the eyes of other people, and that is, in this account, considered the principal reason why people blush. Darwin (1965/1872) already noted that young children do not blush. As already mentioned, it seemed to him that the mental capacities of young children, apparently, were not yet fully developed so as to be able to blush. He based his temporary judgement on the observation that the mentally handicapped seldom blushed. The mental capacities that Darwin associated with the ability to blush, were later circumscribed as the developing awareness of the own self identity, and hence the ability to become publicly self-aware (Buss, 1980). Buss, Iscoe, and Buss (1979) investigated through questionnaire research among parents at what age their children started to show signs of embarrassment, like blushing. Around the age of five, 60 per cent of the children appeared to show such signs, leading the authors to conclude that children form a social identity around the age of five.

Likewise, Darwin (1965/1872), in one of his first careful considerations about the subject, described blushing as a consequence of the concern about other people's judgements. Darwin noted that not the reflecting about our appearance causes the blush, but the wondering what others think about us. According to Darwin, blushing is only the byproduct of self-focused attention and serves no particular function. In his words: "Whenever we believe that others are depreciating or even considering our personal appearance, our attention is vividly directed to the visible parts of our bodies; and of all such parts we are most sensitive about our faces.... Therefore, assuming for the moment that the capillary vessels can be acted on by close attention, those of the face will have become eminently susceptible" (p. 337). "Those who believe in design, will find it difficult to account for shyness being the most frequent and efficient of all the causes of blushing, as it makes the blusher to suffer and the beholder uncomfortable, without being of the least service to either of them. They will also find it difficult to account for Negroes and other dark-coloured races blushing, in whom a change of colour in the skin is scarcely or not at all visible" (p.336).

Many psychologists share the opinions of the literators and Darwin, that shame or fear of negative evaluation precedes blushing, but not all of them agree with Darwin's opinion of blushing being only a byproduct of social attention. For example Buss (1980) considers blushing as ".....the hallmark of embarrassment" (p.129), ".....a signal to others that the blusher is embarrassed..." (p.133), although he cannot answer why it would be necessary for others to know. Edelmann (1987) states that "blushing certainly serves to communicate our embarrassment to others, and as embarrassment is a state that generally we wish to hide, blushing can hardly help us in our efforts at concealment" (p.71). Frijda (1985) also suggests that blushing is an interactive signal, since an overt blusher attracts 
the attention of others. Furthermore, Leary et al. (1992) suggest that blushing is not so much the effect of social attention per se, but rather the effect of undesired social attention. People often receive undesired social attention after having behaved in an improper way (threat to the public identity), which might elucidate the connection between shame and blushing. However, according to this viewpoint, any undesired social attention - even when directed at positive aspects of the person or his behaviour - could, via self-focused attention, result in blushing. The latter explains, according to Cutlip and Leary (1993), why people also blush when receiving compliments, when being accused of blushing, or simply when being stared at.

According to Leary et al. (1992), undesired social attention is a necessary and sufficient condition for the occurrence of a blush reaction. Nevertheless, many people do not blush when receiving undesired social attention. That is, in many instants, people may receive undesired social attention which does not produce blushing (e.g. when a famous television personality is chased by paparazzi, the undesired social attention may result in anger rather than in blushing, cf. De Jong, 1998a). Thus, undesired social attention does not seem to be a sufficient condition for producing blushing. Furthermore, it seems difficult to postulate that undesired social attention is a necessary condition to elicit blushing. That is, defining the term 'undesired' produces difficulties since any situation in which social attention is received while one is blushing may be judged as undesired, simply because of the blushing. In other words, social attention during blushing is per definition a form of undesired social attention. In the absence of independent criteria for defining undesirable social attention, it would be difficult to formulate uncontaminated predictions (De Jong, 1998b).

All in all, it may be concluded that, although the social attention approach focuses mainly on the antecedents ('causes') of blushing, it lacks specificity to predict the circumstances under which people tend to blush. Furthermore, it does not explain why people blush. Yet, in line with this approach, blushing occurs seldom when one is alone, implying that the presence of other people is an important clue.

\section{Blushing as a remedial gesture}

Burgess wrote as early as in 1839 that blushing serves to show to others that one recognizes to have violated certain rules. Several contemporary authors put forward that the appearance of a blush under such circumstances serves a remedial function (e.g. Castelfranchi \& Poggi, 1990; Leary \& Meadows, 1991). More specifically, Castelfranchi and Poggi (1990) argue that people are likely to blush when they violate certain social/ moral rules, but only if the actor and the observer(s) share the values relevant for the violation (or if the actor believes that this is the case). By blushing, the actor shows that he acknowledges to have transgressed the rules, that he shares those rules, and that he is sensitive to the observer's judgements about the violation of the rules. In other words, showing their feelings of embarrassment or shame openly, implies that people respect the rules which they seem to have violated, and that they ask the persons present in an implicit way to not judge their behaviour of that specific moment as a reflection of their personality or character (Goffman, 1955). 
Jmmunicating embarrassment or shame apparently serves appeasement functions. ppeasement is the process by which individuals placate or pacify others in situations potential or actual conflict (Keltner, Young, \& Buswell, 1997). For example, hibition of aggression and avoidance of being ejected from the group are aimed at by e transgressor. Interestingly, embarrassment or shame may be expressed in several nverbal ways, other than blushing. That is, embarrassed people are recognized by the llowing pattern of nonverbal behaviour: gaze aversion, smile control, smile, a second nile control, and then head movements downwards and face touching. Shame is immunicated by gaze and head movement downwards (Keltner et al., 1997). However, ushing cannot be controlled voluntarily, and is, as such, the most reliable sign that one sincere in one's remedial gesture.

The face-saving function of submissive types of behaviour was tested in several speriments. For example, Semin and Manstead (1982) had test individuals watch a deo in which a shopping customer accidentally knocks over a pile of toilet paper hereafter he becomes either openly embarrassed or remains undisturbed. Test dividuals judged the embarrassed person more favourably than the undisturbed one. lthough this study did not specifically address blushing, it indicates that showing nbarrassment helps to repair the damaged image. A more recent study by Keltner et al. 997) shows that embarrassed persons are more likely to elicit the emotion 'amusement' observers than ashamed persons do, whereas ashamed persons elicit noticeably higher vels of sympathy than do embarrassed persons. It is suggested that amusement leads oservers to make light of transgressions (Cupach \& Metts, 1990) and increases social sproach (Keltner \& Bonanno, 1997), whereas sympathy motivates altruistic helping shaviour (Eisenberg et al., 1989) and would be appropriate for rectifying the more rrious transgressions associated with shame (Keltner et al., 1997).

To investigate the relative remedial effects of blushing under such circumstances, e Jong (1999) included another category in a comparable experiment. In a series of udies, test individuals were provided with written scripts involving incidents that took lace in shops. Following the mishap, the actor left while displaying a blush, or while isplaying shame by nonverbal behaviour other than blushing, or without overt signs of lame or embarrassment. Test individuals judged the actor on several aspects. The results learly indicated that blushing attenuated the negative evaluation of the incident, lowered ie responsibility of the actor, and sustained the actor's trustworthiness. The remedial ffects of blushing were stronger than those of behaving in an embarrassed manner rithout blushing. Perhaps the involuntary nature of blushing - it cannot be simulated or xpressed deliberately - contributed to this effect. As such, the blush response may nderline the actor's sincerity in displaying shame and embarrassment.

Taken together, the available empirical evidence sustains the idea that blushing rrves to maintain people's trustworthiness and attenuate possible negative consequences f social/moral transgressions. It appears that the remedial effects of blushing are at least artly due to the communicated message, namely that the actor is sensitive to the other's Idgement and at the same time of his/ her sincere commitment to the group's social rules De Jong, 1999; exp. 2/3). This also explains why not all people blush under the same 
circumstances. That is, blushing propensity might vary conform the actors' sensitivity to the other's judgements and their willingness to commit themselves to the group's social values. Blushing whilst receiving compliments can be explained in a similar vein. The person receiving a compliment might be ashamed, thinking that the compliment is undeserved. By blushing, he communicates the idea that achievements should be rewarded according to their merits (cf. De Jong, 1998a). Or the blusher might fear that bystanders think that he was chasing for a compliment. By blushing, the actor indicates that he shares the idea of the group that compliments should be given unprompted. The process of blushing is started off whenever the actor knows or believes to know that the observers think that this rule is being violated.

The functional view of blushing does not necessarily rule out the attentional viewpoint that was described above. The two perspectives may well complement each other. Although the functional view is better able to predict the conditions under which people will blush and to explain the reasons why people blush, attentional factors may be necessary prerequisites for a functional approach: Self-focused attention is needed to make the actor aware of the potential violation of social rules, and of the fact that others are able to observe and evaluate this event (awareness of social attention). Thus, in order to be able to become embarrassed in the first place, one must be aware of, and must care about, others' evaluations of oneself (Schlenker \& Leary, 1982). Viewing oneself through the eyes of other people (self-focused attention) is necessary to evaluate whether one's behaviour is in conflict with the social rules or with the observer's rules. Indeed, according to Scheier and Carver (1977), one consequence of self-focused attention is the tendency for self-evaluation, possibly revealing a discrepancy between actual behaviour and goals or standards. The functional view and the attentional view share the idea that sensitivity to other's judgements is needed for blushing; the attentional view considers blushing as the effect of self-focused attention (without any other necessary conditions), brought about by the wondering what others might think, whereas the functional view aims to explain blushing as a remedial gesture, the actor being sensitive to the observer's judgement. In Figure 1.1, the above considerations are represented schematically.

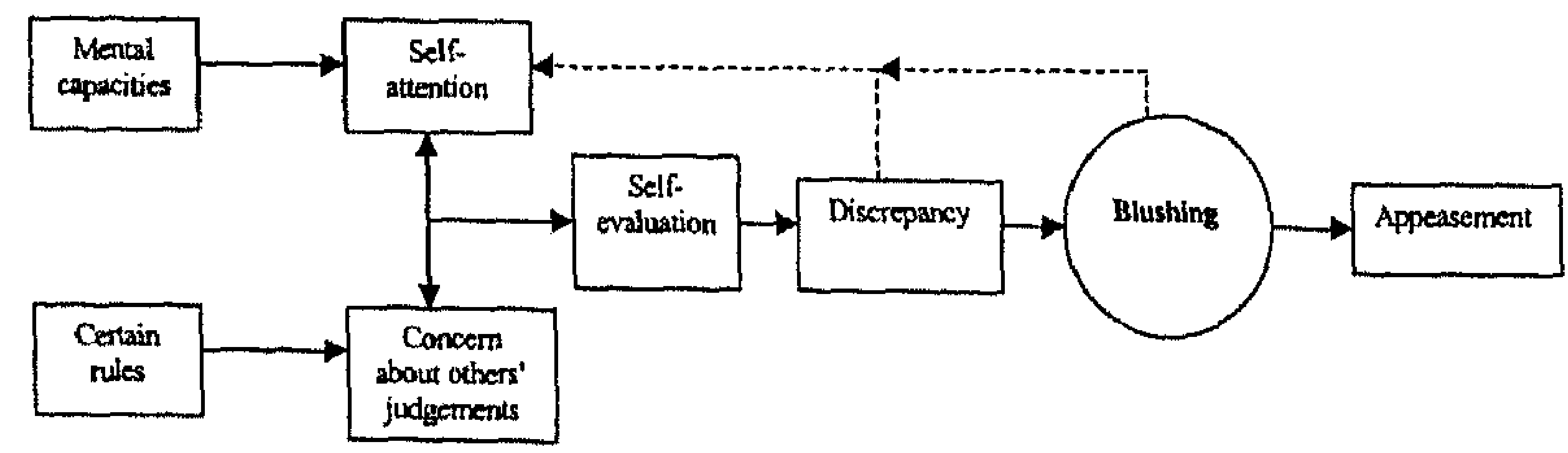

Figure 1.1: Schematic representation of the presumed factors that lead to blushing 


\section{Fear of blushing and social phobia}

\subsection{Evolution of the concept fear of blushing: Brief historical consideration}

It is generally assumed that fear of blushing was first described by Casper in 1846 . In the chapter 'Biographie eines fixen Wahns', Casper (1846) described a patient who, since his thirteenth year, suffered from the fixed idea of becoming red, and finally committed suicide at age 21 . When the fear of blushing started, the boy was suffering, already, from numerous other obsessional thoughts since his childhood. Likewise, the complaint 'fear of becoming red' was referred to as obsessional, an idée fixe, in this description.

The very name 'erythrophobia' was first used by Boucher in 1890 (Friedländer, 1900). Boucher (1890) spoke on a conference for psychiatrists in Rouen about 'Une forme particulière d'obsession chez deux héréditaires (l'érythrophobie)'. It is reasonably certain, however, that - besides Casper's case formulation in 1846 - there is at least one more description of fear of blushing before 1890 (Friedländer (1900) extensively cites a description by Eulenburg in the German Realencyklopädie about 'essential reddening'). Yet, the term 'erythrophobia' had not yet been attached to the phenomenon.

In the literature, several case descriptions appeared in 1897. In January of that year, Pitres and Régis (1897) described cases for which they proposed the diagnosis 'ereuthophobia' (literally 'fear of becoming red'). They preferred that term above 'erythrophobia' because the latter would imply 'fear of the colour red'. However, Friedländer (1900) stated that the term 'erythrophobia' meant just as much 'fear of

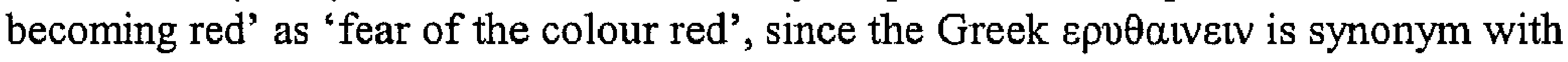
$\varepsilon \rho v \theta$ palveiv. Anyway, both expressions are (still) used as synonyms, whereas erythrophobia is used most frequently. In their manuscript, Pitres and Régis (1897) noted that the emotional reddening was usually accompanied by feelings of desperation and confusion, and that this feeling could sometimes be quite inconvenient, especially for men. That is, according to the writers, women blushed more than men, and seemed to be less affected by it. Perhaps, they thought, because blushing fits well into their delicate sensitive personalities, and provides them with extra charm: "Il semble, en effet, que les femmes, qui rougissent davantage, en soient moins affectées, peut-être parce que la rougeur est une expression en accord avec la délicatesse de leur sexe et leur prête pour ainsi dire un charme de plus."

Pitres and Régis (1897) distinguished, according to the extent of the emotional response, between three degrees of the phenomenon. (1) 'Ereuthose simple', indicating people who redden very easily, under a variety of circumstances, and who are not at all afraid or preoccupied with it. (2) 'Ereuthose émotive', indicating people who not only blush frequently, but are also more or less troubled by it. Yet, this trouble is not as serious as an obsession. (3) 'Ereuthose obsédante', or 'ereuthophobie'. Only the last 
category indicates people who are really afraid of blushing. Their preoccupation entails an actual obsession, an extreme phobia. Thus, in Pitres and Régis' (1897) view, the clinically independent disorder ereuthophobia could only be diagnosed in case of category 3. That is, when there was a propensity to blush relatively frequently, when there was a certain preoccupation with it, and when this preoccupation had taken the form of an extreme phobia.

In 1897, descriptions of patients with fear of blushing were also given in the German Journal 'Neurologisches Zentralblatt'. For instance Bechterew (1897c) described two patients who suffered from fear of blushing. Both patients had written him letters in which they outlined their complaints. Bechterew concluded that it was a matter of neurotic disorder, which manifested itself through reddening of the patient, at undesirable and inconvenient times. In the same year, Hoche (1897), on the other hand, had the opinion that the disorder's central feature were the obsessive phenomena, and warned for the creation of a new disorder on the basis of the content of the obsessions. Bechterew (1897d) responded with counter-arguments. He believed that his own patients and several other cases that were published then, shared some very typical features which were clearly distinct from the typical signs of obsessional disorders. Therefore, he assumed that the name erythrophobia was justified.

In 1900 , Friedländer analysed the 26 cases that had been published in the literature until then plus 5 cases of his own, and claimed erythrophobia to be an independent disease. However, all described patients showed a range of other psychiatric problems, which seemed sometimes more prominent than the fear of blushing. Furthermore, the presumed important aetiological factors in erythrophobia (like heredity, masturbation, sexual hyperaesthesia, hypersensitivity of the vasomotor centre, alcohol intolerance, etc.) were also presumed aetiologic for neurasthenia. Friedländer concluded, therefore, that erythrophobia was primarily a symptom of neurasthenia, just like claustrophobia, agoraphobia, etc. In the second instance, he stated, it could be found in hysteria and other degenerative conditions, but never completely alone.

The clinical connection between erythrohobia and other similar syndromes, led to the fact that erythrophobia was not regarded anymore as a sole disease, but attempts were made to form a distinct group of diseases on the basis of common features (Pollentier, 1992). The composition of the group changed, though, in accordance to what authors thought were important features (Pollentier, 1992). For instance, Janet and Raymond (1903) placed erythrophobia and similar syndromes like dysmorphophobia in the category of 'phobias of social situations'; They differentiated this from (1) 'object phobias' in which there is fear of certain things or animals, and (2) 'phobias of physical situations', like agoraphobia or claustrophobia (Vandereycken \& Pollentier, 1986). Von Stockert (1929) considered the attentiveness to an organ system, and the presence of another person as the two essential criteria for the 'contact neurosis', to which he also counted erythrophobia (Pollentier, 1992). Other disturbances in this category were, for example, stuttering, disturbances in sexual functioning, disturbances in perspiration, and disturbances in the vasomotor system. Dosužkov (1965) fits erythrophobia in with the 'skoptophobia' (literally 'fear of being laughed at'), which he names the fourth 
transference neurosis, after the conversion hysteria, the anxiety hysteria, and the obsessional neurosis. Skoptophobia contains several neuroses that are related to shame, like fear of sweating (idrosophobia), dysmorphophobia, kakotechnophobia (fear of producing bodily sounds, like flatus), the logophobic form of stuttering (fear of speaking), and certain cases of writer's cramp, tics, and psychogenic torticollis (Vandereycken \& Pollentier, 1986). Kasahara and Sakamoto (1971) group erythrophobia into the 'taijiu-kyofu', a collective term for several social phobias.

In 1947, phobias were introduced as separate diagnostic entities into the International Classification of Diseases (ICD) (Marks, 1987). Next, names were invented for all phobias, on the basis of the stimulus or situation that was feared. This resulted in a huge list of phobias. Then, in the sixties, Marks and Gelder (1966) proposed a classification of the phobias into agoraphobia, social phobia, and specific phobia. This classification was more and more used in scientific research and, later (in 1980) adopted in the third edition of the Diagnostic and Statistical Manual of Mental Disorders (DSMIII; American Psychiatric Association, 1980).

\subsection{Diagnostic criteria: From DSM-III to DSM-IV}

Since DSM-III, thus, social phobia has been described as a separate syndrome among the anxiety disorders. Here, it was defined as a persistent, irrational fear of a situation in which the individual is exposed to possible scrutiny by others, in which he or she may act in a way that will be embarrassing, combined with a strong desire to avoid those situations. Beyond this, the individual had to recognize that his/her fear was unreasonable. In DSM-III, it was assumed that an individual, generally, has only one social phobia, which excluded patients with fear of more than one kind of social situations from the diagnosis (Scholing, 1993). The latter group, with a more generalized fear of social situations, often met the criteria for avoidant personality disorder, which is characterized by hypersensitivity to criticism or potential rejection, an unwillingness to enter into social situations unless unusually strong guarantees of uncritical acceptance are provided, social withdrawal despite a desire for social interaction and low self-esteem (Scholing, 1993). The most important difference between the definitions of social phobia in DSM-III and in its revised edition DSM-III-R (APA, 1987) is that in the latter edition, social phobia also applies to individuals with fear of more than one kind of social situations. The 'generalized type' should then be specified.

In DSM-IV (APA, 1994), the criteria for social phobia were further adjusted (see Box 2.1 for a full presentation of the current criteria). In this edition, fear of showing anxiety symptoms was, for the first time, explicitly mentioned. Thus, in the present diagnostic criteria for social phobia, fear of blushing is explicitly included as part of the diagnosis. On the basis of the current criteria, differentiations might be made between several types of social phobia. Firstly, the diagnostic criteria demand a specification for the generalized type (fear of most social situations), as opposed to the nongeneralized type (fear of only one or few social situations), when necessary. Secondly, a group of 
social phobics for whom fear of showing bodily symptoms is the main concern, can be identified using the present criteria. Recent research indeed demonstrates that generalized social phobics can be discriminated from specific social phobics, using the Social Phobia and Anxiety Inventory (SPAI: Turner, Beidel, Dancu, \& Stanley, 1989; Dutch translation: Scholing, Bögels, \& Velzen, 1995), and that social phobics with fear of blushing, trembling and sweating as the primary concern can be discriminated from social phobics without fear of bodily symptoms as the main complaint, using the newly developed Blushing, Trembling, and Sweating Questionnaire (BTS-Q: Bögels \& Reith, 1999).

\section{Box 2.1}

\section{DSM-IV criteria for social phobia}

A. A marked and persistent fear of one or more social or performance situations in which the person is exposed to unfamuliar people or to possible scrutiny by others. The individual fears that he or she will act in a way (or show anxiety symptoms) that will be humiliating or embarrassing. Note: in children, there must be evidence of the capacity for age-appropriate social relationships with familiar people and the anxiety must occur in peer settings, not just in interactions with adults.

B. Exposure to the feared situation almost invariably provokes anxiety, which may take the form of a situationally bound or situationally predisposed Panic Attack. Note: In children, the anxiety may be expressed by crying, tantrums, freezing, or shrinking from social situations with unfamiliar people.

C. The person recognizes that the fear is excessive or unreasonable. Note: In children, this feature may be absent.

D. The feared social or performance situations are avoided or else are endured with intense anxiety or distress.

E. The avoidance, anxious anticipation, or distress in the feared social or performance situation(s) interferes significantly with the person's normal routine, occupational (academic) functioning, or social activities or relationships, or there is a marked distress about having the phobia.

F. In modividuals under age 18 years, the duration is at least 6 months.

G. The fear or avoidance is not due to the direct physiological effects of a substance (e.g. a drug of abuse, a tredication) or a general medical condition and is not better accounted for by another mental disorder (e.g., Panic Disorder Whth or Without Agoraphobia, Separation Anxiety Disorder, Body Dysmorphic Disorder, a pervasive Developmental Disorder, or Schizoid Personality Disorder).

H. If a general medical condtion or another mental disorder is present, the fear in Criterion A is unrelated to it, e.g. the fear is not of Stuttering, trembling in Parkinson's disease, or exhibiting abnormal eating behaviour in Anorexia Nervosa or Bulimia Nervosa.

Specify if Generalized: if the fears include most social situations (also consider the additional diagnosis of Avoidant Personality
Desorder). 
In the group with fear of blushing as the main complaint, the social phobic complaints are centred around the occurrence of blushing. Mostly, patients with this particular form of social phobia belief that their problem would disappear if they would never blush anymore. The individual fears social situations in which blushing could possibly occur and is visible to other people, these situations provoke anxiety, they are avoided or else endured with intense distress, and the fear and/or avoidance interferes significantly with the person's life. The present thesis specifically focuses on this particular subgroup of social phobics.

\subsection{Epidemiology of social phobia and fear of blushing}

In a recent national survey with respect to psychiatric morbidity in the Netherlands (Bijl, Van Zessen, \& Ravelli, 1997), a total lifetime-prevalence of $7.8 \%$ was established for social phobia. For men, separately, this percentage was $5.9 \%$, for women $9.7 \%$. The 12 months prevalence was $4.8 \%$, altogether, and $3.5 \%$ and $6.1 \%$ for men and women, respectively. The 1 -month prevalence came to $3.7 \%$, being $2.8 \%$ and $4.7 \%$ for men and women, respectively. The prevalence rates of social phobia were, compared to the other anxiety disorders, the second highest (specific phobia was the most common disorder, with a lifetime-prevalence of $10.1 \%$ ). This study used the DSM-III-R criteria to establish the presence of mental disorders. No differentiations were made with respect to fear of bodily symptoms.

The 'National Comorbidity Survey' (NCS; Kessler et al., 1994; Magee, Eaton, Wittchen, MacGonagle, \& Kessler, 1996) in the USA, also based on the DSM-III-R criteria, and using a similar method and comparable instruments, demonstrates a much higher overall lifetime-prevalence rate for social phobia - $13.3 \%$ - whereas lifetime gender prevalence rates of $11.1 \%$ for men and $15.5 \%$ for women were reported. The overall 12 -months prevalence were $7.9 \%$, being $6.6 \%$ for men, and $9.1 \%$ for women. In this survey, social phobia appeared to be the most common anxiety disorder, followed by specific phobia. When social phobia was more closely examined, one-third of the people with lifetime social phobia reported exclusively speaking fears, while the other two-thirds had at least one of the other social fears assessed (i.e. using a toilet away from home, eating or drinking in public, writing while someone watches), with or without a speaking fear. The vast majority of the latter had multiple social fears including, in most cases, both performance and interactional fears. Furthermore, it was found that the social phobia characterized by pure speaking fears was less persistent, less impairing, and less highly comorbid with other DSM-III-R disorders than was social phobia characterized by other social fears (Kessler, Stein, \& Berglund, 1998).

Both surveys, thus, indicate that social phobia is a common disorder among the anxiety disorders. Furthermore, both epidemiological studies show social phobia to be more prevalent in women than in men. In the majority of clinical samples, however, social phobia appears to be equally common across genders (Mannuzza, Fyer, Liebowitz, \& Klein, 1990; Amies, Gelder, \& Shaw, 1983; Montejo \& Liebowitz, 1994). For 
comparison, agoraphobia and panic disorder are both much more common in women, both in clinic subjects and in the general population (Kessler et al., 1994; Montejo \& Liebowitz, 1994). In clinical social phobic patients, higher socioeconomic classes are overrepresented, whereas among epidemiological patients, lower socioeconomic classes are predominant (Schneier, Johnson, Homig, Liebowitz, \& Weissman, 1992b). These differences between epidemiological and clinical studies (with respect to gender and socioeconomic status) may reflect selection bias in clinical research samples for patients seeking treatment (Schneier et al., 1992b). That is, male social phobic patients, generally, have a better education level and a higher socioeconomic status, and may therefore be more likely to experience impairment in functioning and thus be more likely to seek treatment (Schneier et al., 1992b). This might account for the lack of gender difference, and the higher socioeconomic status and better educational level, observed in clinical studies (Montejo \& Liebowitz, 1994). Research by Caspi, Elder, and Bem (1988) indeed indicated that shy women more often led their lives as housewives, whereas men, due to social pressure, are less able to hide social anxious symptoms because they are expected to have a job.

Mean reported age of onset of social phobia in the NCS (Kessler et al., 1994) was $15.5+/ .13 .3$ years, and occurred in a bimodal distribution, with peaks at the interval $0-5$ years and at age 13. Onset after the age of 25 was uncommon (Kessler et al., 1994). Other studies indicated mean ages of onset between 16 and 20 years (see Scholing \& Emmelkamp (1990) for a review). All results taken together, it could be stated that about $70 \%$ of the patients reported that their social phobia started between 10 and 19 years. It should be noted, however, that it is difficult to obtain reliable data concerning the age of onset, given the retrospective nature of the material (cf. Taylor, Deane, \& Podd, 1999).

Still, little is known about the epidemiology of social phobia with fear of blushing as the predominant complaint. A German community-based study among 1035 adolescents aged $12-17$ years reported that $1.6 \%$ met the diagnosis of social phobia once in their lives, whereas the frequency of social fears/anxiety was much higher $(47.2 \%$ of the entire sample; $42.0 \%$ and $50.8 \%$ for boys and girls, respectively) (Essau, Conradt, \& Petermann, 1999). Within this sample of social fears, the fear of getting red was quite prominent ( $38.9 \% ; 35.0 \%$ and $41.0 \%$ for boys and girls, respectively). According to Scholing (1993), in about one third of the patients who apply for treatment for social phobia, fear of blushing, trembling, or sweating is the predominant complaint. Clinical impression suggests that fear of showing bodily symptoms may not be adequately recognized by therapists, because patients are ashamed to present these kinds of fears (e.g. Boggels \& Scholing, 1995). In two mental health centers in different regions of the Netherlands (Groningen and Maastricht), Bögels and Scholing (1995) held intakes with 70 patients with fear of blushing, trembling, and/or sweating as the main complaint. It appeared that $49 \%$ of all patients were women, that the patients' mean age was 33.2 years, and the mean duration of the complaint was 11.7 years. Of all patients, $58 \%$ had fear of blushing as the predominant complaint, whereas $32 \%$ feared trembling most, and $10 \%$ sweating. In the majority (59\%), the complaint had developed after age 18 , in $31 \%$ it had started between age 12 and age 18 . 
1 a more recent investigation, 40 patients of the total of 92 social phobic patients articipating in that study, appeared to have fear of blushing, trembling and/or sweating i the predominant complaint (Bögels \& Reith, 1999). Mean age of this subpopulation as 33.5 (SD 10.9; range $19-57) ; 55 \%$ were men. Their mean educational level was 7.5 i $D$ 2.3; range $3-11$; on an 11-point scale, where each point was defined in terms of ghest completed education, from $1=$ no completed education, $2=$ elementary school, $11=$ master's degree). Fifteen patients from the above mentioned 40 suffered only from ar of blushing (and not trembling and/or sweating), their mean age being 31.9 (SD 1.1; range 19-57); 46.7\% were men, mean educational level was 7.5 (SD 1.8) (Bögels Reith, 1998). Taken together, an estimated $33 \%$ to $43 \%$ of the people with social robia have fear of blushing/ trembling and/or sweating as the main complaint, whereas $5 \%$ to $18 \%$ of social phobics suffer predominantly from fear of blushing.

\subsection{Comorbidity and consequences}

he term 'comorbidity' implies in the field of psychiatry the co-occurrence of two or ore psychiatric disorders in the same individual within a defined period of time 1ontejo \& Liebowitz, 1994). Social phobia often co-occurs with other psychiatric sorders, in epidemiological studies, as well as in clinical samples. For example, results om the Epidemiologic Catchment Area (ECA) study indicated that the most common morbid disorders were simple phobia and agoraphobia, occurring in 59\% and $44.9 \%$ "participants with social phobia, respectively (Schneier et al., 1992b). For individuals ith comorbid disorders, social phobia preceded the comorbid disorder in $76.8 \%$ and had Iset in the same year in 7.2\%; only $31 \%$ of individuals with social phobia had no other etime disorder (Schneier et al., 1992b).

In clinical studies, high comorbidity rates among psychiatric disorders have been ported, as well. For example, de Ruiter, Rijken, Garssen, van Schaik, and Kraaimaat 989) reported that social phobia was associated with one or more additional anxiety sorders in $67 \%$ of the sample. When they used a procedure, based on the temporal quence of disorders, simple and social phobia were more often assigned as primary agnosis. However, when they used the relative interference with patient functioning to :fine primary diagnosis, panic disorder with agoraphobia was most often assigned as imary diagnosis. Dther common disorders, co-existing with social phobia, are mood sorders and substance abuse (de Ruiter et al., 1989; Schneier et al., 1992b; Sanderson, Nardo, Rapee, \& Barlow, 1990).

Given the high degree of life interference, especially interference with terpersonal relationships (Rapee, 1995), it is not surprising that a large proportion of cial phobics meet the criteria for major depression or dysthymic disorder (Sanderson al., 1990; Schneier et al., 1992b). Indeed, when present, the mood disorder has been und to begin after the onset of social phobia in the majority of cases (Schneier et al., 92b). Increased rate of suicide attempts in social phobia is mostly explained by the esence of comorbid disorders (Schneier et al., 1992b).

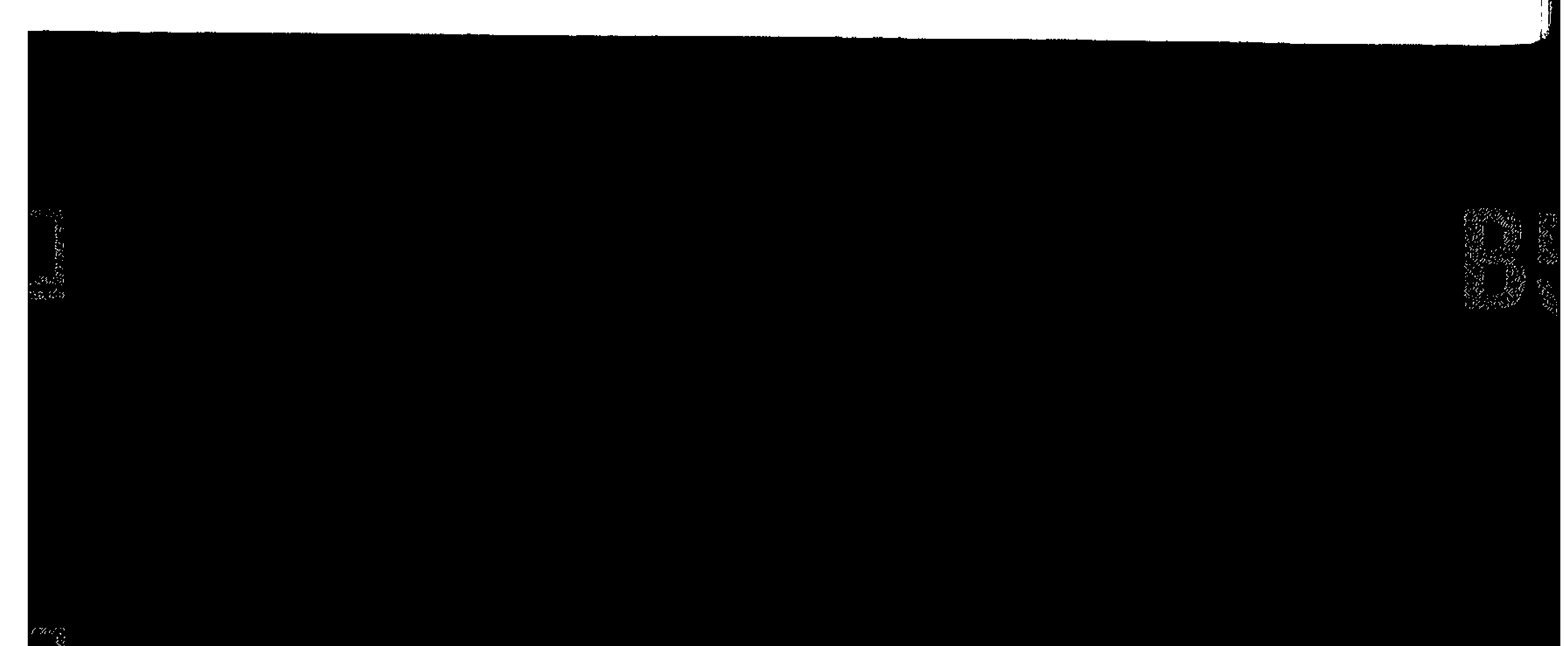


Rates of excessive alcohol consumption have been found to be higher in social phobics than in subjects with most other anxiety disorders (Amies et al., 1983; Tumer, Beidel, Dancu, \& Keys, 1986a), although data on formal diagnoses of alcohol abuse have been mixed (Rapee, 1995). That is, in a community sample, $18.8 \%$ of social phobics have been diagnosed with an additional diagnosis of alcohol abuse (Schneier et al., 1992b), whereas in clinical settings, this figure varied from around $2 \%$ (Herbert, Hope, \& Bellack, 1992) to $16 \%$ (Schneier, Martin, Liebowitz, Gorman, \& Fyer, 1989). This discrepancy may be partly a result of the exclusion of individuals with severe alcohol problems from many anxiety units (Rapee, 1995). Most individuals with the dual diagnosis reported using alcohol for self-medication reasons (Schneier et al., 1989; Kushner, Sher, \& Beitman, 1990).

According to DSM-IV (APA, 1994), the course of social phobia is often continuous, and duration mostly lifelong, although the disorder may attenuate in severity or remit during adulthood. Severity of impairment may fluctuate with life stressors and demands, e.g. social phobia may diminish after a person with fear of dating marries and reemerge after death of a spouse (APA, 1994). People with the diagnosis social phobia more often remain unmarried than people with other anxiety disorders (Schneier et al., 1992b). In fact, social phobics have been found to suffer from impairment in many important areas of functioning: academic (e.g. difficulty speaking in class, joining clubs or teams, being elected as leaders, participating in class discussions), occupational (e.g. inability to make informal contributions and presentations at meetings which has resulted in lack of promotions or career development), and social functioning (e.g. inability to attend social events and join philanthropic or civic organizations, limited heterosocial functioning, and difficulty establishing intimate relationships) (Turner et al., 1986a; Turner, Beidel, \& Townsley, 1990).

In sum, social phobia is a common anxiety disorder with severe consequences. Patients suffering from the disorder can be strongly impaired by the symptoms and by avoidance behaviour, in all aspects of their lives. Patients may be suffering from generalized or nongeneralized social phobia, whereas a subgroup has fear of blushing, trembling, and/or sweating as the predominant complaint. Social phobia may lead to subsequent comorbid disorders, like mood disorders or alcohol abuse, and may even result in suicide (attermpts). As a rule, patients do not recover spontaneously, implying that, without proper treatment, impairment may remain lifelong.

\subsection{Etiology and maintenance of fear of blushing}

Theories and ideas about the origins and the maintenance of social phobia and fear of blushing are varied. This thesis focuses on the most relevant factors in this respect. It is assumed that several factors contribute to the etiology and maintenance of fear of blushing and might, therefore, have implications for the treatment of the disorder.

In a bird's-eye view, the following aspects are considered: since fear of blushing concerns a physical hallmark, biological factors may be important in the origins, 
maintenance, and treatment of fear of blushing. That is, erythrophobics might objectively blush more readily/intensely than nonphobic individuals (biological explanation). In addition, they might overestimate their physiological reactions (cf. McEwan \& Devins, 1983) and/or the consequences of their blushing (cognitive explanation). Thus biological, behavioural, and cognitive aspects may play a role as will be further outlined below.

\section{Biological vulnerability}

Psychophysiological studies, attempting to differentiate social phobics from normal individuals, have focused on level of arousal (potentially chronically increased in social phobics), physiological reactions (perhaps stronger in social phobics), and habituation (potentially less in social phobics) in social situations (e.g. Lader, 1967; Lader \& Mathews, 1968). These types of physiological reactions might lead to a greater vulnerability for developing fear of disapproval, especially because of bodily reactions. Research findings, however, are not univocal in this respect, some studies indicating that social phobics have stronger psychophysiological reactions (i.e. heart rate and blood pressure) and less habituation than normals in social situations (e.g. Beidel, Turner, \& Dancu, 1985; Turner, Beidel, \& Larkin, 1986b), whereas other studies found no psychophysiological differences between social phobics and normal individuals in feared social situations (e.g. Hofmann, Newman, Ehlers, \& Roth, 1995). In the latter study, however, differences in heart rate between subgroups of social phobics (with or without avoidant personality disorder) were identified.

Conflicting research findings might be partly due to the variety of subgroups within social phobic patients, making it difficult to investigate specific physiological reaction patterns. That is, patients might be identified as, for example, having performance versus interaction anxiety, generalized versus nongeneralized social phobia, social phobia with or without avoidant personality disorder, social phobia with or without fear of bodily symptoms. A specific social stimulus under investigation (e.g. a social interaction task with stooges or an impromptu speech for an audience), thus, might not be relevant to all types of social phobics. Furthermore, a limitation of these types of studies is that physiology was measured during social situations only, leaving unclear whether differences in physiological reaction patterns are due to state or trait variables. Finally, it remains uncertain whether increased physiological arousal is a cause or a consequence of social phobia.

Apart from peripheral psychophysiological mechanisms also central physiological mechanisms have been implied in social phobia. More specifically, it has been suggested, for example, that the central dopaminergic system might be an important biological variable, because of social phobics' treatment response profile to Mono Amine Oxidase Inhibitors (MAOI's) (Levin, Schneier, and Liebowitz, 1989). Still, this effectiveness does not automatically imply that the dopaminergic system is a vulnerability or causal factor for social phobia; the response pattern could also be a consequence of social phobia.

Family studies indicated that social phobic symptoms more often occurred in family members of social phobic patients (Perugi et al., 1990; Reich \& Yates, 1988; Turner \& Beidel, 1989; Fyer, Mannuzza, Chapman, Liebowitz, \& Klein, 1993). 
Although such studies might suggest a genetic component or the influence of biological factors in social phobia, it can not be ruled out that the results are (partly) due to environmental factors. In a large twin study, in which 2163 female twins were personally interviewed, heredity estimates of $30-40 \%$ were given for any phobia, agoraphobia, social phobia, and animal phobia, but it was concluded (on the basis of the best-fitting multivariate genetic model) that social phobia resulted from the combined effect of a relatively strong genetic influence and nonspecific environmental experiences (Kendler, Neale, Kessler, Heath, \& Eaves, 1992).

All in all, there is no evidence for the idea that biological factors play a dominant role in social phobia. However, it should be acknowledged that most of the studies only referred to the broad concept of social phobia. Therefore, it can not be ruled out that biological factors do play a role in fear of blushing. Germane to this, Marks (1986) suggested that some social phobias (e.g. fear of blushing) may arise from autonomic specificities under genetic control: ".... when anxious, those with labile blood flow in the cheeks might blush more readily than others, and so be liable to become phobic about blushing..." (p.3). Indeed, research using self reports about blushing confirm the alleged connection between blushing propensity and fear of blushing (e.g. Bögels, Alberts, \& De Jong, 1996). However, since research on individual differences in blushing propensity has only relied on self report measures, it remains unclear whether these reports indeed reflect objectively observable differences rather than subjective feelings. Therefore, in this thesis, an attempt is made to further examine the relationship between self-reported blushing propensity, actual blushing, and fear of blushing.

\section{Learning experiences}

There is evidence for aversive learning experiences playing a role in the acquisition of irrational fear. These learning experiences are not necessarily of a direct nature, but may also reflect indirect learning pathways. Rachman (1977) introduced 'the three pathways to fear', supposing that fear could be acquired by (1) conditioning (direct pathway), (2) vicarious leaming (indirect pathway), and (3) informational transmission (indirect pathway). Assuming also indirect pathways to account for the acquisition of fears might explain phobia in the absence of traumas (direct pathway). By and large, several studies have found evidence supportive of this three-pathways-model (see for a review Merckelbach, De Jong, Muris, \& Van den Hout, 1996).

It is assumed that social phobia may develop in the same way as do many specific phobias. That is, as a consequence of one or more traumatic conditioning experiences (Mineka \& Zinbarg, 1995). The difference in whether someone develops a specific versus a social phobia would be in the nature of the conditioned stimuli (CSs) that acquire the capacity to elicit fear: social situations such as public speaking versus discrete stimuli, such as spiders or snakes (Mineka \& Zinbarg, 1995). In the case of classical conditioning (direct pathway) leading to blushing phobia, a contingent occurrence of a traumatic experience (UCS, e.g. being bullied, such as being called names like 'tomato' or 'lighthouse') and a, formerly, neutral stimulus (blushing) result in blushing becoming the feared CS. Vicarious learning refers to observing someone else behaving fearfully 
in the presence of some object or situation. With regard to blushing phobia this might consist of, for example, observing your mother while she obviously tries to hide her face when blushing. An example of fear of blushing fuelled by learning through the transmission of information is reading in a magazine that blushing is something strange, or seeing on television that someone finds it stupid.

It seems plausible that learning experiences play a role in the acquisition of fear of blushing, since it concerns a visible bodily reaction, which might attract attention and, in the worst case, forms a source of bullying and other traumatic learning experiences.

\section{Dysfunctional cognitions}

Several authors assume that pathological fear is maintained by the way in which anxiety disordered patients process fear-related information (Beck, Emery, \& Greenberg, 1985). Three kinds of distortions in information processing are central in these authors' view: phobics overestimate danger, overestimate their own fear reaction, and underestimate their skills to handle such a situation (Beck et al., 1985). Moreover, recent cognitive models of social phobia assume that social phobics are troubled by a negative self-image which is activated, or threatens to be activated, in contact with other people (Clark \& Wells, 1995; Bögels \& Mulkens, 1997). In this view, social phobics are believed to hold? negative opinions about themselves and they are inclined to see others as critical and judging. Negative ideas and opinions about oneself are assumed to be developed along the course of life (e.g. within the individual's learning history). Indeed, research has shown that socially anxious people were more likely to choose negative interpretations of ambiguous social situations and more likely to choose catastrophic interpretations of mildly negative social events than other anxious patients or nonpatient controls (Stopa \& Clark, 2000). Furthermore, it was found that high socially anxious individuals overestimate how anxious they appear to others (McEwan \& Devins, 1983), and underestimate their performance (Rapee \& Lim, 1992; Stopa \& Clark, 1993). Finally, both high socially anxious analogue samples and social phobic patients have been found to report more negative self-statements than low socially anxious samples (Cacioppo, Glass, \& Merluzzi, 1979; Beidel et al., 1985; Dodge, Hope, Heimberg, \& Becker, 1988; Stopa \& Clark, 1993). The cognitive explanations which are used to explain the maintenance of social phobia, also seem applicable for fear of blushing. That is, negative and catastrophic interpretations of the (social) consequences of blushing might influence the observation, selection, interpretation, and memory of information from social interactions, and, thus, maintain the fear. Research directed specifically at fear of blushing indicated that social phobics with fear of blushing, indeed, gave higher credibility ratings than normal control individuals to negative beliefs with regard to blushing (Bögels \& Reith, 1999).

The so-called 'self-presentation approach' (Schlenker \& Leary, 1982) provides a hypothesis with regard to the conditions under which humans become socially anxious. The model originates from social psychology, but might be applied to clinical populations, as well. Self-presentation is defined as the attempt to control images of self before real or imagined audiences (Schlenker \& Leary, 1982). The type of impression an 
actor would prefer to create must be defined in terms of the actor's other goals and selfbeliefs in the particular situation. Therefore, the preferred impression is not necessarily a positive one. According to the theory, people are interpersonally secure in social settings where (a) they do not intend to create a particular impression on other people (and thus are not concerned about others' responses), or (b) they are attempting to create a certain impression, and believe they will be successful in doing so. Social anxiety arises when two cognitive factors co-occur: (1) The person in question is highly motivated to make a certain impression on other people and (2) he/she has doubts about one's ability to do so (Schlenker \& Leary, 1982). In case of blushing phobia, the individual might have wanted to make a certain impression, whereas blushing might indicate that he/she has not succeeded in doing so, this discrepancy leading to fear. Furthermore, blushing while not wanting to blush is a discrepancy between a desired and an actual situation in its own right, which, according to this theory, leads to fear.

Several processes might contribute to the maintenance of the dysfunctional ideas of phobic patients. For example, selective attention for schema-congruent information might contribute to the preservation of once formed ideas. That is, schema-congruent information is detected, whereas schema-discongruent information is not picked up or is reasoned away. Furthermore, selective memory for schema-congruent information might serve to maintain beliefs. The so-called 'post-mortems' (Clark \& Wells, 1995) are specific forms of selective memory. 'Post-mortems' refer to social phobics' tendencies to, retrospectively, (re)evaluate their social interactions on the basis of their anxious feelings and self-perceptions (i.e. "I felt very anxious, thus it went wrong"). Additionally, the nature of social phobics' social interactions might prevent them from receiving (spontaneous) non-ambiguous feedback from other people, whereas ambiguous information is interpreted in a negative way. For example, behaving in a less warm and outgoing fashion (being socially inhibited, due to high levels of fear) may elicit less friendly behaviour from others and hence partly confirm their fears (Stopa \& Clark, 1993). Being afraid of rejection, social phobics avoid situations or behaviours that allow to disconfirm their dysfunctional ideas. In addition, carrying out subtle avoidance behaviour and/or safety behaviours (cf. Wells et al., 1995) prevents social phobics from experiencing corrective experiences (e.g. someone who is afraid to be judged negatively because of sweating armpits may press his arms tightly to his body).

\section{Self-awareness theory}

An important condition for successful social interactions is an appropriate balance between self- and other-awareness (Argyle \& Williams, 1969). From this perspective, it has been suggested that social phobics direct too much attention to themselves - that is, to their emotions, self-thoughts, behaviour, physical appearance, and arousal - (e.g. Schlenker \& Leary, 1982; Hartman, 1983; Clark \& Wells, 1995), resulting in a distorted balance. The distorted balance might lead to unfavourable outcomes in social interactions (e.g. making mistakes), which further intensifies fear and increases avoidance behaviour.

Self-focused attention can result from both situational and dispositional factors (Buss, 1980). Situational self-focused attention is known as self-awareness, and may be 
induced by the presence of an audience, a mirror or a video camera. The dispositional form of self-focused attention is referred to as self-consciousness. In both situational and dispositional self-focused attention, a public as well as a private component can be distinguished (Buss, 1980). That is, private self-consciousness refers to awareness of one's own thoughts and feelings. A state of private self-consciousness is referred to as private self-awareness. Public self-consciousness refers to the tendency (trait) to be highly self-aware of public aspects of the self like appearance, or style (manners, expressive components). The state is called public self-awareness. Wicklund (1975) defines self-awareness as "a state in which a person takes himself/herself to be an object" (p. 234). This definition nicely covers most of the above descriptions of the term.

Two lines of research from the social psychological tradition have produced evidence which might be related to the above suggestions with regard to self-awareness. Firstly, the relationship between self-awareness, and task performance, emotions and internal attributions has been investigated (see Hope, Gansler, \& Heimberg, 1989, for a review). According to limited-capacity models of attention (e.g. Wine, 1980), excessive self-focused attention should result in performance decrements because the increase in self-attention leaves insufficient attentional resources to focus adequately on the task at hand. Indeed, this was found to be the case in several experiments, but only in situations where the person was insecure about his abilities or had low self-esteem (Burgio, Merluzzi, \& Pryor, 1986). Scheier and Carver (1977) found that mirror-induced selfawareness and self-consciousness resulted in increased attention to affective states, thereby intensifying self-report of affective reactions. Fenigstein (1979) further extended these findings, drawing similar conclusions. Finally, Duval and Wicklund (1973) found that individuals in whom a state of heightened self-awareness was induced, made more internal causal attributions about the consequence of a social situation than individuals who were not brought into this state. Given the above, heightened self-awareness might increase social anxiety via at least three pathways: firstly, directly through intensification of fear reactions in social situations; secondly, through a decrease in task performance; thirdly, through an increased sense of responsibility for the success of social interactions.

A second line of research in social psychology provided plausible evidence to suggest that heightened physiological arousal (e.g. as a result of physical exercise) leads to increased self-focused attention (Wegner \& Giuliano, 1980). In a similar vein, blushing may lead to increased self-focused attention. Thus, ironically, self-focused attention may lead to blushing, whereas blushing further increases self-focused attention, finally resulting in a negative loop (cf. Bögels, Mulkens, \& De Jong, 1995).

With respect to social phobia and, more specifically, fear of blushing, the theory of self-awareness has several implications. It has, thus, been found that physiological arousal (or awareness of physiological processes, for example blushing) leads to selffocused attention. Next, it has been suggested that self-focused attention interferes with task performance under some conditions, and intensifies emotional reactions (such as fear and blushing). Finally, it has been suggested that self-focused attention increases the probability of internal attributions (e.g. blaming oneself for social failure, perhaps for blushing). 
Review of the literature indicates that self-focused attention is a component of several dysfunctional states (Ingram, 1990). That is, heightened levels of self-focused attention have been found in a variety of psychological disorders, such as depression (Lewinsohn, Hoberman, Teri, \& Hautzinger, 1985), test anxiety (Sarason, 1975; Wine, 1971), alcohol abuse (Hull, 1981), and social anxiety (Buss, 1980). It might be that chronically high levels of self-focused attention serve as a vulnerability factor by placing individuals at risk for the onset or prolonged maintenance of dysfunction (Ingram, 1990). Two vulnerability dimensions can be identified: (1) An intensification factor, suggesting that levels of salient internal dimensions should be magnified by self-focusing; (2) The initiation of psychologically dysfunctional states. That is, self-focused attention would serve to contribute to the constellation of variables that bring about disorder.

\section{A heuristic model}

Given the above considerations, a speculative model might be proposed, to gain insight in the potentially causal and maintaining mechanisms of fear of blushing. Figure 2.1 schematically represents the presumed interrelations between the factors that may cause and/or maintain fear of blushing.

In this model, it is assumed that fear of blushing stems from the presence of certain (irrational/dysfunctional) cognitions about blushing and its consequences (certain rules/cognitions), and/or from a history of negative learning experiences (learning experiences) with respect to blushing. Besides, learning experiences are thought to contribute to the development of 'certain rules and cognitions' (cf. Beck et al., 1985). A biological vulnerability to blush relatively easily (blushing propensity) is assumed to facilitate the possibilities of experiencing negative learning events (for example, if one blushes relatively often and/or easily, one may be more likely to become the object of derision). Furthermore, when one blushes relatively often and/or easily, one is more likely to direct attention (self-focused attention) to the self/ the blushing (see also Figure 1.1). Once a person is fearful of blushing, he/she will be inclined to direct more attention to the self and blushing, which might result in poorer performance, which, in its turn, increases self-focused attention, et cetera.

Additionally, self-focused attention causes a person to make self-evaluations (e.g. "Am I coming across the way I wanted?"), which may reveal discrepancies between the actual and the desired self (e.g. "I'm saying silly things" or "I'm blushing, which is the least thing I wanted"), potentially causing more self-focused attention, and also confirming already existing cognitions about the self and blushing (certain rules/ cognitions), further maintaining the fear and the blushing (see also Figure 1.1). The model also suggests that already existing cognitions about blushing and its consequences cannot be disconfirmed because attention is focused mainly inward. This hampers the process of gaining new, objective information to test the tenability of the existing cognitive schemas. 


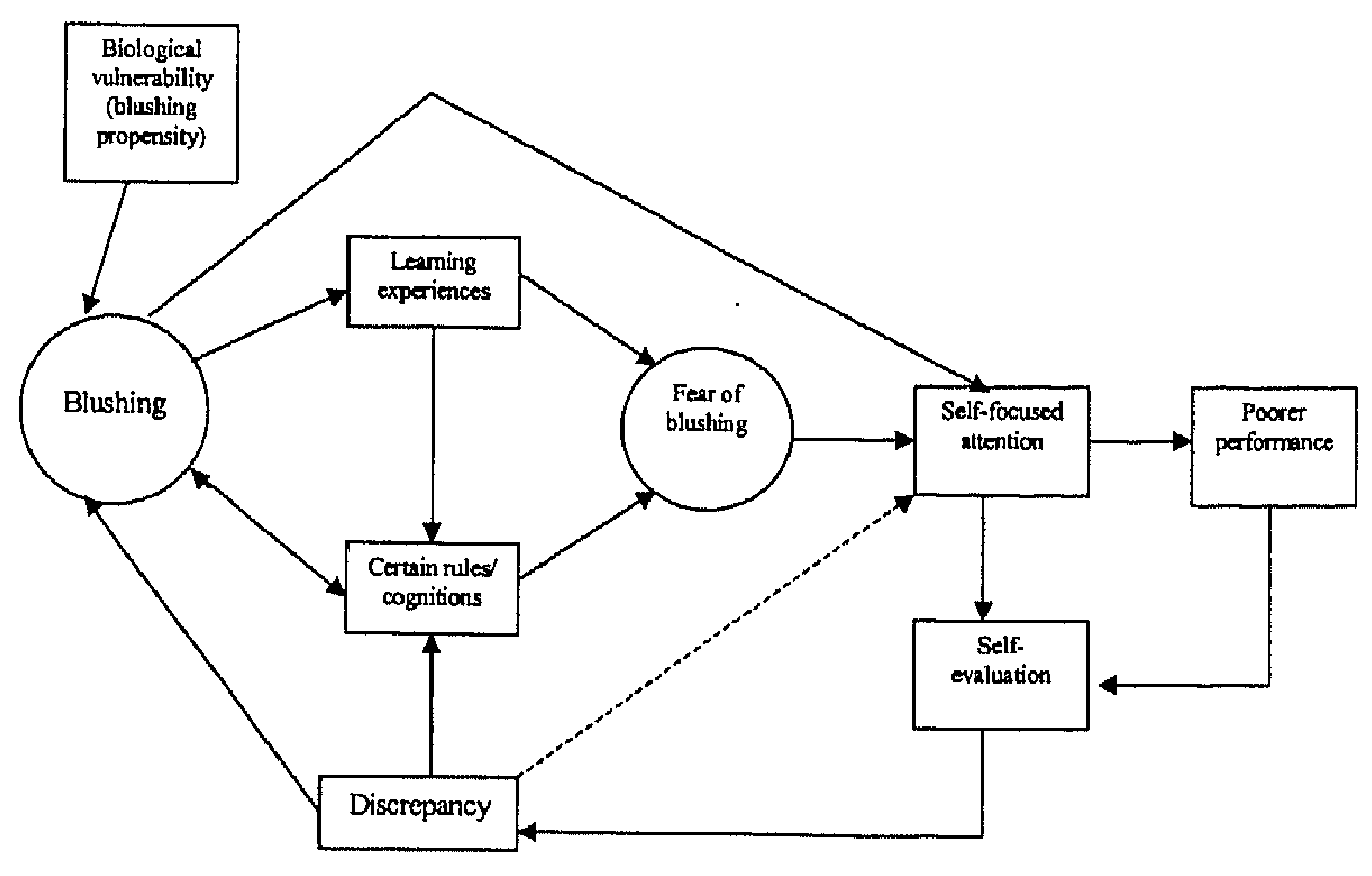

Figure 2.1: Schematic representation of the presumed factors that cause and/or maintain fear of blushing

\subsection{Therapeutical interventions}

In the following section, therapeutical interventions for fear of blushing will be outlined. These interventions largely follow from the heuristic model. That is, interventions based on biological principles are described, as well as commonly used behavioural and cognitive techniques, and a newly developed method, aimed to reduce self-focused attention.

The effectiveness of the biologically based interventions and the common behavioural and cognitive treatments, respectively, are discussed in successive paragraphs, followed by a brief discussion in which effects of biologically oriented interventions will be compared to those of traditional behavioural and cognitive techniques. The chapter ends with a paragraph in which a newly developed treatment is outlined.

\section{Biological interventions}

Biological interventions are divided into surgical procedures, aimed to remove the ability to produce a blush response, and psychopharmacological treatments, aimed to reduce social phobic symptoms, and, perhaps, fear of blushing. 


\section{Surgical procedures}

The most radical way to get rid of fear of blushing may be to get rid of the possibility to blush, at all. Sufferers may apply for surgical treatment called endoscopic transthoracic sympathicotomy (ETS) (Drott et al., 1998; Telaranta, 1998). This operation consists of surgical interruption of the nerve supply by the upper thoracic sympathetic chain, by which the innervation of the cutaneous blood vessels of the face is mediated (Drott et al., 1998). This method was previously used in treating patients with hyperhidrosis, but seemed also useful as a treatment for fear of blushing, according to the authors (Julius \& Van Mourik, 1985; Wittmoser, 1985; Drott et al., 1998; Telaranta, 1998). The consequences of this surgery are that patients will never be able to blush anymore and, according to the above authors, there were transient, but no severe side-effects of the operation.

Although surgical treatment of blushing, thus, seems promising for severe blushing, some critical remarks are in order. Firstly, no measure for the severity or intensity of blushing was used in the studies investigating the effects of surgical methods. That is, patients' self-reports were used as the primary source to indicate patients for surgical treatment. As such, it remains unclear to what extent blushing was really a severe problem, at the physiological level. Secondly, the effect studies made use of patients only; no comparisons were made with control groups, or with psychological treatment. Next, effects were, mostly, measured with retrospective questionnaires. That is, complaints and feelings of both before and after the operation were examined at the same moment: after surgery (e.g. Drott et al., 1998). Furthermore, although surgical treatment may have beneficial effects, there is a considerable risk of developing post-surgical complications, primarily compensatory sweating and pathological gustatory sweating and flushing, these conditions being the rule rather than the exception (Drummond, in press). Moreover, besides the question whether surgical treatment is significantly better than any other form of treatment for fear of blushing, it seems unwise to lose the bodily reaction of blushing, especially when considering that it may have important communicative functions (see Chapter one, paragraph Blushing as a remedial gesture).

\section{Psychopharmacological treatment}

There are no pharmacological trials directed specifically at fear of blushing. Social phobia, however, has been given considerable attention within the area of pharmacological research. The goals of pharmacotherapy for social anxiety disorder are to: (1) relieve fearful affect and cognitions, (2) reduce anticipatory anxiety, (3) attenuate avoidance behaviour, (4) reduce the autonomic and physiological symptoms of arousal and anxiety, and (5) produce a concomitant improvement in disability and quality of life (Davidson, 1998). Beta-blockers are thought to block physical symptoms of anxiety and, as such, they have attracted some attention as treatments for performance anxiety (Hayward \& Wardle, 1997). Beta-blockers seem to be of particular interest with social phobics who experience many somatic symptoms, like palpitations, sweating, trembling, and blushing (Scholing \& Emmelkamp, 1990). However, beta-blockade does not seem to be involved in a decrease in blushing, as indicated by research of Drummond (1997). 
Furthermore, most research with beta-blockers was done with volunteers suffering from some kind of performance anxiety (often musicians), which makes it difficult to generalize the results to social phobia or fear of blushing. Finally, only a few studies investigated the effect of beta-blockers in social phobia, showing inconclusive effects of regular administration with clinical social phobics: For example, no significant differences were found between a beta-blocker (propranolol) and a placebo on measures of specific fears, generalized social anxiety, self-image, and global tension and anxiety (Falloon, Lloyd, \& Harpin, 1981), and Liebowitz et al. (1992) found social phobics to be responsive to the MAO-inhibitor phenelzine, but not to the beta-blocker atenolol. In sum, beta-blockers, seem to be an effective treatment for stage fright, to be administered once-only before performance, but not for regular use in social phobics (Emmelkamp, Bouman, \& Scholing, 1995) or blushing phobics.

The effects of benzodiazepines (e.g. diazepam) have hardly been investigated in controlled trials, although they are probably very commonly prescribed for social phobics (Scholing \& Emmelkamp, 1990). Still, dependency problems associated with long-term use form an important disadvantage of benzodiazepines. Relatedly, despite the - perhaps positive effects of benzodiazepines in reducing social phobic symptoms, it is important to note that these medications have strong sedative properties. This hampers the investigation as to whether symptom reductions are due to the sedative effect or whether a specific anxiolytic effect has lead to the diminished avoidance behaviour (Den Boer, Van Vliet, \& Westenberg, 1995). Just like for social phobia, benzodiazepines are certainly not the treatment of choice for fear of blushing.

The efficacy of the MAO-inhibitor phenelzine, especially in the treatment of generalized social phobia, has been established in several placebo-controlled trials (Gelernter et al., 1991; Liebowitz et al., 1992; Versiani et al., 1992), leading to the status of 'Gold Standard' (Lydiard \& Falsetti, 1995). Furthermore, phenelzine has been proved to produce better results than a beta-blocker (Liebowitz et al., 1992). A major risk, however, of the use of the conventional and irreversible MAOI's has been the development of hypertensive crises, due to potentiation of the tyramine pressor effect (Den Boer et al., 1995). Therefore, phenelzine has limited its utility as first-line pharmacotherapy for social anxiety disorder (Davidson, 1998). Treatment with the new generation of selective and Reversible MAO-A Inhibitors (RIMA's), like moclobemide and brofaromine, requires no dietary measures. Still, whereas the earlier trials by Versiani et al. (1992) and The International Multicenter Clinical Trial Group (1997) have reported moclobemide to be more effective than placebo, the more recent studies published with moclobemide have suggested that this drug has only modest efficacy (Davidson, 1998; Noyes et al., 1997; Schneier et al., 1998). Brofaromine is no longer available (Davidson, 1998).

Finally, some promising case reports and open trials have reported that the Selective Serotonin-Reuptake Inhibitors (SSRI's) fluoxetine (Schneier, Chin, Hollander, \& Liebowitz, 1992a), paroxetine (Mancini \& Van Ameringen, 1996; Ringold, 1994), and sertraline (Van Ameringen, Mancini, \& Streiner, 1994) may be effective in generalized social phobia. Recent placebo-controlled trials on paroxetine (Allgulander, 1999; 
Baldwin, Bobes, Stein, Scharwächter, \& Faure, 1999; Stein et al., 1998) indeed support these findings, leading to paroxetine rapidly being considered as a first-line treatment (Davidson, 1998). Preliminary findings with the other SSRI's need to be further validated in large, controlled studies.

\section{Cognitive-behavioural treatment}

The starting point for cognitive therapy for fear of blushing, is that the fear is maintained through the negative interpretation of the (social) consequences of the physiological reactions (i.e. blushing) (Bögels \& Scholing, 1995). Patients think that blushing is interpreted by other people as a sign of insecurity or incompetency, that their behaviour is constantly monitored by a critical audience, and that they will be judged solely with respect to their physiological reactions (Bögels \& Scholing, 1995). Gradual exposure in vivo as a treatment for social phobia (including fear of blushing) is not always easy to carry out. Butler (1985) reviews the potential problems to be encountered while formulating a fear hierarchy and when practising fearful social situations, thereby providing helpful solutions. For example, the social situations that provoke fear are not always predictable, making it difficult to order them hierarchically. Furthermore, many social situations last too shortly (e.g. entering a social situation) to make a satisfactory fear reduction possible. A possible solution for this problem might be to practice this situation frequently, instead of staying in the situation prolongedly. Another problem might be that, during many exposure exercises, the central fear of negative evaluation is not diminished; although the patient practices frequently and/or prolongedly, he remains afraid. Wells and colleagues (1995) have proposed that, in such cases, patients might still engage in so-called safety behaviours or subtle avoidance behaviour, preventing them from experiencing the actual exposure situation. Therapists should be prepared to investigate patients' safety behaviours and include the refraining from these behaviours in the fear hierarchy, as well.

Only a few empirical studies have been carried out investigating treatment effectiveness for fear of blushing. In fact, thus far, only two controlled treatment outcome studies have been reported, investigating the effects of cognitive-behavioural treatments for social phobics with fear of bodily symptoms as the central complaint. One study compared exposure followed by cognitive therapy, cognitive therapy followed by exposure, and a package in which both methods were integrated from the start (Scholing \& Emmelkamp, 1993a), whereas the other study compared cognitive therapy to applied social skills training (Bögels, 1994). All treatment methods that were used in these studies proved equally effective. However, effect sizes were rather modest. That is, the uncontrolled effect size (i.e. the effect of the treatment proper, unrelated to the effect of control treatments) for the outcome measure 'social phobia' after eight sessions of the integrated treatment in the Scholing and Emmelkamp (1993a) study was only 0.58 (see the meta-analysis by Feske \& Chambless, 1995), whereas uncontrolled effect sizes of the other social phobia studies included in the analysis fluctuated between 0.5 and 1.73 (Feske \& Chambless, 1995). For comparison, mean controlled overall effect size (that is, the effect of the investigated treatment, relative to the effect of control treatment, 
based on all of the dependent measures within one study) for cognitive-behavioural treatments for panic disorder was 0.68 , as computed in a meta-analysis (Gould, Otto, \& Pollack, 1995). Effect sizes of the study by Bögels (1994) were reasonably higher (that is, 1.29 vs 1.37 for social skills training and cognitive therapy, respectively, on a measure of trouble of blushing, trembling, and/or sweating at 1-month follow-up). Yet, this study used outcome measures that were specifically directed at fear of blushing, whereas the meta-analysis by Feske and Chambless (1995) used a measure of generalized social phobia to compare the Scholing and Emmelkamp (1993a) study with the other studies. These findings support the clinical impression that social phobics with fear of bodily symptoms are relatively difficult to treat, at least with the existing types of treatment. Furthermore, these data warrant the need for specific instruments to measure changes in fear of blushing.

Social phobia has been investigated more often in treatment outcome studies. In the last fifteen years, several studies have been conducted on treatment of social phobia, investigating the effectiveness of mainly exposure in vivo and cognitive strategies, in individual and group treatment (e.g. Butler, Cullington, Munby, Amies, \& Gelder, 1984; Emmelkamp, Mersch, Vissia, \& Van der Helm, 1985; Mattick \& Peters, 1988; Mattick, Peters, \& Clarke, 1989; Scholing \& Emmelkamp, 1993b; Heimberg et al., 1990; Mersch, 1995).

The first controlled study in which a behavioural intervention (in vivo exposure) was compared to cognitive interventions (rational emotive therapy and self-instruction training) was done by Emmelkamp et al. (1985). Each of the three therapeutic procedures resulted in significant decrements on various self-report measures of social anxiety and avoidance. Other comparative studies indicate that the effects of exposure, social skills training, cognitive therapy, and cognitive-behavioural treatment are not very far apart. For instance, compared to exposure, cognitive-behavioural treatment did not lead to greater pretest-posttest or pretest-follow-up improvement on self-report measures of social anxiety, cognitive symptoms, or depressed/anxious mood (Feske \& Chambless, 1995). The effects of the different treatments are modest, though (see for example the reviews by Donohue, Van Hasselt, \& Hersen, 1994; Feske \& Chambless, 1995). Patients do improve, but they are generally not complaint-free after treatment (Bögels, 1997).

Yet, it remains largely unclear whether the results of the above social phobia studies can be applied to social phobic patients with fear of blushing as the predominant complaint. For in the above-mentioned studies, no difference was made between subcategories of social phobia (i.e. generalized social phobia, specific social fear of only one or a few circumscribed social situations or fear of showing bodily symptoms). In other words, there seems to be room for improvement of treatments for fear of blushing. 
Effectiveness of biological treatments versus cognitive-behavioural treatments for social phobia

Although the efficacy of several pharmacological treatments for social phobia has been demonstrated, there is also a considerable amount of evidence for the effectiveness of cognitive-behavioural treatments. In comparison to the so-called 'gold standard' MAOinhibitor phenelzine, cognitive-behavioural treatments appear to be about equally effective and seem to have more lasting effects (Lydiard \& Falsetti, 1995). Nevertheless, the potential effect of psychopharmacological treatment in fear of blushing, specifically, remains to be investigated.

Recently, Gould, Buckminster, Pollack, Otto, and Yap (1997) reported a metaanalysis, in which they compared all available controlled treatment outcome studies of cognitive-behavioural and pharmacological treatments for social phobia (24 studies; $\mathrm{N}=1079$ individuals). Again, it should be stressed that this analysis concerned social phobia, and not fear of blushing, specifically. The authors only included treatment outcome studies for patients with social phobia that employed a control group (notreatment or wait-list control, drug or psychological placebo). Excluded were also opentrial pharmacological studies because they tend only to report outcome on individuals who complete the trial, thereby artificially inflating effectiveness rates. Cognitivebehavioural interventions were defined as studies that utilized cognitive restructuring, situational exposure, social skills training, systematic desensitisation, flooding, and anxiety management techniques. Individuals ought to meet either DSM-III , DSM-III-R, or DSM-IV criteria.

Eventually, a total of sixteen studies with 27 treatment groups employed cognitive-behavioural interventions without pharmacotherapy. Ten studies that included thirteen treatment interventions provided data on the efficacy of pharmacotherapy relative to pill placebo, pill placebo plus exposure, or a no-treatment control group. Two studies attempted to combine medication and CBT components. The studies that met the required criteria were very heterogenous with respect to dependent measures used to assess treatment outcome. That is, some studies used behavioural avoidance tests as their primary outcome measure, others used self-report questionnaires, blind and unblinded clinician-rated measures of change, and physiological measures (i.e. heart rate or galvanic skin response). The authors reduced a potential source of measurement bias in their own meta-analysis by deriving effect sizes from validated self-report questionnaires. Selfreport questionnaires were the most frequently employed assessment tool, and were used in all 24 studies.

Three effect sizes were calculated for each social phobia study: a measure of social anxiety and avoidance, a cognitive measure, and a measure of depression (cf. Feske \& Chambless, 1995). The effect sizes were computed for each dependent variable at postreatment and, when available, at follow-up. Mean social anxiety ES for the two studies that combined CBT with medication was .49 . No mean ES for cognitive change in psychopharmacological treatments was provided, since this was measured in one study only. Detailed results with respect to effect sizes can be obtained from Gould et al. (1997). Mean social anxiety ES across all CBT studies was .74. When compared to the 
effect sizes of pharmacotherapy (mean social anxiety $E S=.62$ ) or combined treatment of CBT and medication $(E S=.49)$, these differences appeared to be not statistically significant.

The authors used a minimum follow-up period of three months. From the original 24 studies, only eight studies (including seventeen interventions) provided data, suitable for calculating follow-up effect sizes. The mean within group ES for all studies at followup was .21 , suggesting that subjects continued to make modest improvement in their social anxiety after treatment had ended (Gould et al., 1997). Notably, almost all (seven) of these studies employed CBT interventions (mean ES=.23). Medication studies have largely failed to assess patients beyond initial 3-month trials, and need to examine the course of disorder after discontinuation from these agents (Gould et al., 1997), especially because of potential withdrawal effects and relapse.

More recently, Heimberg and colleagues (1998) conducted a treatment outcome study in which they compared a program of 12 weeks cognitive behavioural group therapy (CBGT) with the MAO-inhibitor phenelzine, pill placebo, and an attention placebo group. The results indicated that after 12 weeks, phenelzine therapy and CBG'T led to superior response rates and greater change on dimensional measures than did either control condition. Long term follow-up results are, however, not yet available.

In conclusion, although both $\mathrm{CBT}$ and medication provide equal effects, the fact that medication is often disadvantageous because of side effects, dependency, and withdrawal effects, and because long term effects remain to be further investigated, CBT seems to be the preferred treatment for social phobia, to date.

\section{Task Concentration Training}

From the above, it seems justified to conclude that cognitive-behavioural treatment interventions for social phobia are most effective. That is, when long-term effects are also considered, there is evidence that CBT interventions provide lasting effects, relative to psychopharmacological interventions. The effect sizes are, however, modest and there seems to be some room for improvement. Furthermore, it remains unclear to what extent the above findings account for fear of blushing.

The alleged importance of heightened self-focused attention in the maintenance of fear of blushing provides one clue to improve traditional CBT for blushing phobics. It seems worthwhile to include strategies to teach social phobics with fear of bodily symptoms to redirect their attention in social situations; that is, away from themselves and the bodily symptoms, and towards the task and their environment. Attention training is not a new phenomenon; the method became known in sports psychology (e.g. Owen \& Lanning, 1982; Singer, Cauraugh, Murphey, Chen, \& Lidor, 1991a; Singer et al., 1991b). It is not unusual to train athletes to direct their attention to the task at hand and to seclude themselves from interference of, for example, noise, insecurity, doubt, or tiredness. Furthermore, attention training has been successfully applied for test anxiety (Ribordy, Tracy, \& Bernotas, 1981), and in cases with panic disorder (Wells, 1990).

Recently, such a Task Concentration Training (TCT) has been designed for fear of blushing (Bögels et al., 1995; Bögels, Mulkens, \& De Jong, 1997). This TCT involves 
the following components: (1) explanation of the rationale; (2) registration of the direction of attention in fearful social situations; (3) TCT in non-threatening situations; (4) TCT in threatening situations. The rationale explains how someone, as a result of self-focused attention, may be troubled by anxiety in social situations and by (fear of) blushing. Diaries are used for registration of the direction of attention. In the sessions, patients are trained to redirect their attention, with the help of listening and talking exercises. This skill is then used in non-threatening situations, first. For example, patients are instructed to walk through a quiet forest and direct their attention to one aspect of the situation (e.g. all the auditive information), and then to another aspect (e.g. all olfactory aspects), etc. Finally, they are instructed to experience all information as a whole. Another exercise is to follow the news for a few minutes, and to summarize it afterwards. The goal of these exercises is learning to concentrate for a while on one thing, and to switch attention to something else, whenever necessary. Finally, this skill is practised in increasingly threatening social situations.

Case studies applying TCT for fear of blushing at the Maastricht mental health center indeed showed successful reductions in fear, avoidance, and negative cognitions (Bögels et al., 1995, Bögels et al., 1997). To see whether it concerns reliable effects, it seems important to further investigate the effectiveness of TCT in larger patient groups. 


\section{Outline of this thesis}

The present thesis aims to elucidate some of the issues on fear of blushing mentioned in the previous chapter. In doing so, seven studies were performed, dealing with several aspects of the model that was outlined in Chapter two. Five studies concern the more theoretical aspects of fear of blushing, and two studies deal with specific treatment issues that derived from the model. The shaded parts in Figure 3.1 indicate the parts of the model that were investigated in some way. The numbers in Figure 3.1 refer to the research questions that address a particular part of the model. The research questions of this thesis will be further delineated below.

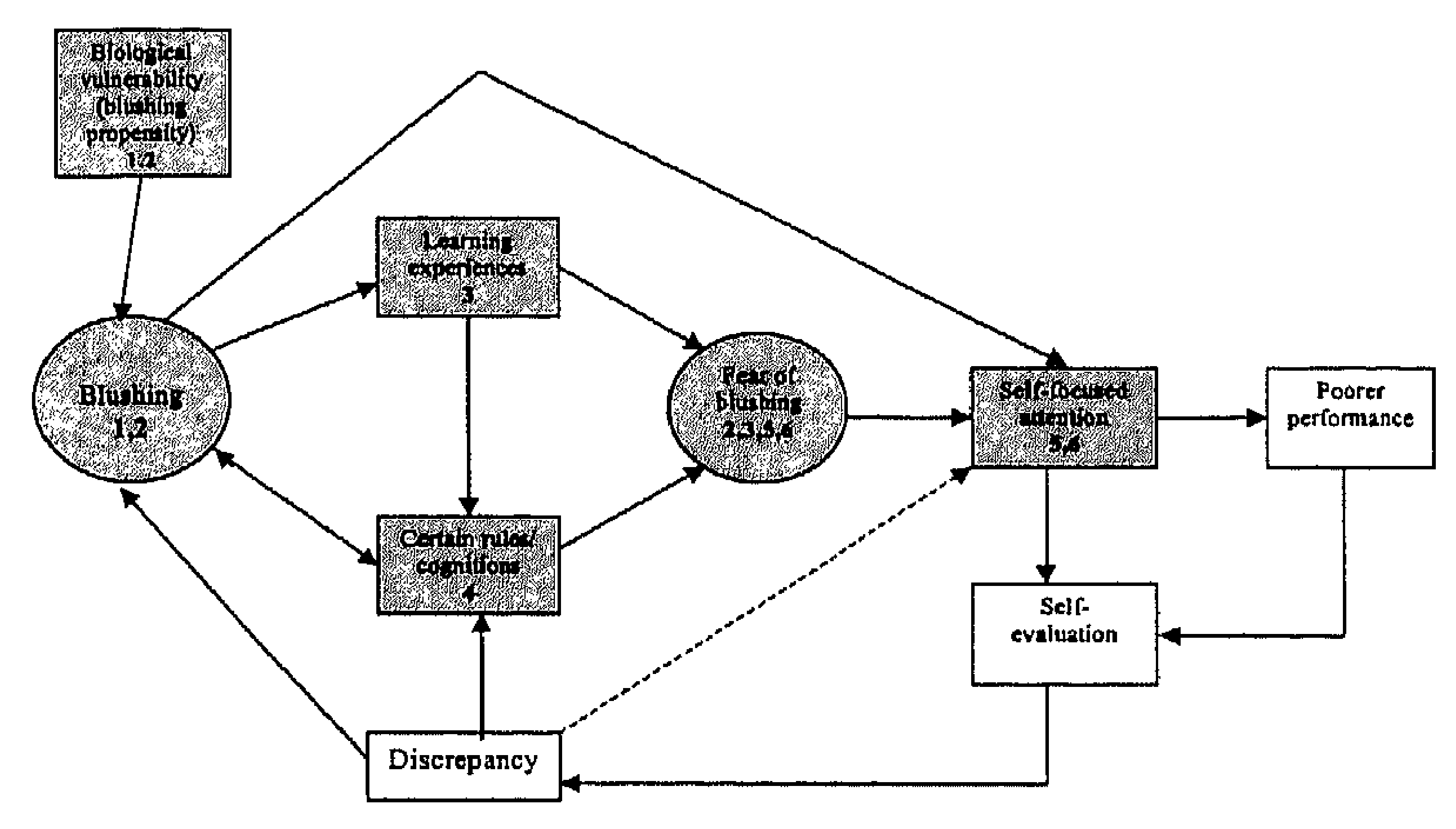

Figure 3.1: Parts of the model that were investigated in this thesis (shaded parts), and indication of research questions addressing these parts

\section{Research Questions}

1 Do people who consider themselves high in blushing propensity indeed blush more easily or more intensely than people who consider themselves low in blushing propensity?

High blushing propensity might be a vulnerability factor for developing fear of blushing, and self-reported blushing propensity is, indeed, associated with fear of blushing. 
However, it remains unclear to what extent self-reports about blushing are accurate Therefore, Section 4.1 describes a study in which blushing is objectively measured in several contexts, in people with high and low scores on a self-report measure of blushing propensity. Such a procedure allows to draw conclusions with respect to the validity 0 self-report measures of blushing propensity.

2 Do people who are afraid of blushing indeed blush more easily or more intensely in response to several types of social stressors, than people who are not afraid oj blushing?

Section 4.2 elaborates on the theme in Section 4.1, namely that high blushing propensity might be a vulnerability factor for developing fear of blushing. In Section 4.1, actual blushing is measured in individuals with high and low scores on blushing propensity, in several contexts. However, although self-reported blushing propensity and fear of blushing are related, there is no perfect correlation. Therefore, Section 4.2 aims to investigate potential differences in actual blushing between individuals high and low in fear of blushing. Furthermore, several hierarchical levels of social stressors were used in order to preclude potential ceiling effects in blushing reactions.

3 To what extent have individuals with fear of blushing been exposed to aversive conditioning experiences, vicarious learning experiences, and/or informational learning experiences, compared with control individuals?

Learning history is assumed to be an important determinant in the acquisition of fears and phobias. This might also account for fear of blushing, especially since blushing is a visible bodily reaction that might attract attention and may form a source of bullying. In Section 4.3, two studies are presented in which the learning history of blushing phobics and their nonphobic counterparts is investigated. In the first study, this was attempted by using a self-report questionnaire, in the second study a systematic interview procedure was used, applying strict classification rules for learning experiences.

Cognitive factors are also assumed to play an important role in the acquisition and maintenance of phobias, like fear of blushing. Accordingly, individuals with fear of blushing report high credibility ratings pertaining to negative beliefs about blushing and its social consequences. Section 4.4 aims to clarify how nonphobic individuals view often associated with feelings of shect that nobody actually enjoys blushing since it is 
attention. Even if blushing would serve a remedial function and would be helpful or necessary to display in particular instants, it might still be an event that is rather avoided as much as possible. In the case that nonphobic individuals view blushing as negative, this might complicate the distinction between nonphobic individuals and blushing fearful individuals on the basis of negative, dysfunctional cognitions.

One of the model's major predictions is that fear of blushing and increased self-focused attention or self-awareness are maintained reciprocally, via several intermediate steps. When this assumption is true, this vicious circle could be broken by an intervention that aims to redirect blushing phobics' attention towards the task and the environment, instead of towards the self and blushing. Section 4.5 describes a single case study in which the effects of multiple successive attention switches (inward versus outward during several weeks, respectively) were investigated in a patient suffering from fear of blushing. The method that was used was based on the newly developed Task Concentration Training (TCT) that was already briefly described in Chapter two.

What are the relative effects of Task Concentration Training versus Exposure in Vivo in the treatment of fear of blushing?

The attention training method called TCT includes several elements. One element is the practising of the newly acquired technique, first in nonsocial, nonthreatening situations. After that, situations with an increasing level of difficulty are trained. This part resembles the commonly used Exposure in Vivo technique, making it difficult to determine what a potentially active ingredient of TCT might be: the redirecting of attention in threatening social situations, or the exposure to feared situations that has been avoided for some time. In Section 4.6, a treatment study is described in which individuals with fear of blushing are treated with either TCT or Exposure in Vivo, half of them serving as waiting-list control individuals. The effect of treatment on subjective as well as physiological indices of (fear of) blushing were tested. 


\section{Empirical studies}




\title{
4.1 High blushing propensity: Fearful preoccupation or facial colouration?
}

\begin{abstract}
Twenty-seven women with high scores on the Blushing Propensity Scale (BPS) and 26 women with low BPS scores were exposed to two different video excerpts. One video showed the subject's own singing, recorded in a previous session and the other video showed an excerpt of Hitchcock's movie Psycho. During the experiment, facial colouration, facial temperature, and skin conductance level were measured. In addition, subjects' blushing intensity was judged by raters. Finally, subjects were asked to rate their blushing intensity and fear of blushing during the video presentations. Subjects generally blushed more during the presentation of their singing than during comparison stimulation, as measured physiologically. There were no between group differences in this respect. No differences were found between the two groups on raters' judgements about blushing intensity. However, high BPS subjects dramatically overestimated their blushing intensity and were more afraid of blushing than low BPS subjects. During the mere presence of the raters, there was a non-significant tendency for high BPS subjects to show a relatively strong colouration. Thus, the BPS seems to reflect both a fearful preoccupation and a stronger facial colouration.
\end{abstract}

${ }^{2}$ This section is a slightly adjusted version of the article Mulkens, S., De Jong, P.J., \& Bögels, S.M. (1997). High blushing propensity: Fearful preoccupation or facial coloration? Personality and Individual differences, 22, 817-824.

Acknowledgements

We thank Don Shearn for his helpful advice concerning the use of the photoplethysmograph and Theo van Aerts for modifying the photoplethysmograph device and his technical assistance. 


\section{Introduction}

Blushing is a quite common physiological reaction that is seen across cultures and among persons of different age and sex (Darwin, 1872; Edelmann et al., 1989). People blush in a wide variety of situations. Yet, the stimuli that can elicit a blush seem to be restricted to the following four categories: threats to public identity, praise and other forms of positive attention, scrutiny, and accusations of blushing (Leary, Britt, Cutlip \& Templeton, 1992). Virtually all people blush at least occasionally (Edelmann, 1990b). There are people, however, who report that they blush more frequently than other people (Leary \& Meadows, 1991).

Some people find it extremely aversive to blush and even develop a blushing phobia. It seems reasonable to assume that high blushing propensity might be a vulnerability factor for developing fear of blushing or even blushing phobia. In line with this, it has been demonstrated that fear of blushing is, indeed, associated with blushing propensity, as indexed with the Blushing Propensity Scale (BPS; Bögels, Alberts, \& De Jong, 1996).

Thus far, studies on individual differences in blushing propensity have only relied on self report measures. Therefore, it cannot be excluded that these measures primarily reflect a subjective feeling rather than objectively observable phenomena. From a cognitive perspective, it might be argued that people high in blushing propensity falsely believe that they blush more easily/intensely/visibly than other people and, therefore, consider themselves as deviating from social standards (e.g. Clark \& Wells, 1995; Edelmann, 1987). If so, blushing may become an aversive stimulus. In other words, it might be that some people only think that they blush more easily/intensely/visibly than other people and become anxious as a consequence. Alternatively, it might be that people who display high scores on the BPS, indeed, objectively blush more easily/intensely than people with low scores on the BPS and, as a result, might be vulnerable for developing fear of blushing.

To investigate whether people who consider themselves high in blushing propensity (i.e. high scores on the BPS), indeed blush more easily/intensely than people who consider themselves low in blushing propensity, we had people high and low in blushing propensity undergo an induction, intended to elicit blushing. Subjects visited the laboratory twice. On the first day, they sang a song in front of a camera; on the second day, they watched the recorded tape of their singing in the presence of research confederates, while blushing was recorded (cf. Shearn, Bergman, Hill, Abel, \& Hinds, $1990,1992)$. Singing has been used successfully to induce embarrassment in face-saving experiments (Brown \& Garland, 1971; Garland \& Brown, 1972; Shearn et al., 1992). Furthermore, watching one's own singing in the presence of other people incorporates at least two of the four situations in which people tend to blush: threat to the public identity and scrutiny.

During the experiment proper (i.e. watching the videos), blushing was measured physiologically as well as subjectively. Physiological parameters were changes in blood flow which were expected to reflect visibility of the blush, and temperature changes, 
which were expected to reflect interoceptive cues of blushing (i.e. warmth). In addition, the visibility of the blush was assessed by two raters, who were blind with respect to the classification of subjects (high or low in blushing propensity). Finally, subjects were asked to rate their blushing intensity during the video presentation. If the BPS is an adequate index of the degree/frequency of blushing, one would expect subjects who consider themselves high in blushing propensity to show a stronger physiological blushing reaction, to indicate higher scores on a subjective measure of blushing, to receive a higher score on blushing as judged by raters and have a retarded recovery rate, compared to subjects who score low on blushing propensity.

With the above mentioned procedure, it is also possible to test the alternative hypothesis, namely, that people who are high in blushing propensity according to the BPS do not objectively blush more easily/intensely, but tend to overestimate their blush reaction. Additionally, this procedure provides the opportunity to investigate whether self-reported blushing propensity is connected with interoceptive signals (i.e. temperature changes) rather than with the visibility of the blush as determined by blood flow and raters' data. That is, it may well be that subjects with high BPS scores are characterized by relatively large temperature changes rather than by large visible bloodflow changes.

Following Shearn's design, we also used a control stimulation that was not intended to produce blushing but to elicit autonomic activity (a scene from Hitchcock's thriller Psycho). Skin conductance levels were measured as a physiological correlate. When arousal levels remain the same while watching both video excerpts, a stronger blushing reaction in response to the 'sing' video would support Leary's view that people blush in circumscribed social situations instead of in general arousal-inducing situations.

\section{Method}

\section{Subjects}

Between eight months and three weeks prior to the experiment, 286 female undergraduate students from Maastricht University completed the Blushing Propensity Scale (BPS; see below). From this sample, 53 subjects were selected on the basis of their scores on this questionnaire and their willingness to cooperate in research. In order to create two extreme groups, only subjects with a BPS score in the lowest third and the highest third of the distribution were invited to participate in the experiment. At the time of the experiment, we had subjects complete the BPS again, to be sure that subjects were properly classified as high or low in blushing propensity.

Subjects were 26 women low in blushing propensity and 27 women high in blushing propensity. Mean BPS scores of low and high frequent blushers were 11.4 (SD 3.9; range 3-17) and 51.3 (SD 5.3; range 40-63), respectively. At the time of the experiment, mean BPS score of low frequent blushers was 18.3 (SD 8.5; range 2-32) and mean BPS of high frequent blushers was 52 (SD 8.3; range 36-65). Mean age of low BPS subjects was 19.7 (SD 3.0; range 18-33) and mean age of high BPS subjects was 19.1 (SD 1.2; range 17-22). Subjects received a small financial compensation for their participation in the experiment. 


\section{Assessment}

The BPS originally consisted of fourteen circumscribed social situations for each of which the subject has to indicate how often she feels herself blushing (Leary \& Meadows, 1991). In the Dutch version, five items were added to the original version, in order to cover a wider range of situations in which people tend to blush, including the dimension of being accused of blushing, proposed by Leary and co-workers (1992). The additional items are "When I'm being accused of blushing", "When I think I may start blushing", "When the subject of conversation is sex", "When I'm interacting with someone whom I find attractive", "When I'm criticized". Answers range from ' 0 ' (II never feel myself blushing in that situation") to '4' ("I always feel myself blushing in that situation").

According to the results of a psychometric study of Bögels et al. (1996), the internal consistency of the BPS is high (Cronbach's $\alpha=.92$ ). The BPS is a stable instrument, as the test-retest reliability in this study indicates $(r=93 ; n=53)$.

Design

The design consisted of one within-subjects factor: type of stimulation (intended to evoke blushing vs intended to generally arouse) and two between-subjects factors: blushing propensity (high or low), and order of presentation of stimulation (the song first or the movie scene first). The dependent variables were cheek temperature, cheek colouration, finger skin conductance, self reported fear of blushing, self reported blushing intensity, and raters' judgement of blushing intensity.

\section{Apparatus and recordings}

Cheek colouration was recorded from a HP model $15230 \mathrm{~A}$ plethysmograph transducer that was modified in such a way that it was de coupled rather than ac coupled. The probe operates in the infrared spectrum. Cheek temperature was assessed by means of a temperature dependent resistor (PT100) that was dc coupled.

Skin conductance level was recorded using two Beckman $\mathrm{Ag}-\mathrm{AgCl}$ electrodes ( $8 \mathrm{~mm}$ diameter), placed on the medial phalanges of the middle finger and ring finger of subjects' non-dominant hand, using the method of constant voltage $(0.5 \mathrm{~V})$. The electrodes were filled with an isotonic paste and connected to a Beckman Skin Conductance Coupler (type 9844). All physiological signals were sampled with a frequency of $1000 \mathrm{~Hz}$ by a Compaq $486(33 \mathrm{MHz})$ computer.

Colour video recordings of the subject's singing were made with a Sony $\mathrm{Hi}-8$ video camera recorder (CCD-TR650E) and a JVC video cassette recorder (HR$\mathrm{D} 800 \mathrm{EG} / \mathrm{E}$ ). The subject was seated $2 \mathrm{~m}$ from a $51 \mathrm{~cm}$ diameter Sony colour television (KV-M2101D) when stimulation was presented during the second session.

\section{Stimulation}

Three different types of videotapes were used in the experiment: a neutral baseline video (i.e. a steady television test card), a video that was intended to elicit blushing (i.e. the individual's singing, recorded during the first session) and a video that was intended to 
generally arouse (i.e. the shower murder scene from Hitchcock's Psycho). Prerecorded videotapes were presented in the following order: $5 \mathrm{~min}$. of neutral baseline material, one type of stimulation (song or Psycho), 5 min. of neutral baseline material, other kind of stimulation (song or $P_{s y c h o}$ ), $5 \mathrm{~min}$. of neutral baseline material. Order of presentation of both types of stimulation was counterbalanced across subjects high and low in blushing propensity.

The stimulation, intended to elicit blushing, was the subject's own prerecorded singing presented on the television set in the presence of two male confederates, who responded with neutral eye contact. The duration of this stimulation varied because some individuals sang faster than others, but it lasted at least $20 \mathrm{sec}$. and at most $40 \mathrm{sec}$. The duration of the other type of stimulation was always $50 \mathrm{sec}$. To assess the rate of recovery, psychophysiological measures were recorded for an additional $40 \mathrm{sec}$. after both types of stimulation. In case of the stimulation intended to produce blushing, the two male confederates had left the room already when the recovery assessment started.

\section{Procedure}

Subjects were informed about the general nature of the study but were not told that it was concerned with blushing until debriefing after the last session.

On the first day of the experiment the subject first completed the BPS, whereafter she was asked to stand in front of both the video camera/television set and the experimenter, and sing the Dutch version of 'Happy Birthday' (i.e. 'Lang zal 'ie/ze leven') using facial and bodily expressions as much as possible.

During the second session, which was at least two days and at most nineteen days after the first session, the subject was asked to sit in a chair at a table in front of a television set. A photoplethysmograph probe was attached to the left cheek and a temperature probe was attached to the right cheek of the subject. In addition, skin conductance electrodes were placed on the medial phalanges of the middle finger and ring finger of subjects' non-dominant hand. The subject was informed that these instruments would record physiological responses and that they would not cause pain. The subject was instructed to watch the television screen and to move as little as possible. After each video excerpt, the subject was asked to judge how she felt using 100 mm Visual Analogue Scales (VASs). The pertinent questions that participants had to answer on each occasion were "How much were you afraid to start blushing during the presentation of the video excerpt?" (ranging from $0=$ "not afraid at all" to $100=$ "very much afraid") and "How much did you blush during the presentation of the video excerpt?" (ranging from $0=$ "I didn't blush at all" to $100=$ "I blushed very much").

After the subject had completed the VASs (after each excerpt), the experimenter entered the room to change the video tape in the videorecorder and to turn the sound on or off, depending on what excerpt would follow (during the presentation of the base-line material no sound was used). If the subject talked to the experimenter, she responded in a neutral manner, without using words. Just before the stimulation started that was intended to produce blushing, the experimenter introduced two male confederates. During the 'sing' video the confederates remained in the lab and were seated to the side, 
between the subject and the television set. These confederates were asked to judge, independent from each other, the subjects' blushing intensity on a VAS (ranging from $0=$ "she did not blush at all" to $100=$ "she blushed very much").

Data reduction and analysis

All physiological parameters were analysed off-line by means of a specifically designed computer program. For both the first and the second baseline assessment, mean responses for all three physiological parameters (i.e. skin conductance level, facial temperature and facial colouration) were calculated by averaging the values on $4 \mathrm{~min}$., $4.5 \mathrm{~min}$., and 5 $\mathrm{min}$. Then, for all three physiological measures difference scores were computed between the highest level during stimulation and the mean baseline response that preceded that stimulation. In addition, we took values at $40 \mathrm{sec}$. after ending of the stimulation and subtracted mean baseline values from this value, to evaluate the rate of recovery.

The intensity of subjects' blushing reactions during the presentation of the fragment of her singing was judged by two confederates. The means of both ratings were used in the analyses.

The difference scores of all physiological and subjective measures (i.e. fear of blushing and self reported blushing intensity) were subjected to an Analysis of Variance (ANOVA) with two between-subjects factors (Group: High vs Low blushing propensity and Order: song first vs Psycho first) and one within-subjects factor (Stimulation: intended to produce blushing vs intended to generally arouse).

To examine the accordance between subjectively reported blushing and objectively observed blushing, Pearson's product-moment correlations were computed between raters' scores and subjects' scores of blushing during the 'sing' video. In addition, Pearson correlations were calculated between raters' judgments of blushing reactions and subjects' physiological parameters. Finally, we explored the interrelationship between subjective blushing intensity and subjects' physiological responding. Therefore, Pearson product-moment correlations were computed between all three physiological difference scores (that is, the difference scores between the highest level during stimulation and the mean baseline response that preceded that stimulation) and subjects' self reported blushing intensity as indicated on a VAS.

\section{Results}

Due to technical problems, no colouration data were available for three cases. For an additional three cases, recovery data on all three physiological measures were not available. This is reflected in the degrees of freedom. In Table 1 , all outcomes are
summarized. 
Cheek colouration

A 2(Group) x 2(Stimulation) x 2(Order) ANOVA on difference scores between mean baseline level and highest level during stimulation revealed a significant main effect for Stimulation, $F(1,46)=160.88, p<.05$. That is, subjects generally displayed more facial colouration during watching their singing than during watching Psycho. No main effect of Group was found, $F(1,46)=0.30$, nor a main effect of Order, $F(1,46)=0.08$. Contrary to our expectations, there was no significant interaction between Group and Stimulation, $F(1,46)=0.01$. Thus, the relative increase in colouration was similar for subjects with high and low BPS scores during the presentation of the 'sing' video. No other significant interaction effects emerged.

The ANOVA on the difference scores between mean baseline level and $40 \mathrm{sec}$. after the end of the stimulation, revealed a significant main effect for Stimulation, $F(1,43)=44.11, p<0.05$, indicating that subjects' cheek colouration was still more increased $40 \mathrm{sec}$. after the 'sing' video than $40 \mathrm{sec}$. after Psycho. The retarded rate of recovery after the 'sing' video was not especially prominent in the high BPS group. That is, no interaction between Group and Stimulation appeared, $F(1,43)=.30$. No other significant main or interaction effects appeared.

Table 1: Mean differences between baseline and highest level during stimulation (Stimulation) and mean differences between baseline and $40 \mathrm{sec}$. after stimulation (Recovery) in high and low BPS subjects for the song and Psycho video.

\begin{tabular}{|c|c|c|c|c|c|}
\hline & & \multicolumn{2}{|c|}{ Song } & \multicolumn{2}{|c|}{ Psycho } \\
\hline & & High & Low & High & Low \\
\hline \multicolumn{6}{|l|}{ Colouration (V) } \\
\hline & Stimulation & $3.6(1.7)$ & $3.4(1.7)$ & $.61(1.1)$ & $.44(.6)$ \\
\hline & Recovery & $1.5(1.4)$ & $1.4(1.6)$ & $.04(.5)$ & $.11(.4)$ \\
\hline \multicolumn{6}{|l|}{ Temperature $\left({ }^{\circ} \mathrm{C}\right)$} \\
\hline & Stimulation & $.28(.33)$ & $.23(.27)$ & $.08(.21)$ & $-.03(.34)$ \\
\hline & Recovery & $.52(.44)$ & $.41(.48)$ & $.03(.25)$ & $-.08(.41)$ \\
\hline \multicolumn{6}{|l|}{ SCL } \\
\hline & Stimulation & $1.83(1.00)$ & $2.04(.85)$ & $1.01(.69)$ & $1.18(.78)$ \\
\hline & Recovery & $1.02(.72)$ & $1.08(.63)$ & $.42(.44)$ & $.41(.45)$ \\
\hline Fear of blushing & & $66.0(27.0)$ & $28.4(25.9)$ & $21.7(21.5)$ & $6.9(11.7)$ \\
\hline \multicolumn{2}{|c|}{ Subjective blush intensity } & $70.6(23.7)$ & $38.9(26.3)$ & $17.5(18.1)$ & $7.4(9.4)$ \\
\hline \multicolumn{2}{|c|}{$\begin{array}{l}\text { Raters' judgement of blushing } \\
\text { intensity }\end{array}$} & $46.0(16.5)$ & $39.1(19.6)$ & & \\
\hline
\end{tabular}




\section{Temperature}

By and large, temperature data showed the same pattern as the colouration data. A 2 (Group) $\times 2$ (Stimulation) $\times 2$ (Order) ANOVA on difference scores between mean baseline level and highest level during stimulation, revealed a significant main effect for Stimulation, $F(1,49)=18.75, p<0.05$, indicating that the temperature increase was generally stronger for the 'sing' video than for Psycho. No significant main effect of Group, $F(1,49)=2.22, p=0.14$, nor of Order, $F(1,49)=0.05$, emerged. Contrary to our expectations, there was no significant interaction effect between Group and Stimulation, $F(1,49)=03$. That is, both groups did not differ regarding their temperature changes, while watching both videos. A significant interaction effect emerged between Order and Stimulation, $F(1,49)=19.13, p<0.05$. Post hoc $t$-tests indicated that in order one (the "sing" video before $P$ sycho) subjects showed an increase in temperature during watching the 'sing' video whereas a slight decrease was found during watching Psycho $(t(25)=4.67, p<0.05$, means being 0.04 and -0.01$)$. In order two, where Psycho was shown first, there were no significant differences in temperature changes between the two kinds of stimulation $(t(26)=.01$, means being 0.01 for both kinds of stimulation). The order effect is due to the fact that skin temperature was generally increasing (stabilizing) during the session. Skin temperature changes are relatively slow, as compared to colouration changes. When blush stimulation was given first, temperature increased more, above the general increase, in that first part and because it had risen to a maximum, it was able to decrease during Psycho. However, when Psycho was shown first, skin temperature was generally increasing in order to stabilize and at the time of the second part of the experiment, during the blush stimulation, facial temperature could not rise much further.

The ANOVA on the difference scores between mean baseline level and $40 \mathrm{sec}$. after the end of the stimulation, again revealed a significant main effect for Stimulation, $F(1,46)=41.34, p<0.05$, indicating that subjects' temperature $40 \mathrm{sec}$. after the stimulation was still more increased $40 \mathrm{sec}$. after the 'sing' video than $40 \mathrm{sec}$. after Psycho. Contrary to our expectations, there was no significant interaction between Group and Stimulation, $F(1,46)=0.08$. A significant interaction effect between Stimulation and Order, $F(1,46)=$ $12.08, p<0.05$, was found, however. This reflects the spurious finding that the differences in recovery rate between both stimulations were especially prominent in order one (song first). No other significant main or interaction effects emerged.

\section{Skin conductance}

A 2(Group) $\times 2$ (Stimulation) x 2(Order) ANOVA on difference scores between mean baseline level and highest level during stimulation showed, again, a significant main effect for Stimulation, $F(1,49)=90.33, p<0.05$. That is, subjects showed generally greater skin conductance level elevations during the stimulation intended to produce blushing than during the other type of stimulation (mean elevations being 1.9 and 1.1 , $F(1,49)=0.86, p=0.36$, emerged $F(1.49)=0.86, p=0.36$, emerged. Again, there was no significant Group x Stimulation interaction, $F(1,49)=0.05$. Yet, a significant interaction effect between Group and Order 
was found, $F(1,49)=4.30, p<0.05$. This reflects the accidental finding that the low BPS group displayed relatively large SCL increases for order 1 (song first), whereas high BPS subjects displayed relatively large SCL increases for order 2 (Psycho first). No other significant effects were found.

The ANOVA on the difference scores between mean baseline level and $40 \mathrm{sec}$. after the end of the stimulation, again revealed a significant main effect for Stimulation, $F(1,46)=61.03, p<0.05$, which indicates a slower recovery rate after the presentation of blush-inducing material than after Psycho. Again, there was no significant Group $\mathrm{x}$ Stimulation interaction, $F(1,46)=.00$. Yet, again a significant interaction effect between Group and Order was found, $F(1,46)=4.57, p<0.05$. This reflects the spurious finding that the low BPS group displayed relatively retarded recovery rates in order 1 (song first), whereas high BPS subjects displayed relatively retarded recovery rates in order 2 (Psycho first).

\section{Self report measures}

Fear of blushing

A 2(Group) $\times 2$ (Stimulation) $\times 2$ (Order) ANOVA on subjectively reported fear of blushing revealed a significant main effect for group, $F(1,49)=27.24, p<0.05$, and for Stimulation, $F(1,49)=84.52, p<0.05$. In line with our predictions, a significant interaction effect between Group and Stimulation was found, $F(1,49)=11.07, p<0.05$. These results indicate that subjects with high BPS scores were generally more afraid to blush than subjects with low BPS scores, and especially so during the presentation of their song. The main effect of Stimulation indicates that subjects were generally more afraid to start blushing during the presentation of their song, compared to the presentation of Psycho. Blushing intensity

A 2(Group) $\times 2$ (Stimulation) $\times 2$ (Order) ANOVA on subjectively reported blushing intensity revealed significant main effects of both Group, $F(1,49)=23.0, p<0.05$, and Stimulation, $F(1,49)=158.0, p<0.05$, and a significant interaction effect between Group and Stimulation, $F(1,49)=11.59, p<0.05$. These results implicate a stronger subjective feeling of blushing in general in subjects with high BPS scores, as compared to subjects with low BPS scores, and especially so during the presentation of their song. Furthermore, it indicated that all subjects had the idea that they blushed more during the presentation of their song.

\section{Raters' judgements}

Mean raters' judgement about subjects' blushing intensity was similar for both groups, $(t(51)=-1.40, p=0.17$ (see also Table 1). There was a significant correlation between raters' blushing judgements and subjects' blushing judgements within the group with low BPS scores $(r=.62 ; p<0.05)$. In contrast, no such correlation was found between raters' blushing judgements and subjects' blushing judgements within the group with high BPS scores $(r=-.24, p=.23)$. Thus, for low BPS subjects, perceived blushing intensity was strongly related to observed blushing intensity, whereas for high BPS subjects, this relationship was absent. Interestingly, $t$-tests indicated that self reported blushing 
intensity of the low BPS subjects was not only linearly related but also similar to that of the raters $(t(25)=0.05, p=0.96$, see also Table 1$)$, whereas self reported blushing intensity of the high BPS subjects differed significantly from that of the raters $(t(26)=-4.0, p<0.05$, see also Table 1).

Physiological measurements, raters' judgements and subjective judgements of blushing intensity.

For neither group were there significant correlations between physiological indices of blushing and self reported blushing intensity on the one hand, and raters' judgement about blushing intensity on the other hand. This finding suggests that changes in physiological parameters, such as changes in colouration as measured plethysmographically, are not easily detected by either raters or subjects.

\section{Discussion}

The major results can be summarized as follows: (1) Physiological indices of blushing (i.e. blood flow and skin temperature) indicated that the female undergraduates blushed more intensely when watching their own 'sing' video than when watching Psycho; (2) There were no differences in this respect between subjects with high and low blushing propensity (BPS); However, (3) high BPS subjects were more afraid to start blushing and reported that they blushed more intensely than low BPS subjects. In other words, high BPS subjects overestimated their blushing reaction; Finally, (4) for neither group were there significant correlations between self-reported blushing intensity and physiological indices of blushing.

The present finding that subjects blushed more intensely during the 'sing' video than during Psycho, is in accordance with previous studies of Shearn and colleagues $(1990 ; 1992)$. This pattern was evident for the skin temperature of the cheek as well as for subjects' cheek colouration. In line with the physiological registration, the subjects also reported that they blushed more intensely during the song than during Psycho. Yet, in contrast to our expectation, the blush reactions as indexed by changes in blood flow and observed reddening were similar for subjects with high and low BPS scores. In other words, subjects who reported that they blushed relatively easily did not react with stronger blood flow responses or with a slower recovery rate than subjects who reported blushing only seldom. In addition, no differences were evident with respect to the temperature responses of both groups. Thus, the differential BPS scores neither referred to differences in observable components of the blush response during the 'sing' video nor to differences in the intensity of interoceptive cues related to blushing (i.e. increased skin temperature of the cheek).

One explanation for the absence of a differential response pattern for high and low BPS subjects with regard to their blushing response might be that our manipulation (i.e. watching one's own 'sing' video) has been too strong. That is, it may be that such a situation makes most people blush, thereby masking the individual differences between 
high and low BPS subjects. In other words, the absence of a difference between high and low BPS subjects might be due to a 'ceiling effect' for blushing reactions. The present experimental set-up provides a possibility to tentatively explore this issue. That is, it seems reasonable to argue that the mere presence of confederates is a relatively mild social stressor, which might more sensitively index between groups differences than watching one's own 'sing' video. As, in the current experiment, subjects' physiological responding was registered continuously, it was possible to (post hoc) investigate the influence of the mere presence of the two confederates (i.e. just before the video started) on subjects' cheek temperature and colouration. To explore this issue, we carried out two additional analyses. More specifically, we conducted a 2(Group: high/low BPS) $x$ 2(Moment: baseline/confederates present) ANOVA for both cheek temperature and colouration $^{3}$. The results indicate that subjects generally reacted with increased cheek colouration and temperature in the presence of the confederates. Most pertinent to the present context, there was a non-significant trend of an interaction between Group and Moment for subjects' cheek colouration, indicating that high BPS subjects reacted with more facial colouration than low BPS subjects. Thus, the present findings provide some tentative evidence for the idea that high BPS subjects, indeed, have a tendency to blush more intensely in case of relatively mild social stressors.

During the 'sing' video, high BPS subjects reported a stronger blushing reaction than low BPS subjects, whereas no differences between both groups were reported by the confederates and no differences were evident at the physiological level (see supra). Moreover, for the low BPS subjects self-reported blushing intensity and observers' judgements were highly similar, whereas the self-reported blushing intensity of the high BPS group was much higher than those of the observers. The present finding that high BPS subjects not only overestimated their blushing intensity but also reported to be much more afraid to start blushing than low BPS subjects suggests, that their estimation of blushing frequency (as indexed by the BPS) may be inflated by a fearful preoccupation with blushing (cf. Bögels et al., 1996). That is, such a preoccupation may lower the threshold for perceiving interoceptive cues and/or may lead to an overrepresentation of 'blush events' in memory. In line with this suggestion, several studies have demonstrated that self-focused attention increases subjects' awareness of physiological reactions and causes a tendency to overestimate the intensity of such arousal (see for a review, Scheier, Carver, \& Mathews, 1983).

Following this line of reasoning, it can be argued that the strong relationship which has been demonstrated between blushing propensity and fear of blushing (e.g. Bögels et al., 1996) might not be merely due to the fact that high blushing propensity is

${ }^{3}$ Two separate 2(Group) $\times 2$ (Moment) ANOVAs showed no main effects of Group for either colouration, $F(1,48)=1.30, p=0.26$, or temperature, $F(1,51)=0.00$. There were significant main effects of Moment for both colouration, $F(1,48)=57.91, p<0.05$, and temperature, $F(1,51)=4.60, p<0.05$. For facial colouration, the analysis revealed a non-significant trend of an interaction effect of Group and Moment, $F(1,48)=2.78, p=0.10$. There was no significant interaction effect of Group and Moment for temperature, $F(1,51)=1.68, p=0.20$. 
a vulnerability factor for the etiology of fear of blushing, but that fear of blushing results in a high blushing propensity. To further explore this issue, it would be interesting to see whether the present results can be replicated if subjects are selected on the basis of their fear of blushing rather than on the basis of their blushing propensity and whether manipulation of attentional focus differentially affects subjects with high and low fear of blushing. If so, such results would sustain clinical interventions that are designed to reduce self-focused attention or preoccupation with blushing (e.g. Bögels, Mulkens, \& De Jong, 1997).

Taken together, the present findings clearly showed that high BPS subjects overestimate their blushing intensity. In addition, the present data tentatively suggest that high BPS subjects, indeed, have a tendency to show relatively strong colouration reactions in case of mild social stressors. In other words, higher scores on the BPS seem to reflect both a fearful preoccupation and a stronger facial colouration. Further research employing social stimulations with varying intensity are necessary to more definitely settle this issue. 


\title{
4.2 Fear of blushing: Fearful preoccupation irrespective of facial colouration
}

\begin{abstract}
Women, with high $(\mathrm{n}=29)$ and low $(\mathrm{n}=28)$ fear of blushing, were exposed to a mild social stressor (watching a television test card in the presence of two male confederates) and to an intense social stressor (watching their own prerecorded 'sing' video, in the presence of two male confederates). Facial colouration and facial temperature were measured and participants rated their own blush intensity. No differences in actual blushing emerged between both groups. Meanwhile, high fearful individuals' self-reported blush intensity was significantly higher than that of low fearful individuals. Thus, fear of blushing seems to reflect a fearful preoccupation, irrespective of differential facial colouration. The present findings concord with cognitive models of social phobia.
\end{abstract}

'This section is a slightly adjusted version of the article Mulkens, S., De Jong, P.J., Dobbelaar, A., \& Bögels, S.M (1999). Fear of blushing: Fearful preoccupation irrespective of facial coloration. Behaviour Research and Therapy, 37, 1119-1128.

This article was awarded the 'Artikelprijs EPP, academisch jaar 1997/1998' by the Dutch Institute for Research and Postgraduate Education Experimental Psychopathology 


\section{Introduction}

Although blushing is a very common emotional response, the majority of people consider blushing as a highly undesirable reaction (Shields, Mallory \& Simon; 1990). Some individuals even experience so much distress as a result of blushing that they develop a blushing phobia and seek treatment (Bögels, Mulkens \& De Jong, 1997; Scholing \& Emmelkamp, 1993a). One of the factors that may facilitate the acquisition and maintenance of such a phobia is individuals' blushing propensity. In line with this, it has been demonstrated that self-reported fear of blushing is associated with self-reported blushing propensity, as indexed with the Blushing Propensity Scale (BPS; Bögels, Alberts \& De Jong, 1996).

Apart from a relatively low threshold for blushing, attentional processes may also play a role in this respect. Germane to this possibility, several theorists have mentioned attentional processes as central complicating factors for social phobics who are in a social situation (Daly, Vangelisti \& Lawrence, 1989; Hope, Gansler \& Heimberg, 1989; Clark \& Wells, 1995). That is, interpersonal situations seem to result in heightened self-focused attention (SFA) (Hartman, 1983; Woody, 1996), which, in turn, is assumed to intensify the individual's negative emotional state as well as the perception of their physiological responses (Hope et al., 1989; Bögels et al., 1997; Wells, White \& Carter, 1997). The perception of the physiological responses, in its turn, is likely to further enhance the individual's SFA, etc. Pertinent to this suggestion, it has been found that salient physiological arousal serves to focus attention inward (Fenigstein \& Carver, 1978; Wegner \& Giuliano, 1980), which, in turn, was found to increase individuals' awareness of physiological reactions (see Scheier, Carver \& Matthews, 1983, for a review). Because blushing is an especially salient physiological reaction (warm cheeks), these processes may be especially prominent in social phobics with fear of blushing as the predominant complaint. Its (presumed) visibility is likely to add further to the SFA eliciting properties of the blush response.

Thus, people with fear of blushing seem to be caught in a vicious circle in which fear of blushing leads to heightened SFA, which increases the awareness of the blush, resulting in a further increase of fear of blushing, etc. Following this, attentional processes may well lead to an overestimation of the actual blush response, which in turn is likely to perpetuate blushing phobics' fear of blushing (cf. McEwan \& Devins, 1983).

The present study was designed to investigate further the alleged role of blushing propensity and the overestimation of facial colouration in fear of blushing. Therefore, we exposed individuals with high and low fear of blushing to social predicaments of low and high intensity. Meanwhile, we assessed facial colouration by means of a photoplethysmograph device. Photoplethysmography has been shown to be a reliable and valid method to measure facial blushing (Shearn, Bergman, Hill, Abel \& Hinds, 1990; Shearn, Bergman, Hill, Abel \& Hinds, 1992; Mulkens, De Jong \& Bögels, 1997). In addition, we recorded temperature changes of the cheek which are thought to serve as interoceptive cues of facial blushing. This was done to investigate possible differential blushing propensity at the interoceptive level, irrespective of its visibility. Furthermore, 
we recorded changes in skin conductance level as a correlate of general arousal. Finally, participants indicated their own blush intensity, to explore potential differences between high and low fearful individuals with regard to the perceived intensity of their blush response.

The intense social predicament consisted of the individual's watching of her own, prerecorded 'sing' video, in the presence of two male confederates. As previous research clearly showed that virtually all people display some facial colouration under such conditions (cf. Shearn et al., 1990), it might be that the 'sing' manipulation is too strong to detect subtle between group differences with regard to individuals' blushing propensity. Therefore, we also included a relatively mild social stressor in the present study. The mild stressor consisted of the participants watching a television test card in the presence of two male confederates. As this is a rather unusual activity, it was expected to cause slight feelings of uneasiness, but not extreme discomfort.

\section{Method}

\section{Participants}

Prior to the experiment, 319 female undergraduate students from Maastricht University completed the 'fear of blushing' subscale of the Blushing, Trembling, and Sweating Questionnaire (BTS-Q; Bögels \& Reith, 1999). From this sample, 57 women were selected on the basis of their scores on this subscale. To create two extreme groups, only women with the most extreme scores in the lowest and highest third of the distribution were randomly approached by phone and invited to participate. Virtually all individuals who were reached, agreed to participate in the experiment.

Participants were 28 women with low fear of blushing and 29 women with high fear of blushing. Mean scores of women with low and high fear of blushing were 3.8 ( $S D$ 2.6; range 0-8.8) and 45.1 (SD 12.0; range 30.4-81.0), respectively. The scores of the high fearful group were considerably higher than those of the general population ( 22.0 (SD 17.0); Bögels et al., 1996); Yet, the scores were still lower than those of a treatmentseeking group (66.0 (SD 26.0); Bögels \& Reith, 1999). Mean Fear Questionnaire-Social Phobia scores (FQ; Marks \& Mathews, 1979) of the high and low fearful women were $16.8(S D$ 7.2) and 10.2 (SD 5.4), respectively. Mean BPS scores of the high and low fearful women were 43.4 ( $S D$ 10.1) and 22.1 (SD 13.7), respectively. Mean age of low fearful individuals was 19.5 years $(S D 1.67$; range 18-24), while high fearful individuals' were slightly younger, mean age 19.0 years $(S D .82$; range 18-21). Individuals received a small financial compensation for their participation.

\section{Assessment}

Participants completed the BTS-Q and the Blushing Propensity Scale (BPS; Bögels et al., 1996). The BTS-Q subscale 'fear of blushing' consists of 5 visual analog scales (VASs), ranging from "not at all" (0) to "very much" $(100)$. The score of this subscale is derived by averaging scores over the 5 items. This subscale includes the following 
questions: "How afraid are you to start blushing?", "How afraid are you while you blush?", "To what extent are you hindered in your daily functioning by blushing?", "How often do you think in a certain situation: I hope I'm not going to blush?", and "To what extent do you avoid situations in which you are likely to blush, or do you avoid others noticing that you blush?" Research concerning the psychometric properties of the BTS-Q indicates that it is a highly reliable instrument. The internal homogeneity of the subscale is high (Cronbach's $\alpha=95$ ). In addition, the subscale intercorrelates with the Dutch Social Phobia and Anxiety Inventory (SPAI-N; Scholing, Bögels \& Van Velzen, 1995) $(r=.71)$, and with the Dutch BPS (r=.56). Furthermore, the BTS-Q has good discriminant validity; it is able to discriminate not only social phobics from controls, but also social phobics with fear of bodily symptoms like blushing from social phobics without such fears (Bögels \& Reith, 1999).

The BPS originally consisted of fourteen circumscribed social situations for each of which respondents have to indicate how often they feel themselves blushing (Leary \& Meadows, 1991). In the Dutch version (Bögels et al., 1996), five items were added to the original version, in order to cover a wider range of situations in which people tend to blush. Answers range from 0 ("I never feel myself blushing in that situation") to 4 ("I always feel myself blushing in that situation"). The internal consistency of the Dutch BPS is high (Cronbach's $\alpha=.92$; (Bögels et al., 1996), as is its test-retest reliability ( $r=.93$, $n=53$; Mulkens et al., 1997).

\section{Apparatus and stimulus materials}

Cheek colouration was recorded from a HP model 15230A plethysmograph transducer that was modified in such a way that it was dc coupled rather than ac coupled. Cheek temperature was assessed by means of a temperature dependent resistor (PT100) that was dc coupled. Skin conductance level was recorded from two Beckman Ag-AgCl electrodes ( $8 \mathrm{~mm}$ diameter), placed on the medial phalanges of the middle finger and ring finger of participants' non-dominant hand, using the method of constant voltage $(0.5 \mathrm{~V})$. The electrodes were filled with an isotonic paste and connected to a Beckman Skin Conductance Coupler (type 9844). All physiological signals were sampled with a frequency of $1000 \mathrm{~Hz}$ by a Compaq $486(33 \mathrm{MHz})$ computer.

Two different types of videotapes were used: a neutral baseline video (i.e. a steady television test card), and a video displaying the individual's singing, recorded during the first session. The videotapes were presented in the following (fixed) order: $5 \mathrm{~min}$. of neutral baseline material (phase 1: baseline I), $1 \mathrm{~min}$. of neutral baseline material that was presented in the presence of two male confederates (phase 2: mild stressor), 5 min. of neutral baseline material (phase 3: baseline II), approximately 1 min. 'sing' video, presented in the presence of the same confederates (phase 4: intense stressor). The fixed order from mild to intense social stressor was chosen to minimalize possible
psychological and physiological carry-over effects. 


\section{Procedure}

On the first day of the experiment the participants were asked to stand in front of both the video camera and the experimenter, and sing the Dutch version of 'Happy Birthday' (i.e. 'Lang zal 'ie/ze leven') using facial and bodily expressions as much as possible. After that, participants completed some 'phoney' questionnaires, in order to cover the real aim of the study. After this session, appointments were made for the second session, which was introduced as 'just another experiment'.

During the second session, which was at least one day and at most fourteen days after the first session, participants were asked to sit in a chair at a table in front of a television set. A photoplethysmograph probe was attached to the left cheek and a temperature probe to the right cheek of the individual. Next, skin conductance electrodes were placed. Participants were not informed about the material they were going to watch. The women were only instructed to watch the television screen and to move as little as possible. If the participants talked to the experimenters during the experiment, they responded in a neutral manner.

During baseline I, the individual was alone in the room and watched the silent, steady television test card. After that, the participant judged her blush intensity using 100 $\mathrm{mm}$ Visual Analog Scales (VASs). As a manipulation check, she also rated how afraid she had been to start blushing, and how anxious she had felt. Then, the experimenter introduced two male confederates ("during the next fragment, these two people will sit here and join you, while watching") who were seated to the side, between the participant and the television set. After that, the experimenter left the room, whereafter the participant and the two confederates watched the silent, steady television test card together for $1 \mathrm{~min}$. The confederates were recruited from a pool of nine staff members of our department and were instructed to watch the TV screen and the participant, alternately, and to behave in a neutral fashion. If the participant talked to the confederates, they were instructed to react in a short and neutral manner. Afterwards, the confederates were asked to judge the individual's blush intensity on a VAS (as a rough additional indication of the individual's blush behaviour); In addition, the individual completed the three VASs again.

The procedure of baseline II was identical to the first. Finally, the intense social stressor was administered (note that at this stage participants were still unaware that they were going to watch their prerecorded 'sing' video). Afterwards, the two confederates rated the individual's blush intensity; the individual herself completed the same three VASs once more.

\section{Data reduction}

All physiological parameters were analyzed off-line by means of a specifically designed computer program. For both baseline phases of the experiment, mean responses for all three physiological parameters were calculated by averaging the values that were obtained every 30 seconds. For both social predicaments, peak levels for all three physiological parameters were taken (cf. Shearn et al., 1990, 1992). Next, difference scores were calculated between the mean level during baseline I and the peak level 
during the mild social stressor as well as between the mean level in baseline II and the peak level during the intense social stressor. Thus, two difference scores were obtained. Likewise, difference scores were calculated for self-reported blush intensity, fear of blushing and fear. These difference scores were computed to compare the individuals' responsiveness during both types of stressors. The interrater agreement of the confederates' judgements about the individuals' blush intensity was computed. During the mild social stressor, the correlation between the two raters was only .43. For the intense social stressor, interrater agreement was also below conventional levels of reliability $(r=56)$. Therefore, it was decided not to take the confederates' judgements into account in this study.

The difference scores of all physiological and subjective measures (i.e. selfreported blush intensity, fear of blushing and fear) were subjected to separate Analyses of Variance (ANOVA) with one between-subjects factor (Group: high vs low fear of blushing) and one within-subjects factor (Manipulation) with two repeated measures (mild social stressor vs intense social stressor).

A manipulation check, using the obtained difference scores on subjective fear and fear of blushing, was conducted in order to test whether the manipulation successfully produced the expected effects with regard to these variables. The manipulation was considered successful when: (a) high fearful individuals reported stronger increases in level of subjective fear and of fear of blushing than low fearful individuals, during both the interpersonal predicament (mild stressor) and the self-presentational predicament (intense stressor), and (b) high fearful participants reported stronger increases in subjective fear and of fear of blushing during the self-presentational predicament (intense stressor) than during the interpersonal predicament (mild stressor).

\section{Results}

One woman refused further cooperation after she was instructed to sing ' $L$ ang zal 'ie/ze leven' in the first session. Another participant had an epileptic seizure during baseline II, whereafter the procedure was stopped. Due to technical problems, physiological data were not available completely for an additional participant. This is reflected in the degrees of freedom.

\section{Manipulation check}

\section{Self-reperted fear}

Means and $S D$ s are displayed in Table 1. The ANOVA yielded a significant main effect of Group, $F(1,53)=18.7, p<.001$, which indicates greater increases in the level of fear in high fearful individuals. There was also a significant main effect of Manipulation, $F(1,53)=4.9, p<.05$, indicating relatively strong increases in fear level during the intense stressor (see also Table 1). Finally, the analysis revealed a significant interaction effect of Group and Manipulation, $F(1,53)=5.6, p<.05$; inspection of the means indicates that the difference between both groups was relatively large during the more intense social 
stressor. Post-hoc $t$-tests indicated that in both manipulations, the increase of high fearful individuals' self-reported fear differed significantly from that of low fearful individuals $(t(53)=2.5, p<.05$, means for high and low fearful participants being 20.7 and 7.8 , respectively, during the mild stressor; $t(53)=2.6, p<.001$, respective means being 34.4 and 7.3 during the intense social stressor). Furthermore, high fearful individuals reported a stronger increase in subjective fear during the intense social stressor than during the mild social stressor, $t(28)=-2.8, p<.01$ (means being 20.7 and 34.4 for the mild and the intense social stressor, respectively). Low fearful individuals' fear elevations during the intense social stressor were not significantly different from those during the mild social stressor, $t(25)=0.14, p>.05$ (means being 7.8 and 7.3 for the mild and the intense social stressor, respectively).

Self-reported fear of blushing

Means and $S D$ s are shown in Table 1. The analysis yielded a significant main effect of Group, $F(1,53)=16.4, p<.001$, which means that the high fearful group reported being generally more afraid to start blushing than the low fearful group. Furthermore, there was a significant main effect of Manipulation, $F(1,53)=14.2, p<.001$, indicating that participants, overall, reported being more afraid to start blushing during the intense social stressor. This difference between high and low fearful participants was particularly pronounced during the intense manipulation, $F(1,53)=9.3, p<.005$ (see also Table 1). Post-hoc $t$-tests indicated that the difference between high and low fearful individuals in the increase of self-reported fear of blushing was prominent only during the intense social stressor $(t(53)=1.9, p=.07$, means for high and low fearful participants being 23.8 and 13.2 , respectively, during the mild stressor; $t(53)=4.8, p<.001$, respective means being 45.9 and 15.6 during the intense social stressor). Furthermore, high fearful individuals reported a stronger increase in fear of blushing during the intense social stressor than during the mild social stressor, $t(28)=-4.6, p<.001$ (means being 23.8 and 45.9 for the mild and the intense social stressor, respectively), whereas low fearful individuals' fear elevations during the mild and the intense social stressor remained rather unchanged, $t(25)=-0.5, p>.05$ (means being 13.2 and 15.6 for the mild and the intense social stressor, respectively).

As the results on subjective fear and fear of blushing are in line with the predetermined criteria, it can be concluded that our manipulation was successful.

\section{Cheek colouration}

Means and $S D$ s are depicted in Table 1. To normalize the colouration data, transformations were performed. A 2 Group (high vs low fear) $\times 2$ Manipulation (mild vs intense) ANOVA did not reveal a significant main effect of Group, $F(1,52)=0.1$, indicating that, in general, high and low fearful participants displayed similar blush responses. Yet, in line with the prediction, there was a significant main effect of Manipulation, $F(1,52)=6.9, p<.05$. As can be seen in Table 1, this finding indicates that the strongest cheek colouration responses were observed during the intense social stressor. Both groups reacted with comparable degrees of cheek colouration during both social stressors $(F(1,52)=0.0)$. That is, there was no Group x Manipulation interaction. 
Cheek temperature

Means and $S D$ s are displayed in Table 1 . The ANOVA yielded no main effect of Group, $F(1,52)=0.9$. Thus, overall, the two groups showed comparable cheek temperature responses. Yet, the analysis yielded a significant main effect of Manipulation, $F(1,52)=36.4, p<.001$. As can be seen in Table 1, this finding indicates that the strongest increase in cheek temperature took place during the mild social stressor. There was no significant interaction effect of Group and Manipulation, $F(1,52)=2.3, p=13$.

Table 1: Mean values (and SDs) of participants with high and low fear of blushing on all physiological measures and self-report measures, during baselines and both manipulations.

\begin{tabular}{|c|c|c|c|c|}
\hline \multirow[b]{3}{*}{ Varables } & \multicolumn{4}{|c|}{ Mild manipulation (test card + confederates) } \\
\hline & \multicolumn{2}{|c|}{ High fearful } & \multicolumn{2}{|c|}{ Low fearful } \\
\hline & Baseline & Stressor\# & Baseline & Stressor\# \\
\hline Colouration $(V)^{*}$ & $1.04(.05)$ & $1.13(.07)$ & $1.06(.04)$ & $1.16(.06)$ \\
\hline Temperature $\left({ }^{\circ} \mathrm{C}\right)$ & $30.11(1.75)$ & $30.71(1.55)$ & $30.28(1.59)$ & $31.10(1.48)$ \\
\hline $\operatorname{SCL}(\mu \mathrm{mho})$ & $2.23(1.53)$ & $3.50(1.85)$ & $1.96(1.14)$ & $3.29(1.46)$ \\
\hline Subjective blush intensity & $15(18)$ & $37(27)$ & $3(3)$ & $17(17)$ \\
\hline Fear of blushing & $23(25)$ & $47(29)$ & $4(6)$ & $17(15)$ \\
\hline \multirow[t]{2}{*}{ Subjective fear } & $13(15)$ & $34(26)$ & $3(5)$ & $11(15)$ \\
\hline & \multicolumn{4}{|c|}{ Intense manipulation ('sing' video + confederates) } \\
\hline Colouration $(V)^{*}$ & $1.08(.08)$ & $1.19(.09)$ & $1.10(.06)$ & $1.21(.07)$ \\
\hline Temperature $\left({ }^{\circ} \mathrm{C}\right)$ & $31.04(1.47)$ & $31.27(1.37)$ & $31.34(1.36)$ & $31.52(1.28)$ \\
\hline $\mathrm{SCL}(\mu \mathrm{mhho})$ & $2.84(1.67)$ & $3.84(1.77)$ & $2.52(1.36)$ & $3.73(1.57)$ \\
\hline Subjectrve blush intensity & $14(17)$ & $68(25)$ & $3(5)$ & $28(26)$ \\
\hline Fear of blushing & $16(20)$ & $62(26)$ & $4(5)$ & $19(21)$ \\
\hline Subyective fear & $16(21)$ & $51(26)$ & $5(9)$ & $13(18)$ \\
\hline
\end{tabular}


Skin conductance level

Means and $S D$ s are depicted in Table 1. The ANOVA revealed no significant main effect of Group $(F(1,52)=0.6)$. However, there was a significant effect of Manipulation $(F(1,52)=4.2, p<.05)$; inspection of the means indicates that the greatest increase in general arousal took place during the mild social stressor. No interaction effect of Group and Manipulation emerged $(F(1,52)=0.6)$ with respect to changes in skin conductance level.

\section{Self-reported blushing}

Means and $S D$ s are depicted in Table 1. A 2 Group (high vs low fear of blushing) x 2 Manipulation (mild vs intense social stressor) ANOVA revealed a significant main effect of Group, $F(1,53)=13.7, p<.005$. Inspection of the means indicates that, overall, high fearful women reported blushing more intensely than low fearful women. Furthermore, there was a significant main effect of Manipulation, $F(1,53)=49.6, p<.001$, which indicates that participants, overall, reported blushing more intensely during the intense stressor. Finally, the analysis revealed a significant interaction of Group and Manipulation, $F(1,53)=10.5, p<.005$. This finding indicates that the difference between high fearful and low fearful participants was especially pronounced during the intense stressor (see Table 1). Post-hoc $t$-tests indicated that the difference between high and low fearful individuals was not significant during the mild social stressor $(t(53)=1.7, p=.1$, means being 21.8 and 13.5 , respectively). Meanwhile, the difference between high and low fearful participants did reach significance during the intense social stressor $(t(53)=4.3, p<.001$, means being 53.8 and 25.3 , respectively).

\section{Discussion}

The main results of this study can be summarized as follows: (1) Physiological indices of blushing (i.e. blood pooling and cheek temperature) indicated that individuals with high and low fear of blushing responded with equally intense blush responses. (2) For both groups, these responses (i.e. cheek colouration) were significantly higher during the intense social stressor than during the mild social stressor. (3) With respect to selfreports, however, women high in fear of blushing reported that they blushed far more intensely than low fearful participants.

Self-reports of subjective fear and fear of blushing were higher during the intense social stressor than during the mild social stressor for high fearful individuals. Furthermore, high fearful participants' self-reports with regard to these variables were significantly higher than those of low fearful participants. Besides, physiological indices of blushing (i.e. cheek colouration) were higher during the intense social stressor than during the mild social stressor. Taken together, these findings suggest that the experimental manipulation was successful. In contrast to the other indices of blushing, the rise of participants' facial temperature was especially pronounced during the (first) mild social stressor. The relatively small increase as a result of the intense social stressor 
may be due to the fact that the cheek temperature was still rising during baseline II. Note that, compared to the blood pooling of the cheek, the skin temperature is a slow response system (e.g. Shearn et al., 1990). This is mainly due to the fact that the skin is a bad heat conductor and therefore acts as a thermo-protector (Guyton \& Hall, 1996). As the temperature had not yet stabilized during baseline II, the increase from baseline II to the intense stressor is likely to underestimate the actual impact of the self-presentational predicament on the individual's cheek temperature (cf. Shearn et al., 1990).

For both manipulations, physiologically assessed blush behaviour was very similar across both groups. Thus, in contrast to the idea that blushing phobics are characterized by a high blushing propensity, the present data provide no evidence for a relatively low threshold for blushing, nor for a relatively intense blush response in high fearful individuals.

Interestingly, although no differences emerged at the physiological level, high fearful participants strongly differed from low fearful individuals at the subjective level. That is, high fearful women reported that they blushed far more intensely than low fearful women. This difference between high and low fearful individuals does not seem to be attributable to relatively strong interoceptive cues. That is, not only the increase of individuals' facial colouration, but also the increase of individuals' cheek temperature as a function of both manipulations was very similar for both groups. The differences in self-reports between high and low fearful women appeared neither due to differences in general level of arousal (as indexed by the skin conductance level). Thus, taken together, the relatively high self-reported blush intensity of high fearful participants does not seem to arise from hyperresponsive physiological mechanisms. In a similar vein, the relatively high scores on the BPS of the high fearful individuals may reflect a relative overestimation of their actual blushing frequency compared to the low fearful individuals.

Taken together, the present results cast doubt on the idea that high blushing propensity plays an important role in blushing phobia. Meanwhile, the present findings fit comfortably within cognitive explanations of blushing phobia. Note that recent cognitive explanations suggest that attentional processes result in social phobics' being overly preoccupied with aspects of their appearance (e.g. Clark \& Wells, 1995). In addition, these explanations suggest that social phobics process 'the self as a social object', which, in turn, enhances the awareness of feared anxiety responses. Both mechanisms are likely to inflate the perception of pertinent physiological symptoms (e.g. Hope et al., 1989). Thus, such a cognitive account of blushing phobia would indeed predict the present finding that high fearful individuals relatively overestimate their blush response as compared to low fearful individuals.

In sum, the present data undermine the view that a relatively low threshold for blushing or a relatively intense colouration in response to a certain social stressor plays an important role in blushing phobia. Rather, it appears that fear of blushing is fueled by mechanisms that are irrespective of actual facial colouration (e.g. heightened self-focused attention). 


\title{
4.3 Learning historys
}

\begin{abstract}
Two studies, investigating the learning history (i.e. traumatic conditioning experiences, vicarious learning, informational learning) of individuals with and without fear of blushing, are presented. In study 1 , individuals high $(n=61)$ and low $(n=59)$ in fear of blushing completed the (revised) Phobic Origin Questionnaire (POQ; Öst \& Hugdahl, 1981). In study 2 , individuals who applied for treatment for fear of blushing $(n=31)$ and a non-fearful, matched control group $(n=31)$ were interviewed with the same instrument, taking into account only specific memories. High fearful individuals reported more negative learning experiences in connection with blushing than low fearful individuals, irrespective of the type of questioning. Meanwhile, study 1 (written POQ) produced higher percentages of negative learning experiences for both high and low fearful individuals than study 2 (interview). It is concluded that the POQ interview showed a more realistic picture than the written POQ. The possible role of learning history in the acquisition of fear of blushing is discussed.
\end{abstract}

\footnotetext{
'This section is a slightly adjusted version of the article Mulkens, S. \& Bögels, S.M. (1999). Learning history in fear of blushing. Behaviour Research and Therapy, 37, 1159-1167

Acknowledgements

The authors wish to thank Maurice Alberts and Marieke Bezemer for the data acquisition in study 1 , and Annebeth Theunissen for putting together the matched control group in study 2 .
} 


\section{Introduction}

Fear of bodily symptoms, like blushing, is known to be a prominent complaint for many social phobics (Edelmann, 1990b). In various cases, the social phobic fear even concems specifically the appearance of bodily symptoms; that is, the individual is afraid of negative evaluation because of (the supposed visibility of) blushing. Some individuals experience so much distress as a result of fear of blushing that they develop a blushing phobia and seek treatment (Scholing \& Emmelkamp, 1993a; Bögels, Mulkens \& De Jong, 1997).

Little is known about the causes of fear of blushing. Some investigations about the possible developmental course of social phobia do exist, suggesting that multiple factors may be involved (Townsley Stemberger, Turner, Beidel \& Calhoun, 1995), although it often remains unclear whether the variables detected are the cause or the result of the disorder. The presumed influential mechanisms include familial factors and genetic transmission (e.g. Reich \& Yates, 1988; Kendler, Neale, Kessler, Heath \& Eaves, 1992; Fyer, Mannuzza, Chapman, Liebowitz \& Klein, 1993), biological variables, such as increased heart rates and a potential role of the central dopaminergic system in social phobics (e.g. Beidel, Turner \& Dancu, 1985; Levin, Schneier \& Liebowitz, 1989), personality characteristics, such as neuroticism and introversion, shyness, and behavioural inhibition (e.g. Eysenck, 1982; Turner, Beidel \& Townsley, 1990; Bruch, 1989; Kagan, Snidman \& Arcus, 1992), parental rearing styles, like overprotectiveness and stressing the importance of others' opinions (e.g. Parker, 1979; Bruch, 1989; Bruch \& Heimberg, 1994), and learning history, including traumatic conditioning experiences (e.g. Öst \& Hugdahl, 1981).

An investigation by Townsley Stemberger et al. (1995), in which several of the above mentioned variables were taken into account (i.e. family history of anxiety, childhood shyness, extraversion, neuroticism and history of traumatic conditioning experiences), showed that traumatic experiences and shyness were associated with the development of social phobia. It seems reasonable to argue that traumatic experiences also play a major role in the acquisition of fear of blushing. Blushing, like red hair or glasses, is a salient feature and, therefore, an easy object for teasing among children. Moreover, being accused of blushing is enough to evoke a blush (cf. Leary, Britt, Cutlip \& Templeton, 1992), which might reinforce teasing. In line with this, it is our clinical impression that individuals with fear of blushing often report a history of being ragged about blushing. For instance, some patients remembered being called 'tomato' or 'lighthouse' in their childhood.

Learning history is considered to be an important determinant in the acquisition of fears and phobias. In 1939, the two-stage theory of fear and avoidance was introduced by Mowrer, and has become known as the conditioning theory. After varying adjustments and elaborations of the theory, Rachman (1977) proposed 3 possible pathways to fear: (1) conditioning (direct pathway), (2) vicarious acquisition (indirect), and (3) acquisition by transmission of information and/or instruction (indirect). Since the introduction of the 'three pathways to fear, research on the acquisition of fears and phobias drew heavily on 
this proposed integration, several studies (e.g. Merckelbach, Arntz, Arrindell \& De Jong, 1992) using the Phobic Origin Questionnaire (POQ; Öst \& Hugdahl, 1981), a paper-andpencil test that asks phobic patients to what extent their fears developed along a direct or an indirect pathway.

Research by Öst and Hugdahl (1981), using the POQ, indicated that among social phobic patients, a majority (58\%) traced the origin of their fears to an aversive conditioning incident, whereas $13 \%$ traced the origin to vicarious experiences, $3 \%$ to informational learning, and $26 \%$ had no recall. An important limitation of this study is, however, that it failed to take into account the responses of a non-phobic control group. Furthermore, the POQ was criticized because of its supposed inadequate definition of direct conditioning (Menzies \& Clarke, 1994; Menzies, Kirkby \& Harris, 1998): from the type of questioning (no rules with respect to CS-UCS pairings) and answering (yes/no) in the original POQ, it would remain unclear whether conditioning events had indeed taken place. This methodology might have led to an overestimation of the frequency of conditioned cases (e.g. Menzies \& Clarke, 1994).

Townsley Stemberger et al. (1995) used the Social Anxiety History and Interview Questionnaire-Revised (SAHIQ-R; Turner, Beidel, Dancu \& Keys, 1986) to assess whether individuals had experienced an identifiable social 'traumatic' episode. Results indicated that individuals with social phobia and normal control individuals differed significantly on reporting traumatic social experiences. That is, when all participants with social phobia (i.e. generalized social phobia and specific social phobia) in this study were combined into a single group, $44 \%$ of them had a history of traumatic conditioning events, compared with $20 \%$ of those in the normal control group. Compared to the results of Öst and Hugdahl (1981) previously mentioned, the percentages of Townsley Stemberger et al. (1995) are somewhat lower. This difference might well be due to differences in the methodology of questioning.

The aim of the present two studies was to investigate, in an analogous population and in a treatment-seeking population, to what extent individuals with fear of blushing, compared with control individuals, had undergone aversive conditioning experiences, vicarious learning experiences, and/or informational learning experiences with regard to blushing. The inclusion of a non-phobic group might provide a clue as to whether negative learning experiences necessarily give rise to phobic complaints (Merckelbach et al., 1992). Besides, we wondered whether it would make any difference to the pattern of results when a revised version of the original POQ was used (a written version in which the specificity of experiences remained unclear and only yes/no could be answered), or an oral version of the POQ was given (which allowed the interviewer to check the specificity of the reported experiences and the presence of a traumatic CS-UCS pairing, and during which participants' memories were prompted).

In study 1 , individuals high and low in fear of blushing were selected from a large group of students, using the $30 \%$ highest and lowest scores. They were given the written ("yes"//"no") version of the POQ. In study 2, individuals who had applied for treatment for fear of blushing and a non-fearful, matched, control group were given an oral version of the POQ, in which only specific memories were taken into account. 
Study I

Method

\section{Participants}

Participants were taken from a group of 194 (61 men) first year undergraduate students of Maastricht University (69.6\% studied Health Sciences, $28.9 \%$ Medicine, and $1.5 \%$ other) who volunteered to participate in a questionnaire study. Volunteers completed a series of 18 questionnaires in groups of 10-20 persons, for which they received a small fee. The 'Fear of Blushing' subscale of the Blushing, Trembling, and SweatingQuestionnaire (BTS-Q; Bögels \& Reith, 1999) and a slightly revised version of the Phobic Origin Questionnaire (POQ; Öst \& Hugdahl, 1981) were part of the test battery. The other questionnaires were intended to answer different research questions.

To create two extreme groups with regard to fear of blushing, only individuals with scores in the lowest and highest $30 \%$ of the distribution of the scores on the 'Fear of Blushing' subscale were taken into consideration. The high fearful group consisted of 61 individuals ( 15 men) with a mean age of 19.9 years (range $18-40 ; S D 3.0$ ) and a mean Fear of Blushing score of 43.2 (range 28.2-77; SD 11.3). The low fearful group consisted of 59 individuals ( 21 men) with a mean age of 20.4 years (range 18-39; SD 3.2) and a mean Fear of Blushing score of 4.4 (range $0-10.2 ; S D 2.6$ ). The high and the low fearful group did not differ with respect to age $(t(118)=0.90, p>.05)$ and $\operatorname{sex}\left(\chi^{2}(1)=1.7\right.$, $p>.05)$

\section{Assessment}

The BTS-Q Fear of Blushing subscale (Bögels \& Reith, 1999) measures, by visual analogue scales (VASs), the extent to which individuals experience blushing as a problem and are afraid to blush (e.g. "To what extent are you hindered in your daily functioning by blushing?"). Research concerning the psychometric properties of the BTS-Q indicates that it is a highly reliable instrument and that it has good discriminant validity; the subscale Fear of Blushing (or Trembling or Sweating) is able to discriminate not only social phobics from controls, but also social phobics with fear of bodily symptoms from social phobics without such fears (Bögels \& Reith, 1999).

Individuals completed a slightly revised version of the 'learning history' section of the POQ (Öst \& Hugdahl, 1981). This consists of 9 questions that have to be answered in a yes/no format. The revision concerns the phrasing of the conditioning questions: in the original $P O Q$, participants are asked to think back about their phobia and to try to remember how it started; then, they are asked whether they can remember if the fear started with any specific event or situation where they experienced strong discomfort and/or anxiety (no clear CS-UCS pairing). In our POQ, individuals were asked whether they remembered any painful or traumatic events in connection with blushing (conditioning experiences: three questions, e.g. "Have you ever experienced a nasty or painful situation because you were blushing?"). Next, they were asked whether they had family members or close friends who were afraid of blushing (vicarious learning: three 
questions, e.g. "Is your mother afraid to blush?"), and whether they heard negative information about blushing (informational learning: three questions, e.g. "Have you ever heard unpleasant things about blushing in the media - such as on TV, on the radio, in magazines or books?"). The presence of at least one "yes" in a category was considered sufficient to assign an individual to that specific category. This procedure allows for the possibility that participants are assigned to more than one category (see also Merckelbach et al., 1992). Two extra questions were added in order to verify the answers to the conditioning questions: "Have you ever been teased or ragged because of blushing?" and "Have you ever been laughed at or humiliated because of blushing?". When either or both of these questions were answered affirmatively while none of the conditioning questions were, the conditioning category was still considered to be answered in the affirmative.

\section{Results}

The frequency of high and low fearful individuals who answered at least one conditioning item, vicarious learning item, and/or informational learning item with "yes", is presented in Table 1 .

Table 1: Frequency of high $(n=61)$ and low $(n=59)$ fearful individuals who answered at least one conditioning item, vicarious learning item, and/or informational learning item with "yes".

\begin{tabular}{|c|c|c|c|c|}
\hline \multirow[b]{2}{*}{ Type of experience } & \multicolumn{2}{|c|}{ High fearful individuals } & \multicolumn{2}{|c|}{ Low fearful individuals } \\
\hline & $\mathrm{n}$ & $\%$ & n & $\%$ \\
\hline Conditioning & 59 & 96.7 & 39 & 66.1 \\
\hline Vicarious learning & 43 & 70.5 & 25 & 42.4 \\
\hline Informational leaming & 48 & 78.7 & 41 & 69.5 \\
\hline
\end{tabular}

The number of individuals who answered affirmatively to at least one conditioning question was significantly higher in the high fearful group than in the low fearful group $\left(\chi^{2}(1)=18.8, p<.001\right)$. Similar results were obtained for the vicarious learning category $\left(\chi^{2}(1)=9.7, p<.005\right)$. In the case of informational learning, however, no difference emerged between the high and the low fearful group $\left(\chi^{2}(1)=1.3, p=.25\right)$. 


\section{Study II}

\section{Method}

\section{Participants}

Thirty-one individuals ( 7 men) with a primary diagnosis of social phobia, with fear of blushing in social situations as the most prominent fear (DSM-IV; American Psychiatric Association, 1994), were included in the present study. Participants had applied for treatment in a programme in which people who suffered from fear of blushing were offered free treatment in exchange for participating in research (Mulkens, Bögels, De Jong \& Louwers, 1998). Mean age was 25.5 yr (range 14-49; $S D$ 9.3). Mean onset age of the complaint was 13.4 (range 4-38; SD 6.6). Mean score on the BTS-Q subscale Fear of Blushing was 68.2 (range 43.3-93.8; SD 13.4), which is considerably higher than that of a student population (22.0 (SD 17.0)) (Bögels, Alberts, \& De Jong, 1996), but comparable to that of a treatment-seeking group at a mental health centre (66.0 ( $S D$ 26.0)) (Bögels \& Reith, 1998).

Thirty-one control participants $(10 \mathrm{men})$ were recruited by means of an advertisement in the local newspaper, and among students and university employees. They were matched with fearful individuals on age, sex, and educational level. Mean age of the control participants was 26.9 (range 15-47; SD 9.7), mean Fear of Blushing score was 18.1 (range $0-40.5 ; S D$ 12.4). Fearful and control individuals did not differ with respect to age $(t(60)=-0.59, p>.05)$, sex $\left(\chi^{2}(1)=0.73, p>.05\right)$, and educational level $\left(\chi^{2}(4)=0.73, p>.05\right)$.

\section{Assessment}

During the intake session before the treatment, blushing phobics were interviewed using the same revised version of the POQ (Öst \& Hugdahl, 1981). Individuals were given sufficient time to think seriously about every question, and were allowed to hark back to earlier questions. They were also provided with a standard example in each category. The presence of at least one specific memory was considered sufficient to assign an individual to the conditioning, vicarious learning and/or informational learning category. Thus, participants could be assigned to more than one category. When no specific memory could be reproduced with regard to any of the questions in a category, the individual was not assigned to the category concerned. Control participants were given the same oral version of the POQ.

\section{Results}

The frequency of blushing phobics and control participants who could remember at least one specific conditioning experience, vicarious learning experience, and/or informational learning experience is presented in Table 2. 
Table 2: Frequency of fearful individuals $(n=31)$ and control participants $(n=31)$ who could remember at least one specific conditioning experience, vicarious learning experience, and/or informational learning experience in connection with blushing.

\begin{tabular}{lcccccc}
\hline & \multicolumn{2}{c}{ Blushing phobics } & & \multicolumn{2}{c}{ Control participants } \\
\cline { 2 - 3 } \cline { 6 - 7 } Type of experience & $\mathrm{n}$ & & $\%$ & & $\mathrm{n}$ & $\%$ \\
\hline Conditioning & 23 & 74 & & 14 & 45 \\
Vicarious learning & 17 & 55 & & 10 & 32 \\
Informational learning & 11 & 35 & & 4 & 13 \\
\hline
\end{tabular}

The frequency of individuals who reported specific memories with regard to conditioning items was significantly higher in the phobic group than in the control group $\left(\chi^{2}(1)=5.4\right.$, $p<.05)$. Similar results were obtained for the frequency of individuals who reported specific informational learning items $\left(\chi^{2}(1)=4.3, p<.05\right)$. In the case of vicarious learning, however, the analysis revealed a trend $\left(\chi^{2}(1)=3.2, p=.07\right)$, indicating that more phobic individuals than control individuals reported specific vicarious learning items.

\section{Discussion}

The main results of the two studies can be summarized as follows. (1) Individuals with fear of blushing more often reported having experienced conditioning experiences with regard to blushing than control individuals. This was the case for both studies. (2) With regard to vicarious learning, a similar pattern emerged: individuals with high scores on fear of blushing more often reported having had such experiences, as opposed to individuals with low scores. This difference was significant in study 1 , while it reflected a tendency in study 2. (3) Informational learning experiences followed a dissimilar pattern: these experiences were equally present in both high and low fearful individuals in study 1 , whereas in study 2 , specific informational learning events were more prominent in phobic individuals. (4) Globally, the results were equal across both studies, but much higher percentages were obtained in study 1 .

The finding that high fearful individuals more often report negative conditioning experiences than controls suggests that negative conditioning events are at the basis of the development of fear of blushing. However, this is not necessarily the case. High fearful individuals might already have been afraid of blushing before these experiences took place. Neither the questionnaire nor the interview asked the individual if blushing (the CS) was a neutral event prior to the pairing with the aversive UCS. Furthermore, high fearful individuals might be much better able to pay attention to or to recall negative conditioning events with respect to blushing, simply because these events matter more to them now. Next, individuals with fear of blushing might have a lower threshold to 
qualify a situation as negative (due to their fear), or they might be more sensitive to other people's comments and interpret them more readily as negative. On the other hand, since we feel that subjectively experienced seriousness of situations is of utmost importance, this argument seems irrelevant.

Vicarious learning was also more prominent in high fearful participants than in their low fearful counterparts. This finding indicates that high fearful individuals more often seem to have close family members or friends who have a problem with blushing than low fearful individuals do, which might result in more modelling behaviour. Nevertheless, this finding might also be the result of a bias that high fearfuls might have towards detecting, interpreting, or recalling (fear of) blushing in significant others.

The results with regard to informational learning differ between the studies. Using the written $P O Q$, equal numbers of high and low fearfuls report having had informational learning experiences, whereas the oral POQ produces a significant difference between fearful individuals and control participants. The type of questioning might lie at the cause of this difference; however, assuming that the oral version is more accurate, high fearfuls again report more informational learning experiences. Here as well, one might suspect that high fearfuls selectively attend to, interpret, and recall these types of experiences.

With respect to the potential differences in the pattern of results when using a written or an oral version of the POQ, it can be observed from Tables 1 and 2 that the percentages of conditioning, vicarious learning, and informational learning for both high and low fearful individuals are higher in study 1 than in study 2 . Several reasons can be put forward to account for this difference. Firstly, differences in the level of anxiety between the groups in studies 1 and 2 might have resulted in differential reporting of negative learning experiences. However, the phobics and controls in study 2 had higher fear of blushing scores than the high and low fearful individuals in study 1 . If anything, one would therefore expect participants in study 2 to report more negative learning experiences instead of fewer. Secondly, differences in the research populations with regard to age and level of education (university students versus a mixed group) might have accounted for these differences. However, that does not seem to be very plausible: the age differences were not huge (mean age of 20 versus 26 ), and the majority $(70 \%)$ of study 2 consisted of university students, students of higher secondary education, and working individuals with a qualification from one of these kinds of education.

The above arguments lead us to conclude that the differences must be merely due to a methodological aspect; one possibility is that a face-to-face interview (study 2) makes people reluctant to report potentially shameful experiences, compared to a written questionnaire taken anonymously. Another plausible explanation might be the fact that our interview had stricter rules, only assigning someone to a category when a specific memory with respect to that category could be reproduced. The written POQ provided no clue as to whether participants had in mind specific (CS-UCS paired) or general memories with regard to the questions. Therefore, in study 1 , the occurrence of the several types of learning experiences with regard to blushing might have been overestimated. In line with this, Menzies and Clarke (1994) and Menzies et al. (1998) have concluded that the original (written) POQ might overestimate the presence of the 
several learning pathways to phobias. Note, however, that the percentages in our study cannot be compared to those in the study of Öst and Hugdahl (1981), since our participants could be assigned to more than one category: Öst and Hugdahl (1981) made their participants attribute their phobia to only one learning pathway.

Taken together, it appears that individuals with fear of blushing more often have a history of negative learning experiences than control individuals. However, it remains to be investigated whether this is a result of actual differences in the occurrence of negative events, or differences in attention for, and in the interpretation of such events as negative, and/or recall for such events. Furthermore, although the relative pattern of results appeared to be equal across study 1 and 2 , there are reasons to believe that the results of study 2 are more valid. Thus, to obtain a realistic picture with regard to the learning history in fearful individuals, the use of strict instruments is recommended. 


\title{
4.4 How irrational are blushing phobics' beliefs about blushing?
}

\begin{abstract}
People with fear of blushing, hold primarily negative, so-called dysfunctional (i.e. irrational) beliefs about blushing. This study sought to determine the alleged irrationality of blushing phobics' beliefs about blushing. Therefore, we assessed the beliefs of a group of unselected men $(n=26)$ and women $(n=30)$ with regard to blushing. Participants completed a free recall thought-listing inquiry, in which they were asked to report the thoughts that occur to them when (1) they see other people blushing and (2) when they blush themselves. In addition, they were asked to indicate their expectation with respect to thoughts of other people when they see the participant blushing. Finally, participants indicated whether they believed that there are situations in which it would be desirable and/or situations in which it would be undesirable to blush. The results indicate that, being actors, both women and men consider blushing as highly negative. Being observers (i.e. when judging other people), they also report more negative than positive beliefs pertaining to blushing. Remarkably, women as well as men considered blushing as less negative when the actor was of the opposite sex than of their own sex. In a similar vein, participants indicated that observers from the other sex would judge them more favourably than observers of the same sex would. Finally, virtually all participants reported that there are situations in which it would be undesirable to blush, although half of the participants also reported that there are situations in which blushing is a desirable response.
\end{abstract}

${ }^{6}$ This section was presented as a paper at the 24th Congress of the European Association for Behavioural and Cognitive Therapies, September 6-10, 1994, Corfu, Greece (Abstract S16.4) 


\section{Introduction}

Several authors underlined the role of cognitive factors in social phobia (for example Beck, Emery, \& Greenberg, 1985; Beidel, Turner, \& Dancu, 1985; Chambless \& Hope, 1996; Clark \& Wells, 1995; Rapee \& Heimberg, 1997). Studies investigating the content of social phobics' cognitions consistently show the negative orientation of their thinking and their distorted self-perceptions. For example, it was shown that social phobia is characterized by anxious self-preoccupation (Smith, Ingram, \& Brehm, 1983). Furthermore, socially anxious persons endorse a high frequency of negative selfstatements (Glass, Merluzzi, Biever, \& Larsen, 1982), report a higher rate of negative thinking and a lower rate of positive thinking after social interactions than individuals without social anxiety (Dodge, Hope, Heimberg, \& Becker, 1988; Turner, Beide1, \& Larkin, 1986), and negatively evaluate the quality of their social performance (Edelmann, 1985). A specific subgroup of social phobics has difficulties handling social situations because of fear of showing bodily symptoms, like blushing. These socially anxious persons thoughts are centred around (the occurrence of) blushing, and in these people, typically negative automatic thoughts can be detected. For example "When I blush, everyone will notice/ I cannot concentrate anymore/ I will make a fool of myself" (Bögels, 1994).

In general, to reduce anxiety disordered patients' complaints, cognitive behaviour therapies aim to challenge the patients' dysfunctional beliefs and eventually change these irrational beliefs into more rational and functional ones (e.g. Clark, 1989). As a result, patients will become less anxious and better able to deal with negative thoughts. Generally, the beliefs of anxiety disordered patients, like panic patients, are clearly irrational (e.g. "If my heart is pounding, I'm going to have a heart attack"). Yet, these socalled dysfunctional beliefs in blushing phobics are less obviously irrational. That is, almost universally people consider blushing as a highly undesirable response (Shields, Mallory, \& Simon, 1990), which may follow from the fact that blushing commonly occurs in uncomfortable social situations and is associated with embarrassment, shame, and/or unwanted social attention (Buss, 1980; Leary, Britt, Cutlip, \& Templeton, 1992). Therefore, it might well be that the typical negative thoughts that can be found in individuals with fear of blushing are not easily discriminated from thoughts that normals have about blushing. That is, there may be some evidence for a negative belief of the type "If I blush, people will think I'm not telling the truth", or "If I blush, people will think I'm insecure" (see e.g. Bögels, 1994; Bögels \& Reith, 1999, for a list of frequently reported beliefs of blushing phobics). Thus, in contrast to the typical beliefs frequently reported by panic patients (e.g. "If I have heart palpitations, I'm going to have a heart attack"), blushing phobics' beliefs do not seem to be obviously irrational.

The 'non-irrationality' of blushing phobics' beliefs might be considered in two ways. Firstly, blushing may give rise to similar negative beliefs in phobic as in nonphobic individuals. That is, when low anxious people feel themselves blushing, they may also think "They will think of me as guilty". Note that, in contrast, normals experiencing heart palpitations are not likely to have the idea that these are the precursory symptoms 
of heart failure. Secondly, it might be that observers are indeed inclined to think that a person is 'guilty' or incompetent when the person displays a blush.

If so, this would not only be interesting from a theoretical point of view, but might also have important implications for the treatment of individuals with blushing phobia. For example, assuming that blushing phobics' beliefs are not obviously irrational, it would be unwise to challenge the rationality of these beliefs. Therefore, the present study was designed to determine ordinary people's beliefs about blushing. Pertaining to these beliefs, three dimensions can be distinguished: beliefs about blushing when the individuals are blushing themselves, beliefs about other people who are blushing, and the expected beliefs of other people when they see the individual blushing. To this end, the beliefs concerning blushing were collected within a group of unselected individuals from the general population. To investigate potential sex differences in this respect, we included both men and women participants. Besides, to explore potentially functional aspects of blushing, individuals were asked whether they thought there are situations in which it would be desirable and undesirable to blush.

\section{Method}

\section{Participants}

Participants were 30 women (mean age 30; SD 10.9; range 19-70) and 26 men (mean age 30; $S D 10.2$; range 20-58). They were students, researchers and supporting personnel of Maastricht University, and people who had no link with the University (e.g. family members, neighbours). They were approached for participation through their mailboxes and on verbal request. Individuals were given the opportunity to send the inquiries back anonymously; only sex and age were known to the researcher.

\section{Assessment}

A free recall thought-listing inquiry was used to investigate beliefs about blushing. This method was adopted from Cacioppo \& Petty (1981). In the instruction, the importance of filling out the questionnaire as honestly as possible was stressed. All participants anonymously completed the following questions:

1) Think of a situation in which you've seen a male person blushing. Write down all thoughts that leapt to mind then and that do so now.

2) Think of a situation in which you've seen a female person blushing. Write down all thoughts that leapt to mind then and that do so now.

3) Think of a situation in which you were blushing yourself. Write down all thoughts that leapt to mind then and that do so now.

4) What do you think other people (men) think of you when you are blushing? Write down all thoughts that leap to mind.

5) What do you think other people (women) think of you when you are blushing? Write down all thoughts that leap to mind. 
Additionally, participants answered the following two questions:

* Do you think that there are situations in which it would be desirable to blush? If so, in what situations would that be?

* Do you think that there are situations in which it would be undesirable to blush? If so, in what situations would that be?

Data-reduction and analysis

To classify the cognitive responses, they must first be 'unitized' (Meichenbaum, Henshaw, \& Himel, 1982), which means that the responses must be broken down into individual units of cognitive response. All the material that was provided by the participants was examined by two researchers who divided it in units according to the following rule: a stated idea, whether grammatically correct or not, constitutes a unit. The example "I feel stupid and weak" contains two units, namely 'stupid' and 'weak'. The reliability of this procedure was sufficient. That is, the percentage of inter rater agreement with respect to the unitizing of the material was $91 \%$, Cohen's Kappa being .82 .

Next, all cognitive units derived from the five thought-listing questions were rated by two independent raters ( 1 man and 1 woman), who were blind with regard to the sex of the respondents. Rating was done on a polarity dimension of cognitive response, described by Cacioppo and Petty (1981). 'Polarity' is the degree to which the response is in favour of or opposed to the referent. The polarity dimension comprises (1) 'favourable thoughts' - statements that are positive toward or supportive of a referent (e.g. the self or message); (2) 'neutral/irrelevant thoughts' - statements that neither favour nor oppose the referent; and (3) 'unfavourable thoughts' - statements that are negative toward or in opposition to the referent. The two raters received an instructive training with regard to the scoring technique, in order to maximize inter rater reliability. When the raters had different opinions, they discussed and tried to reach an agreement. After the training, the two raters judged all answers independently. The inter rater reliability concerning the scoring of cognitive units as positive, negative or neutral was $85 \%$ (Cohen's kappa was .78) which is a highly satisfactory outcome and indicates that most thoughts were unambiguous.

Per question, the following formula was used to calculate outcomes: ratio=[total number of positive thoughts - total number of negative thoughts $] /$ total number of reported thoughts, negative scores indicating that the majority of thoughts listed by participants was negative, positive scores indicating a majority of positive thoughts listed, scores equalling zero indicating that the number of positive and negative thoughts listed was equal. Three dimensions of thoughts concerning blushing can be identified: (1) Thoughts when seeing other people (men and women) blushing (the 'self-other' perspective); (2) thoughts about the self when blushing (the 'self-self' perspective); and (3) thoughts the respondents expect others (men and women) to think about them when they're blushing ('other-self' perspective).

The obtained ratios from the 'self-other' and the 'other-self' perspectives were subjected to an Analysis of Variance with one between subjects factor (Sex self: male vs female) and one within subjects factor (Sex other: male vs female). The ratios of the 'self-self perspective were analysed by means of a paired $t$-test. 


\section{Results}

The 'self-other perspective'

Figure 1 shows that mean ratios are negative, indicating that individuals responded generally with more negative than positive thoughts when asked to describe their beliefs about blushing from an observer perspective. Examples of positive thoughts in this category are "How sweet/charming", "Disarming", and "Luckily, he's not a macho". Examples of negative thoughts are "You make a fool of yourself", "He/she feels very uncomfortable", and " $\mathrm{He} / \mathrm{she}$ is as red as a lobster!"A paired $t$-test indeed revealed a significant difference between the number of positive and negative thoughts, overall $(t(55)=-2.85, p<.01$ ). With respect to the ratios, a 2(Sex self: male, female) $\times 2$ (Sex other: male, female) ANOVA revealed neither for Sex self $(F(1,54)=0.0)$ nor for Sex other $(F(1,54)=1.39, p>.05)$ significant main effects. That is, overall respondents of both sexes responded similarly, and both sexes were evaluated similarly. However, the analysis revealed a significant interaction effect between Sex self and Sex other, $F(1,54)=11.0$, $p<.005$, indicating that blushing in members of the opposite sex was, generally, evaluated significantly less negatively than blushing in members of the same sex (see Figure 1). Post hoc $t$-tests indicated that this effect was significant for male participants, $t(25)=-3.7$, $p<.005$, but not for female participants, $t(29)=1.4, p>.05$.

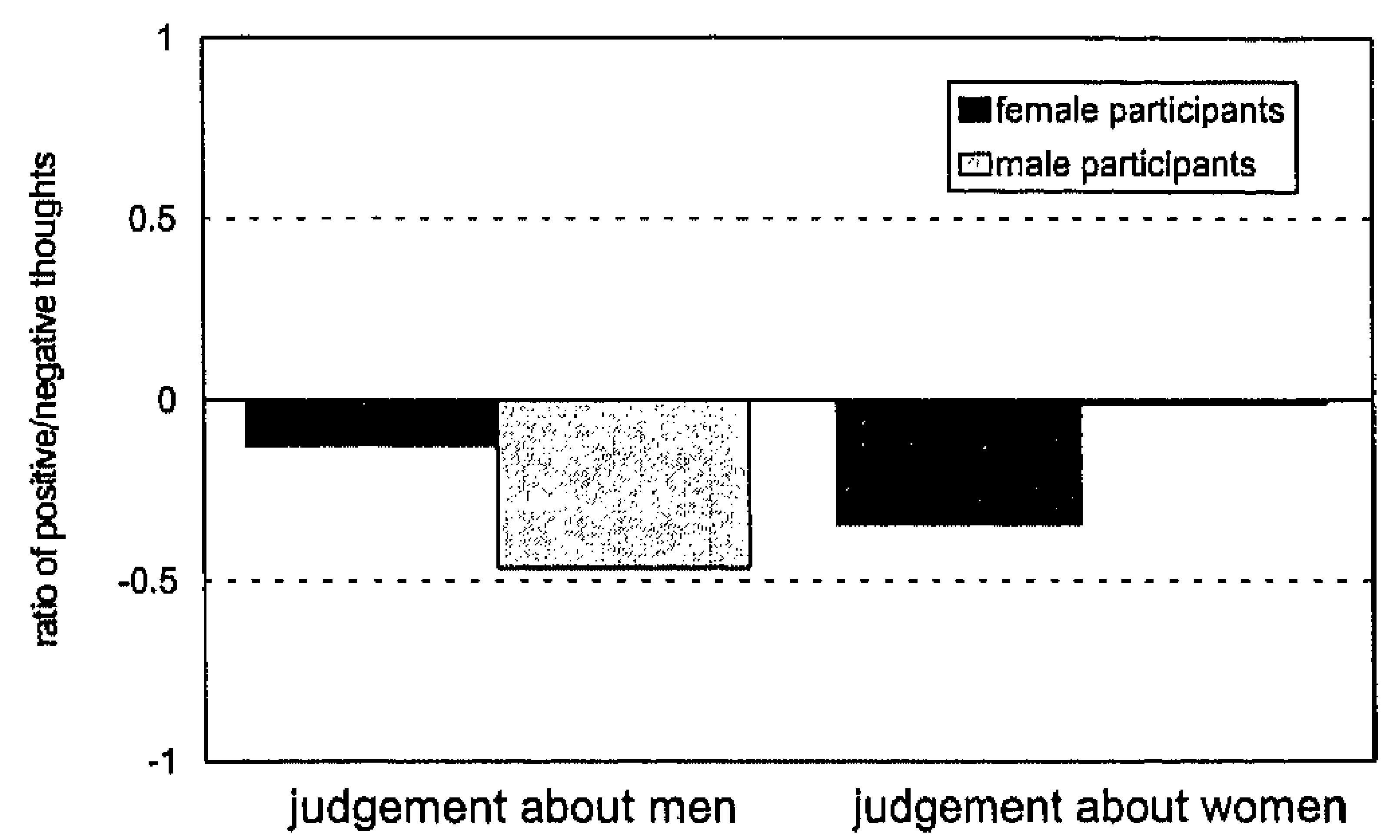

Figure 1: Seeing other people blushing: the 'self-other perspective'. Ratios of positive/negative thoughts about blushing, reported by female and male participants, about men and women. Positive scores indicate that more positive than negative thoughts were listed by participants, negative scores indicate a majority of negative thoughts, zero indicates an equal number of positive and negative thoughts. 
The 'self-self perspective'

Overall, participants reported relatively more negative than positive thoughts when they imagined situations in which they blushed themselves, $t(55)=-7.94, p<.001$. Examples of negative thoughts in this category are "Oh no, I'm turning as red as I could possibly become", "I wish I could stop it", and "Uncomfortable". Thoughts rated as 'positive" are, for example, "It doesn't really matter", "So what? I'm just going to continue talking", and "It's alright when people see that I'm touched". With respect to the ratios, there were no significant differences between men and women $(t(52)=.59)$.

In addition, it was found that the self-self perspective elicited significantly more negative thoughts (mean 2.7 for women and men), than each of the other two perspectives (self-other; seeing a male person (mean 1.8): $t(55)=-3.35, p<.005$; seeing a female person (mean 1.8): $t(55)=-3.65, p<.005$; and other-self: expected thoughts when seen by a male person (mean 1.4): $t(55)=5.7, p<.001$; expected thoughts when seen by a female person (mean 1.1): $t(55)=7.3, p<.001$ ).

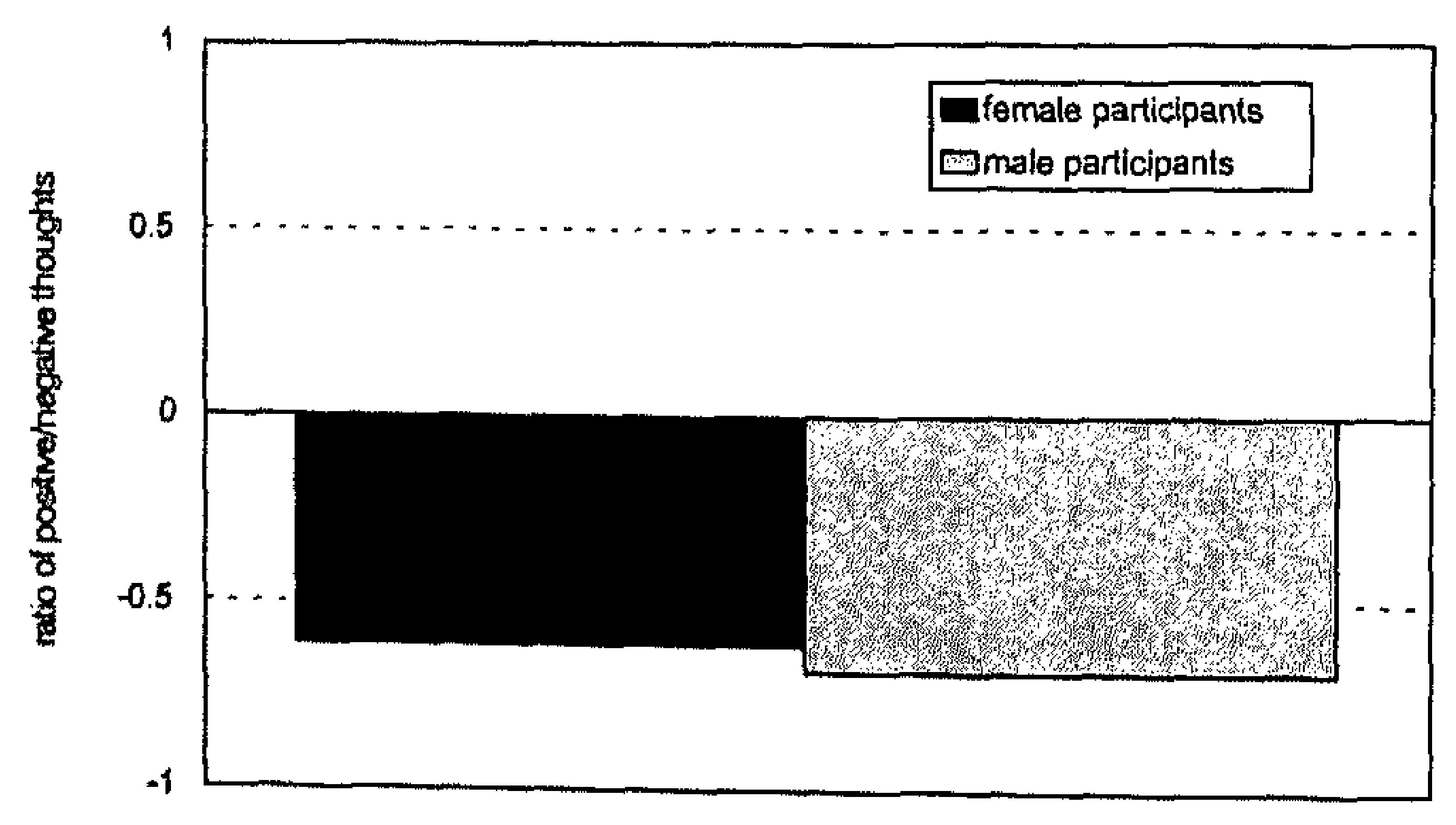

Figure 2: Blushing in the self: the 'self-self perspective'. Ratios of positive/negative thoughts about blushing, reported by female and male participants, about themselves. Positive scores indicate that more positive than negative thoughts were listed by participants, negative scores indicate a majority of negative thoughts, zero indicates an equal number of positive and negative thoughts.

Expected thoughts when seen by other people: the 'other-self' perspective

Examples of negative thoughts in this category are "They think I'm shy", "They think I'm hiding something", and "A sign of immaturity". Positive thoughts are "They might find it charming", "They might find it funny/nice/cute/natural". A 2(Sex self: male vs female blusher) $\times 2$ (Sex other: male vs female observer) ANOVA revealed neither a significant main effect for $\operatorname{Sex} \operatorname{self}(F(1,54)=1.69, p>.05)$, nor for Sex other $(F(1,54)=$ $1.63, p>.05)$. There was, however, a significant interaction effect between Sex self and Sex other $(F(1,54)=5.73, p<0.05)$, indicating that, generally, men and women think they 
are judged more favourably by members of the opposite sex than of the own sex. Post hoc $t$-tests indicated that this effect was significant for male participants, $t(25)=-2.04$, $p=.05$, but not for female participants, $t(29)=1.1, p>.05$.

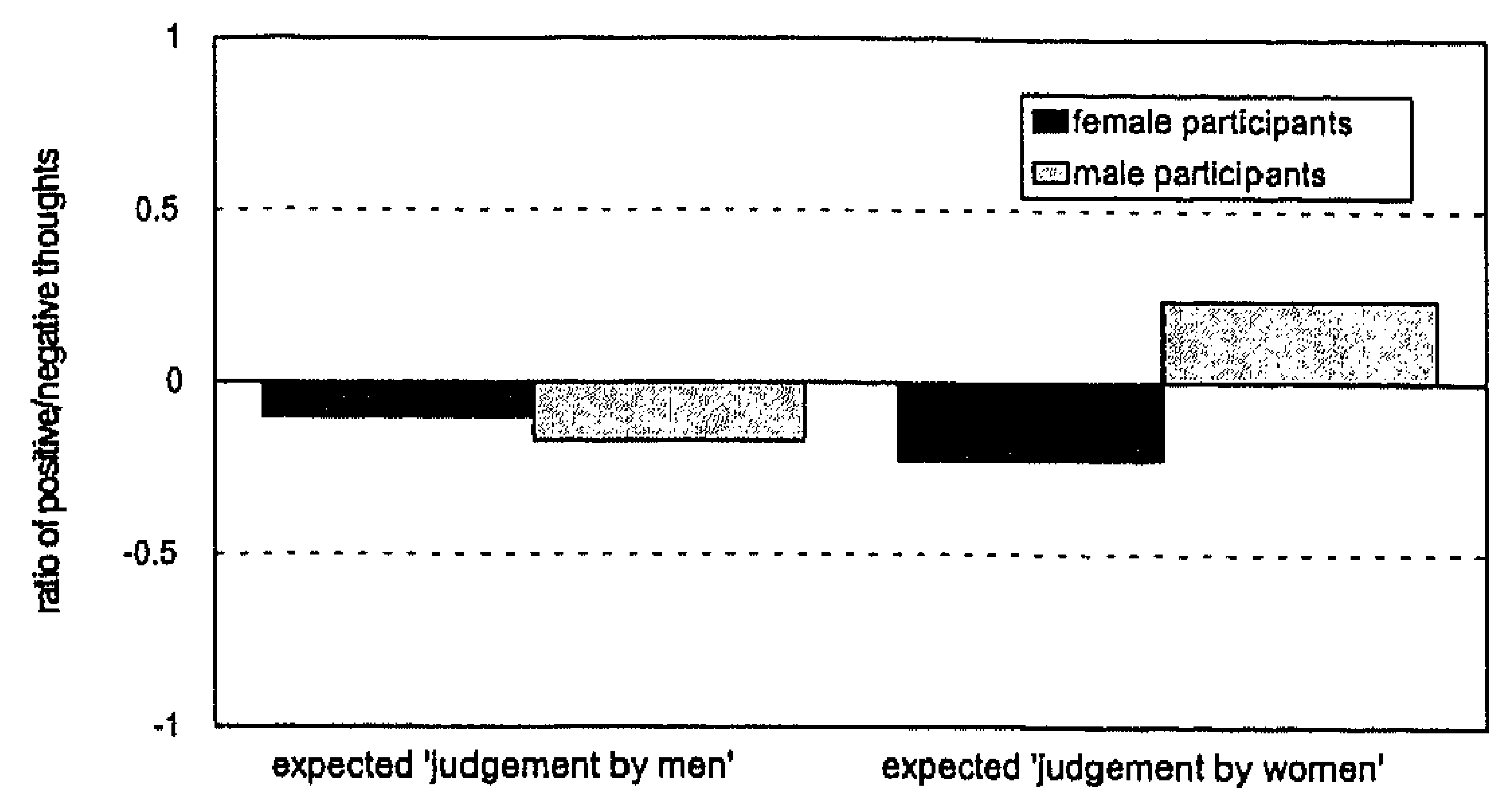

Figure 3: Being watched blushing by other people: the 'other-self perspective'. Ratios of positive/negative thoughts about blushing, reported by female and male participants, concerning the expected judgement by men and women. Positive scores indicate that more positive than negative thoughts were listed by participants, negative scores indicate a majority of negative thoughts, zero indicates an equal number of positive and negative thoughts.

Do normal people think that there are situations in which it would be desirable to blush? According to $45.5 \%$ of the participants, there are. The situations most frequently mentioned here are "when you're being complimented" (22\%), "when you're making advances/ when you're in love" (22\%), and "when you're ashamed" (19\%).

Do normal people think that there are situations in which it would be undesirable to blush?

Nearly $80 \%$ of the participants said "yes". The situation most frequently mentioned here is "when you want to present yourself as a self-confident person/when you want to be taken seriously" (50\%) (e.g. in (business) meetings, when presenting something for a group of people, and a job interview). 


\section{Discussion}

The conclusions that can be drawn from the present results are that normal, unselected individuals have mainly negative beliefs about blushing. This holds true when they blush themselves as well as when they regard members of the same sex blushing. With regard to the opposite sex, participants were less strict: their judgements concerning the opposite sex were less negative than those concerning their own sex. In a similar vein, they think that the opposite sex has a less negative opinion about them than the same sex has.

The question whether normal people have generally negative beliefs about blushing can be answered in the affirmative. Indeed, as actors as well as in the role of observers, participants report mainly negative beliefs about blushing. Thus, results from both perspectives suggest that blushing phobics' beliefs about blushing do not seem to be clearly irrational. That is, people may, in general, indeed think that people are incompetent, guilty, etc. when they blush and, indeed, also in nonphobic individuals a blush response triggers predominantly negative beliefs.

Interestingly, both sexes were less strict for the opposite sex than for members of their own sex, and they also expected members of the other sex to be less negative about them than members of the same sex. Assuming that our population consisted of mainly heterosexual participants, a possible explanation for this finding could be that respondents thought of primarily common, standard, negative, shameful situations when cued for same-sex incidents, whereas more amorous (and thus positive) events are cued when respondents are asked to remember incidents involving the opposite sex. To further investigate this issue, one might choose to use fixed scripts of situations to cue respondents for similar situations involving both sexes. That is, one may ask men and women participants to list their thoughts - in the role of observers - with regard to identical situations.

Most importantly, having established that normals have predominantly negative thoughts pertaining to blushing, like blushing phobics do (e.g. Bögels \& Reith, 1999), the question arises why they did not develop a social phobia. Perhaps the most obvious possibility might be that, although blushing universally gives rise to negative, dysfunctional thoughts, only those people develop a phobia who relatively often (or intensely) display such a blush response. Yet, in contrast to this suggestion, recent empirical evidence (Mulkens, De Jong, Dobbelaar, \& Bögels, 1999b) indicates that people with high fear of blushing did not differ with respect to their physiological blush intensity as a reaction to several types of (social) stressors, compared to individuals with low levels of fear of blushing. Meanwhile, both groups did dramatically differ with respect to self-reported blush intensity. That is, people with fear of blushing seem to overestimate the strength of their actual blush response. Because people's determination whether they blush or not depends on interoceptive cues ('experience') rather than on the (objective) visibility of the blush response, systematic overestimation of the blush intensity logically serves to lower the threshold of triggering negative beliefs in individuals with fear of blushing (cf. Drummond, 1997). Following this, the critical difference between high and low fearful individuals would simply be that, irrespective 
of actual blushing, high fearful individuals more often think that they blush than low fearful individuals do, or overestimate the intensity and/or visibility of their blushing (Mulkens et al., 1999b).

Another possibility might be that blushing phobics exaggerate the catastrophic consequences of a certain belief. Relatedly, phobics may overestimate the chance that a certain belief comes true (e.g. phobics may believe there is a higher chance of someone rejecting them because they blush than normal individuals do). In line with these suggestions, treatment-outcome research with generalized social phobics indeed showed that generalized social phobics gave higher probability and cost estimates of negative social events than nonanxious control individuals; whereas improvement in social phobia was mediated by reduction in cost estimates for social events (Foa, Franklin, Perry, \& Herbert, 1996). Finally, blushing phobics may underestimate their skills to handle such catastrophic consequences.

Given the finding that also ordinary people report predominantly negative beliefs pertaining to blushing, what are the implications for treatment? Having established that blushing has, generally, a negative connotation, and, thus, the 'non-irrationality' of blushing phobics' beliefs about blushing, it seems unwise to challenge the rationality of these beliefs. After all, the beliefs might turn out to be correct. It may, therefore, be more fruitful to concentrate on the feared outcome (i.e. worst catastrophe), assuming that a certain belief is true, and perhaps to reevaluate a belief from 'very negative' to 'less negative' or neutral. To reevaluate blushing in a more positive way, however, seems not a very sensible strategy.

In addition, it may be helpful to teach blushing phobic individuals coping skills to abolish the disruptive consequences of blushing in social situations. For example, by teaching them to redirect attention externally (e.g. at the task at hand) rather than internally (e.g. at the self, the blushing, the negative beliefs). This technique of task concentration, which is based on the assumption that heightened self-focused attention plays an important role in the maintenance of fear of blushing, showed promising results in several case studies (Bögels, Mulkens, \& De Jong, 1997; Mulkens, Bögels, \& De Jong, 1999a).

Finally, it may be worthwhile to learn blushing phobics to differentiate between situations in which it is desirable to blush and situations in which it is undesirable to blush. That is, although under some circumstances blushing may result in unwanted social attention, there is also clear evidence that blushing favourably influences the observers' judgement, e.g. after a social infraction (De Jong, 1999), in a similar vein as other displays of embarrassment (Semin \& Manstead, 1982), or shame (Keltner, Young, $\&$ Buswell, 1997). The present findings suggest that ordinary people are well able to differentiate between situations in which blushing may be desirable. It might well be that blushing phobics are unable to make this distinction. 


\title{
.5 Attentional focus and fear of blushing: A case study?
}

\begin{abstract}
$y$ means of a single case study, the effects of redirecting attention above exposure only I fear of blushing, avoidance, and idiosyncratic dysfunctional beliefs were tested. A cial phobic patient with fear of blushing as the predominant complaint received ssions of Task Concentration Training (TCT) and Exposure in Vivo (EXP) alternately, ter a steady baseline had been established. The treatment consisted of 14 individual ssions. Assessments were held before and after baseline, after treatment, after 4 weeks 1low-up, and after 1-year follow-up. Continuous measurements were held throughout e treatment in order to measure the differential effects of TCT and EXP on fear, -oidance and beliefs. TCT and EXP together, turned out to be an effective treatment for ar of blushing: large effects were observed on all 3 outcome measurements. When fferential effects are closely looked at, EXP seemed more effective in decreasing fear - blushing. However, the patient appeared to have used TCT strategies as well during e EXP weeks, which may have contributed to the favourable effects of EXP.
\end{abstract}

${ }^{7}$ This section is a slightly adjusted version of the article Mulkens, S., Bogels, S.M. \& De Jong, P.J, 199). Attentional focus and fear of blushing: A case study. Behavioural and Cognitive Psychotherapy, 27, 3-164. 


\section{Introduction}

Fear of blushing is known to be an important problem for many social phobics (Edelmann, 1990c). In certain cases, the social phobic's fear is centred around the supposed visibility of blushing. Consequently, social situations are avoided or endured with intense distress, for in the blushing phobic's view, blushing might lead to rejection or negative evaluation by other people.

It is believed that heightened self-focused attention (SFA) - the increased awareness of the self as a social object - plays an important role in the maintenance of social phobia (Hope, Gansler \& Heimberg, 1989; Clark \& Wells, 1995; Rapee \& Heimberg, 1997; Woody, 1996). That is, SFA is believed to intensify negative emotional state and physical responses, to increase dysfunctional thinking, and to decrease effective performance in social phobics (Bögels, Mulkens, \& De Jong, 1997; Wells, White, \& Carter, 1997; Hope et al., 1989).

It might well be that heightened SFA plays, in particular, an important role in individuals with fear of blushing. Since actual blushing can be an especially salient physiological reaction (warm cheeks), it can be expected to increase SFA. That is, it has been found that salient physiological arousal serves to focus attention inward (Fenigstein \& Carver, 1978; Wegner \& Giuliano, 1980), which, in turn, increases individuals" awareness of physiological reactions (see Scheier, Carver, \& Matthews, 1983, for a review). Moreover, a fearful preoccupation with the idea that one is blushing or about to start blushing (irrespective of actual/visible blushing) is likely to result in excessive SFA. Altogether, attentional manipulation (i.e. directing attention externally rather than internally) might be helpful in treating social phobia and especially in treating fear of blushing.

Following this line of reasoning, a strategy called 'Task Concentration Training' (TCT; Bögels et al., 1997) was developed, aiming specifically at redirecting blushing phobics' attention: away from the blush, and towards the social task at hand and relevant environmental aspects. TCT consists of 3 phases: (1) getting insight in attentional processes and the effects of heightened SFA; (2) focusing attention outward in nonthreatening situations; and (3) focusing attention outward in threatening situations. Results of two case studies suggest that TCT can effectively reduce fear of blushing (Bögels et al., 1997).

The purpose of this case study was to explore specifically the effects of TCT on fear of blushing, related avoidance behaviour, and dysfunctional beliefs about blushing. Yet, in phase 3 (practising TCT in threatening situations; cf. Bögels et al., 1997), patients use a hierarchical list of social situations in which they blush or are afraid of blushing. Hence, it remains unclear to what extent the effects of TCT should be attributed to Exposure in Vivo (EXP). The rationale of both treatments, however, is different: in TCT, the patient is taught to focus on the task, using the hierarchy to practise this technique; in EXP, the patient is instructed to remain in the feared situation, to allow feelings of anxiety, to refrain from safety behaviours (cf. Wells, Clark, Salkovskis, Ludgate, Hackmann, \& Gelder, 1995) and to stay until a significant decrease of anxiety is 
perceived (Butler, 1985). On the other hand, one could also reason that TCT is the effective component of EXP: patients could, autonomously, discover that task-focusing is helpful during the EXP exercises.

To explore further the possible effects of TCT and potential differences between TCT and EXP, we conducted a case study, in which we alternated EXP and TCT in a sequential design. We were interested in the effects of these manipulations on fear of blushing, related avoidance behaviour, and dysfunctional beliefs about blushing. Dysfunctional beliefs might be influenced through the experience of disconfirming information, in case of TCT by becoming more aware of the task and the environment (cf. Clark \& Wells, 1995), and in case of EXP by dropping the safety behaviours (cf. Wells et al., 1995). Meanwhile, we checked whether focusing attention on the task or staying in the situation until the anxiety decreases without using any safety behaviours was evident during TCT and EXP, respectively. The treatment started after a steady baseline had been established, and consisted of 14 individual weekly sessions. Followups took place after 1 month and after 1 year.

\section{Method}

\section{Patient}

The patient was a 21-year-old female student with fear of blushing, the primary diagnosis being social phobia (DSM-IV; APA, 1994). She had great difficulties in keeping her studies going: four months before diagnosis she ceased attending classes because of fear of blushing. Since then, she also started worrying about future jobs. As a small child, she had been very lively, becoming quieter in adolescence. After starting her studies at 18 , she became increasingly insecure about herself and her abilities, and she developed a fear of being at the centre of attention, as blushing would occur in those occasions.

\section{Experimental design}

The thrust of single case methodology has been to verify experimentally in individual cases that observed changes in behaviour are really a function of the therapeutic procedures applied to produce these changes (Leitenberg, 1973). In this case study, 2 treatment strategies were analysed that seem to be incompatible in some ways, but also bear similarities. What is similar is the practising of difficult social situations, indicating an inherent exposure component in both strategies. However, dissimilarities lie in the focus of attention in those situations: on the anxiety, while not doing anything to exclude it (EXP), or on the task and the environment (TCT).

Although it is impossible to fully disentangle both strategies in human behaviour, attempts were made to optimize the implementation of the respective techniques. In one week, in-session exercises and homework were carried out along the lines of EXP, in the following week these activities followed the lines of TCT. This design is a variation of the reversal design (for its multiple reversal of techniques), or an extended form of the $\mathrm{ABCB}$ design ( $\mathrm{A}$ is the baseline, $\mathrm{B}$ and $\mathrm{C}$ are two different treatments). When a stable 
baseline with few non-therapeutic sessions is first established, behavioural changes that appear afterwards can be reliably attributed to therapeutic interference. By alternating both treatments frequently, potential differential changes in the outcome measures might be attributed to either of the treatments.

\section{Measures}

Questionnaires

The following questionnaires were completed at assessment occasions (i.e. pre-baseline, post-baseline, post-treatment, 1-month follow-up, 1-year follow-up):

Fear Questionnaire (FQ; Marks \& Mathews, 1979). The main phobia and the social phobia subscale were used. The main phobia is the situation that is most feared, described in the patient's own words, and rated on a 9-point scale for the degree of fearfulness and avoidance ( $0=$ "not fearful"/ "not avoided", $8=$ "extremely fearful"/ "always avoided"). This patient's main phobia was "to blush in a situation where everyone can see me and where I must say something". The social phobia subscale consists of five descriptions of common social situations, to be rated in the same way (range 0-40).

Blushing, Trembling, and Sweating Questionnaire (BTS-Q; Bögels \& Reith, 1999). The 6 subscales of the BTS-Q measure the various aspects of fear of blushing, trembling, and sweating. Four subscales were used: (1) 'Fear of Blushing' measures, by means of visual analogue scales (VASs), the extent to which the respondent experiences blushing as a problem and is afraid to blush (range 0-100). (2) 'Behavioural Problems' indicates to what extent the patient, when blushing, is hindered by disturbances in mental processes, such as black-outs or problems in concentrating (range 0-4). (3) 'Blushing Cognitions' consists of positive and negative beliefs about blushing and its social consequences, each belief rated proportionally from $0 \%$ ("I do not believe it at all") to $100 \%$ ("I'm totally convinced") (range 0-100). (4) 'Avoidance of Blushing' measures the extent to which strategies are used to avoid or hide blushing, such as wearing make-up or avoiding eye contact (range $0-4$ ). Research into the psychometric properties of the BTS-Q indicates that it is a highly reliable instrument and that it has good discriminant validity (Bögels \& Reith, 1999).

Social Phobia and Anxiety Inventory (SPAI; Turner, Beidel, Dancu \& Stanley, 1989; Dutch translation: Scholing, Bögels, \& Velzen, 1995). From the SPAI, the social phobia subscale was used, which measures aspects of social phobia in general. Each item is scored on a 7-point scale, rescaled from 0 ("never") to 6 ("always") (range 0-192).

Blushing Propensity Scale (BPS). The BPS consists of circumscribed social situations for each of which the individual indicates how often she feels herself blushing (Leary \& Meadows, 1991; Dutch translation Bögels, Alberts, \& De Jong, 1996). Answers range from 0 ("I never feel myself blushing in that situation") to 4 ("I always feel myself blushing in that situation") (range 0-76).

Brief Fear of Negative Evaluation Scale (Brief-FNE; Leary, 1983). This scale measures people's concerns about being evaluated unfavourably by others (range 0-48). 


\section{Diaries}

Diary recordings served as continuous measurements. The patient was instructed to daily record blushing, anxiety, and associated behaviour systematically on self-monitoring diaries. On a 5-point scale, she indicated the number of social situations she had encountered (range $0=$ "none" to $4=$ "a lot"), how often she had feared blushing (range $0=$ "never" to $4=$ "each time"), and the intensity of this fear (range $0=$ "no fear at all" to $100=$ "extreme fear"). Furthermore, three diary items inquired into the extent to which she had conducted avoidance behaviour to diminish anxiety (including safety strategies, subtle avoidance behaviour). Finally, the frequency of actual blushing was sought (the patient carried an event marker, to reliably establish the frequency of blushing).

From the diaries, two target outcome variables were chosen: 'fear of blushing' and 'avoidance'. 'Fear of blushing' was calculated by multiplying the item 'how often did you experience fear of blushing' by 'the intensity of this fear', which resulted in a range of $0-400$ (divided by 100 in order to standardize the scores). 'Avoidance' was a composite variable, constructed from the 3 'avoidance' diary items (range $0-4$ ). Note that a 'fear of blushing' score of 4 implies a continuously present, extreme fear of blushing (which would be virtually impossible). A score of 0 , on the other hand, implies that fear of blushing is never experienced.

\section{Idiosyncratic dysfunctional beliefs}

Four idiosyncratic dysfunctional beliefs with regard to blushing were assessed during the intake. Before and after each treatment session, the patient rated these beliefs on VASs. The beliefs of this patient were: (1) "When I blush, I come across as stupid"; (2) "When I blush, everyone will notice"; (3) "When I blush, I come across as insecure"; (4) "When I blush, I will lose face". An average conviction score was computed for each measurement occasion. The mean conviction score at the end of an EXP session and the mean score at the start of the next session (in the meantime, the patient had practised EXP) were averaged; the same was done for TCT weeks. Such a procedure allows one to determine whether changes in conviction occurred during EXP or TCT.

\section{Credibility of the treatment rationale}

Treatment credibility of the different treatments was assessed after the sessions in which the rationale was explained and, again, at post-test. To this end, the patient was asked to answer three questions on a 9-point scale (range 1= "not at all" to $9=$ "extraordinary"): (1) how logical does this form of treatment seem to be for you?; (2) how confident are you that this treatment will help you to overcome your fear of blushing?; and (3) to what extent would you advise this treatment to a friend with similar problems? At post-test, the patient was asked to look back, while the questions were slightly reformulated.

\section{Treatment integrity}

Treatment integrity was assessed on a continuous basis. In the diary, a section was included in which the patient indicated to what extent she had used several techniques to diminish her fear, irrespective of what technique she should have applied in that week. These techniques included relaxation, thinking less catastrophically, concentrating on the 
task at hand (TCT), or simply staying in the situation until the anxiety diminished (EXP). The patient was asked to answer these questions honestly, since this information could show us whether it would be difficult to switch techniques.

\section{Procedure}

The treatment was carried out by the first author and supervised by the second author. First, the patient received a pre-treatment session, in which the procedure was explained globally, and all assessments were made. Furthermore, the diary and the event-marker were introduced to the patient. Then, the baseline period started, during which the patient returned to the mental health centre 3 times in 7 weeks for a short appointment in which she scored the idiosyncratic dysfunctional beliefs, handed in the diaries, and discussed potential completion problems.

In the first post-baseline session, both treatment rationales (TCT and EXP) were explained. The TCT rationale explained how blushing and SFA mutually reinforce each other and, as a consequence, increase anxiety, (perceived) blushing, negative selfthoughts, problems in concentration, and unskilful behaviour. The patient was taught that redirecting her attention to the task would help her to be able to break through the vicious circle and to cope with blushing (Bögels et al., 1997). The EXP rationale emphasized the role of (subtle) avoidance strategies and safety behaviours in the maintenance of fear of blushing. The patient was taught that tolerating fear and blushing, without avoiding or doing anything to decrease the fear, would eventually lead to a decrease in fear. The importance of practising this technique for prolonged time and/or repeatedly was stressed (e.g. Butler, 1985). Furthermore, a hierarchy of social situations in which the patient experienced fear of blushing was constructed in this session.

In the second post-baseline session, the patient was asked to explain in her own words the contents of both treatment rationales. Then, EXP exercises were done in the session (having eye contact without saying anything). For homework, the patient was asked to practise these general EXP exercises with several people, and to describe them on a form, designed for this purpose. In the next session, homework was first discussed, whereafter TCT exercises were done in the session. In TCT, the patient and the therapist sat with their backs to each other (no eye contact), while the patient was instructed to concentrate on listening to short neutral stories, related by the therapist, and to summarize them afterwards. Listening exercises were build up hierarchically (for more details, see Bögels et al., 1997). The patient was instructed to practise neutral TCT exercises for homework and to describe them on a form, designed for this purpose. In the following sessions, TCT and EXP treatments were alternated, while the fear hierarchy was worked through. 


\section{Results}

Treatment credibility

Before treatment, the patient's credibility rating of the TCT rationale was 5.7, whereas she rated the credibility of EXP 3.0. At post-test, she rated TCT 7.3 and EXP 5.3. Thus, both at the start of treatment and afterwards, she believed more in TCT than in EXP. However, there was a positive shift towards both treatments, from pre-test to post-test.

\section{Treatment integrity}

From the diaries, it was deduced that the patient conducted TCT (without anything else) in the weeks that she should have done that. Mean degree of the implementation of TCT (range 0-4) was 1.5 in TCT weeks. In the EXP weeks, however, she combined EXP with another technique in 5 out of 6 weeks (TCT in 4 weeks and relaxation in 1 week). Mean degree of the implementation of EXP was 1.1, combined with 0.2 TCT and 0.01 relaxation in EXP weeks. In the follow-up period of 4 weeks, in which the patient was free to use any technique, she appeared to have applied 0.9 TCT and 0.1 EXP, on average. In the week that preceded the 1-year follow-up, she used 1.0 TCT and 0.7 EXP.

Table 1: Patient's scores on the questionnaires at pre-baseline test (Pre1), post-baseline test (Pre2), post-test, 1-month follow-up (FU-I), and 1-year follow-up (FU-II).

\begin{tabular}{llllll}
\hline Variable & Pre1 & Pre2 & Post & FU-I & FU-II \\
\hline FQ-Main phobia $(0-8)^{1}$ & 6.5 & 6.5 & 2 & 1.5 & 3 \\
FQ-Social phobia $(0-40)^{1}$ & 20.5 & 21.5 & 8.5 & 2.5 & 7 \\
SPAI-Social phobia (0-192) & 94 & 96.7 & 69 & 48 & 53 \\
BTS-Q & & & & & \\
$\quad$ Fear of blushing $(0-100)^{2}$ & 61 & 63 & 31 & 10 & 17.7 \\
$\quad$ Behavioural problems $(0-4)^{3}$ & 3 & 3 & 2 & 1 & 1.3 \\
$\quad$ Positive beliefs $(0-100)^{4}$ & 37 & 46 & 41 & 35 & 35 \\
$\quad$ Negative beliefs $(0-100)^{4}$ & 64 & 59 & 15 & 5 & 13 \\
$\quad$ Avoidance (0-4) & 1 & 1 & 0 & 0 & 0.23 \\
Mean blushing frequency per day in the & & & & & \\
past week (diary) & 2.4 & 2.3 & 0.3 & 0.3 & 0.4 \\
Blushing Propensity Scale (0-76) & 45 & 50 & 13 & 14 & 30 \\
Brief-FNE (0-48) & 18 & 9 & 7 & 5 & 8 \\
\hline 'Mean fear and avoidance score & & & & & \\
\hline
\end{tabular}

${ }^{1}$ Mean fear and avoidance score

${ }^{2}$ Mean VAS score

${ }^{3}$ Mean items score

${ }^{4}$ Mean \% score 
Questionnaires

As can be seen in Table 1, pre- and post-baseline values were not very far apart, indicating a stable baseline. An exception was the Brief-FNE score, showing a reasonable decrease at post-baseline. Next, strong decreases can be observed between pre-treatment (i.e. post-baseline) and post-treatment on most variables. Exceptions are the Brief-FNE and the BTS-Q positive beliefs, showing little or no change. The strong improvements indicate that the treatment, altogether, had favourable effects. From posttest to 1-month follow-up, further improvements can be noticed on almost all variables (except for the BTS-Q positive beliefs and the BPS). The BTS-Q avoidance value, which was 0 at post-test, remained 0 at 1-month follow-up. At 1-year follow-up, most variables increased slightly, although most values fluctuated around post-test values. Thus, the obtained treatment effects remained at long-term follow-up.

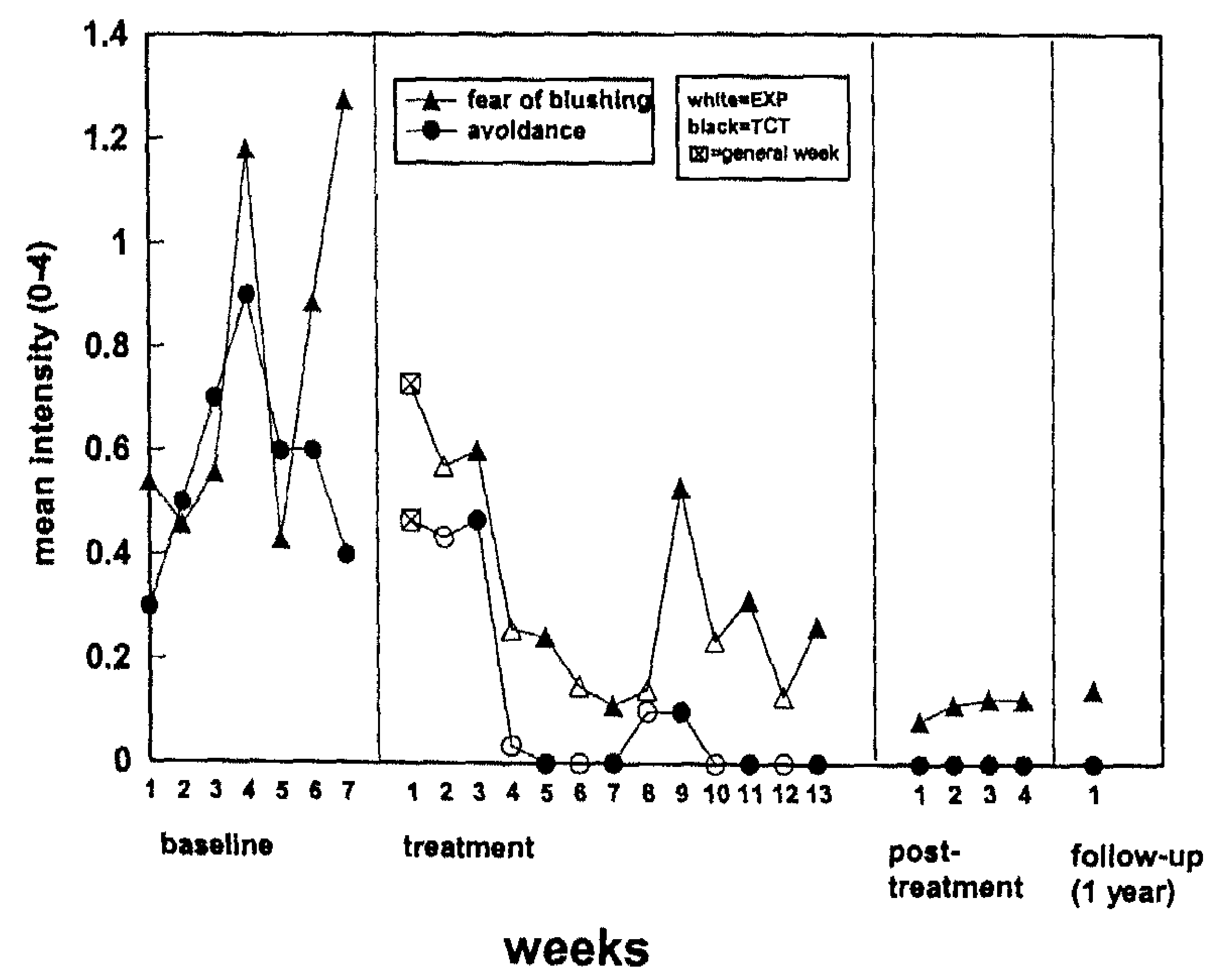

Figure 1: Diary weekly averages on fear of blushing and avoidance during baseline, treatment, I-month follow-up and 1-year follow-up. Means during treatment represent the weeks following EXP and TCT sessions (implying the practising of either of the techniques), respectively.

\section{Continuous measurements: diaries}

As can be seen in Figure 1, baseline values of fear of blushing and avoidance fluctuate between 0.4 and 1.3 , and between 0.3 and 0.9 , respectively. Subsequent values of fear and avoidance, obtained during treatment, fluctuate between 0.1 and 0.7 , and between 
0 and 0.5 , respectively. This indicates an apparent decrease in the treatment phase, compared to baseline. During the post-treatment phase, fear of blushing values decrease even further, while avoidance values stabilize at 0 . At 1-year follow-up, scores remained almost unchanged. Taken together, the treatment was successful in diminishing fear of blushing and avoidance behaviour.

With regard to potential differential treatment effects, EXP seems to have had a more powerful influence on the reduction of fear of blushing than TCT. That is, EXP values decline more strongly, compared to TCT values, on most occasions. In TCT weeks, values sometimes even increase, indicating an elevation of fear. With respect to avoidance values, differential effects are somewhat less pronounced, because the values drop rather fast to a minimum. In the fourth week of treatment, however, the strongest decline is observable. In this week, EXP was practised.

Continuous measurements: idiosyncratic dysfunctional beliefs

As can be seen in Figure 2, the conviction of the idiosyncratic dysfunctional beliefs decreased during the treatment phase, compared to baseline. Moreover, conviction declined even further at 1-month follow-up and at 1-year follow-up. Thus, beliefs changed as well as a result of treatment.

When examining differential treatment effects, EXP weeks seem to have had more influence on the decrease of the conviction than TCT weeks.

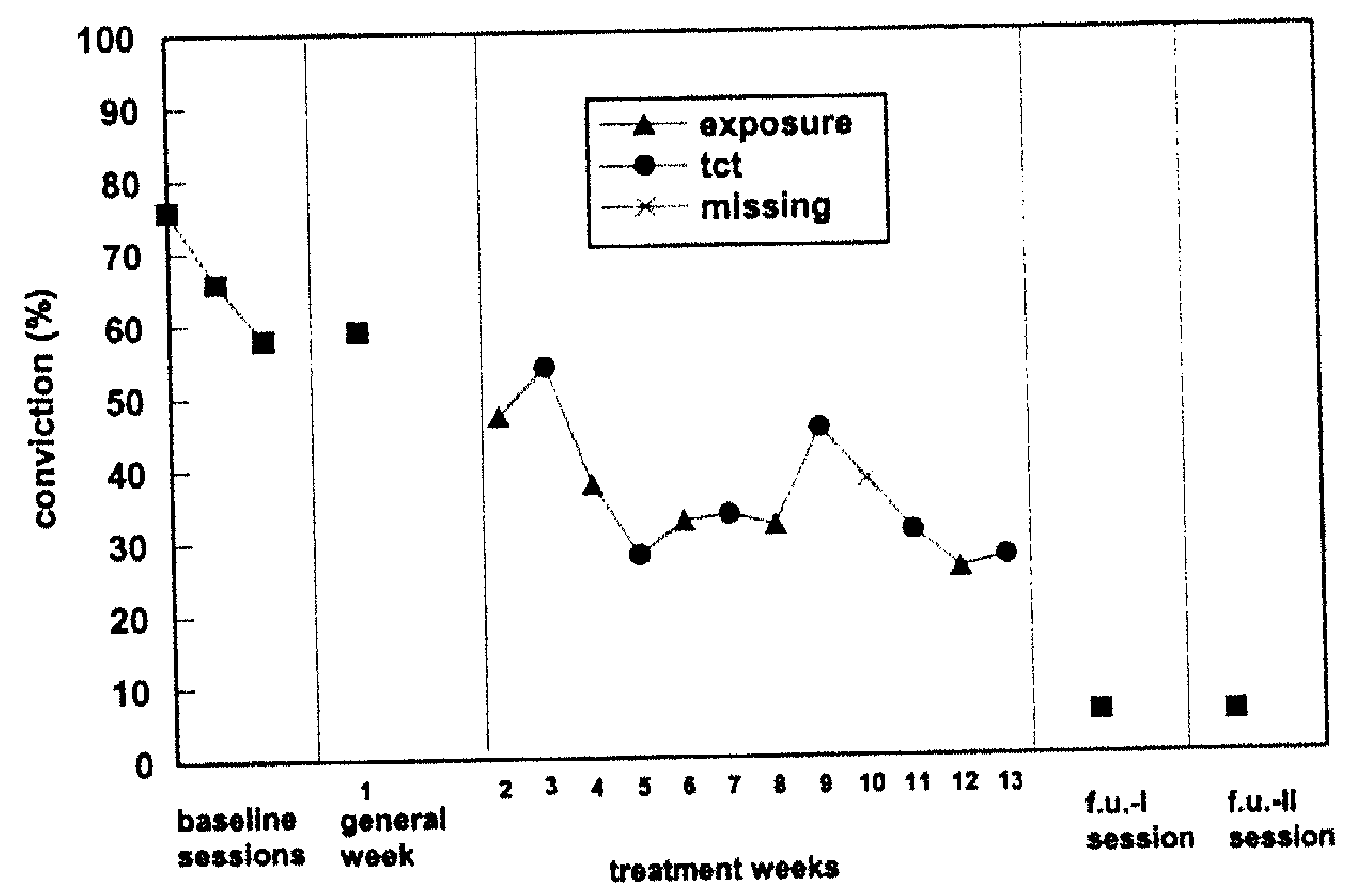

Figure 2: Mean conviction of idiosyncratic dysfunctional beliefs, scored before and after sessions, during baseline, general week (explanation of the rationales), treatment, 1-month follow-up and 1-year follow-up. Note that values taken at the end of a session and values taken at the start of the next session are averaged. 


\section{Discussion}

The results of this case study can be summarized as follows: (1) Fear of blushing was lastingly reduced by behavioural treatment; (2) EXP seemed to have produced more favourable results than TCT; (3) the conviction of idiosyncratic dysfunctional beliefs decreased, while no specific cognitive techniques were implemented.

The finding that fear of blushing can be reduced with behavioural treatment is in line with earlier findings concerning the effectiveness of behavioural treatment for social phobia (see Feske \& Chambless, 1995, for a review). Furthermore, the effects of different cognitive-behavioural treatment methods for fear of blushing are not very far apart (Scholing \& Emmelkamp, 1993a).

However, the finding that EXP seemed to lead to more progress than TCT was somewhat unexpected. After all, TCT aimed specifically at reducing SFA, which was expected to be of major importance in the maintenance of fear of blushing. Perhaps the effect of dropping the safety behaviours in EXP is more powerful than influencing SFA. With respect to the efficacy of this type of EXP, Wells et al. (1995) clearly indicated that EXP plus decreased safety behaviours was significantly better than EXP alone in reducing within-situation anxiety and belief in the feared catastrophe.

At the same time, however, the present results should be interpreted with some caution. That is, at times when TCT leads to an increase in fear (in weeks 9, 11, and 13), important events happened to take place: in week 9 , the patient resumed her studies after quite a while (note that her studies were the main reason for seeking treatment); in week 11 , she was the panel chairperson in her study group for the first time after a very long time (a task that all students fulfill once in two months); in week 13, she performed the most difficult item in her fear hierarchy: practising the job of a lawyer in a court roleplay, with many spectators present. In weeks 10 and 12 , no events of comparable difficulty had taken place. Furthermore, the integrity results showed that the patient appeared to have combined EXP with TCT in the EXP weeks, whereas she had applied TCT purely in the TCT weeks. This indicates that a combination of EXP and TCT provided the ameliorative effects in the EXP weeks. Apparently, the patient was not able to switch techniques totally. Indeed, it would be difficult for her to 'forget' what she did in the past week. Yet, this 'forgetting' appeared to be most difficult after TCT weeks, when she kept using it together with EXP, while the opposite did not seem to occur. Note also that the patient had far more confidence in the TCT rationale than in the EXP rationale. After treatment, confidence remained more positively for TCT. Thus, at least, this study evaluated the effectiveness of a combination of TCT and EXP. At best, it turned out to be a test of TCT versus EXP plus TCT. For the time being, we have at least established that in this case, a combination of both techniques produced favourable effects. Controlled treatment outcome research in which a true independent comparison of both techniques can be made is needed to specifically address the question whether TCT or EXP is more effective.

Interestingly, the treatment led to significant cognitive change, as measured by 4 idiosyncratic dysfunctional beliefs. This finding is in accordance with the finding of 
Newman, Hofmann, Trabert, Roth \& Taylor (1994), who showed that cognitive restructuring can occur without specific cognitive treatment, and that interventions for phobia are not necessarily mode-specific. Both EXP and TCT might address cognitions implicitly, by giving patients the opportunity to experience disconfirming information: TCT by making patients aware of their environment, and EXP by dropping the safety behaviours, which had prevented them from experiencing the true outcome of a social situation. This finding has an important practical implication: whereas the techniques of TCT and EXP can be acquired by therapists relatively easily, cognitive therapy is a complex technique, requiring experienced therapists (Bögels et al., 1997). Thus, since TCT and EXP both lead to cognitive changes, these treatments might be efficient alternatives to cognitive therapy.

A remarkable result of this case study is, finally, that the self-reported blush frequency decreased after treatment, and remained low at long-term follow-up. It is, however, unclear whether the physiological blush frequency indeed has decreased, or that the patient's self-report reflects a reduced preoccupation with blushing. It might also be that the patient always overestimated her blush frequency and is able to report a more factual picture after treatment. In line with that suggestion, Mulkens, De Jong, Dobbelaar, \& Bögels (1999b) found that individuals with fear of blushing tended to overestimate their physiological blush reaction.

In sum, this case study showed that a combination of TCT and EXP substantially and lastingly decreased fear of blushing, related avoidance behaviour, and dysfunctional beliefs about blushing. Future research, however, should determine the relative contribution of TCT and EXP in the treatment of erythrophobia. 


\title{
4.6 Effects of Task Concentration Training versus Exposure in Vivo on fear and physiology
}

\begin{abstract}
Patients with fear of blushing as the predominant complaint $(\mathrm{N}=31)$ were randomly assigned to (1) Exposure in Vivo (EXP), or (2) Task Concentration Training (TCT), in order to test the effect of redirecting attention above exposure only. In addition, it was investigated whether treatment reduced actual blush behaviour; therefore, physiological parameters of blushing were measured during two behavioural tests. Half of the patients served as waiting-list controls first. Assessments were held before and after treatment, at 6-weeks, and at 1-year follow-up. Both treatments appeared to be effective in reducing fear of blushing and realizing cognitive change. Yet, at post-test, TCT tended to produce better results with respect to fear of blushing. At 6-weeks follow-up, TCT produced significantly more cognitive change. At 1-year follow-up, patients further improved, while differential effects had disappeared. The reduction in fear of blushing was not parallelled by a reduction in actual blush behaviour during the behavioural assessments. Thus it seems that fear of blushing reflects a fearful preoccupation, irrespective of actual facial colouration.
\end{abstract}

${ }^{8}$ This section is submitted for publication. A more extensive version of this article was awarded the 'Prof. Dr. P. E. Boeke-prijs 1999' by the Stichting Postacademiale opleiding Psychotherapieën Groningen.

Acknowledgements

The authors are grateful to Annebeth Theunissen, Iris Engelhard, and Annie Raven for their helpful assistance with the data acquisition and to Helene Andrea, Stefanie Duijvis, Meike Tiesema, Ingrid Vorage, and Saskia Weiberg who conducted the treatments. We also wish to thank Agnes Scholing for her helpful advice, and Erik Schouten and Herbert Hoijtink for their statistical assistance. 


\section{Introduction}

Individuals with social phobia almost always experience symptoms of anxiety in social situations (e.g. blushing, palpitations, tremors, sweating, etc.) (American Psychiatric Association, 1994). In various cases, anxiety seems to be centred around the showing of physical symptoms (like blushing), turning the occurrence of these bodily reactions into the source of fear; in many social phobics, fear of blushing appears to be a prominent complaint, indeed (Edelmann, 1990b).

In the last fifteen years, several controlled treatment outcome studies have been conducted on social phobia, including individual as well as group treatment, and concerning comparisons between purely behavioural, purely cognitive, and combined cognitive-behavioural treatment methods (e.g. Butler, Cullington, Munby, Amies, \& Gelder, 1984; Mattick \& Peters, 1988; Mattick, Peters, \& Clarke, 1989; Emmelkamp, Mersch, Vissia, \& Van der Helm, 1985; Heimberg et al., 1990; Gelernter et al., 1991; Scholing \& Emmelkamp, 1993b; Hope, Heimberg, \& Bruch, 1995). The results of these studies generally show that, although social phobia has been linked to cognitive distortions, behavioural and cognitive treatments are equally effective (Feske \& Chambless, 1995).

Yet, it remains largely unclear whether the results of these studies can also be applied to social phobia with fear of blushing as the predominant complaint. Thus far, only two controlled treatment outcome studies have investigated the effects of cognitivebehavioural treatments for social phobics with fear of bodily symptoms as the central complaint. One study compared exposure followed by cognitive therapy, cognitive therapy followed by exposure, and a package in which both methods were integrated from the start (Scholing \& Emmelkamp, 1993a), whereas the other study compared cognitive therapy to applied social skills training (Bögels, 1994). All treatment methods that were used in these studies proved equally effective. However, in both studies effect sizes were rather modest, supporting the clinical impression that social phobics with fear of bodily symptoms are relatively difficult to treat.

One way to enhance treatment efficacy in blushing phobics may be to specifically address detrimental attentional processes. That is, social phobics tend to focus attention excessively on themselves in social situations ('heightened self-focused attention (SFA)', e.g. Daly, Vangelisti, \& Lawrence, 1989; Hope, Gansler, \& Heimberg, 1989; Clark \& Wells, 1995; Wells \& Matthews, 1994). As a result, feelings of anxiety, (awareness of) physical symptoms, and awareness of negative ideas about the self might be caused. Furthermore, less attention might be available to be directed at the task at hand, which is likely to result in poor social performance (Bögels, Mulkens, \& De Jong, 1997; Clark \& Wells, 1995).

It is important to note that the experience of social attention might be especially detrimental to people with fear of blushing. It is known that undesired social attention and concern over appearance are elicitors of blushing (cf, Leary, Britt, Cutlip, \& Templeton, 1992), whereas the experience of blushing is likely to intensify public selfconsciousness (e.g. Wegner \& Giuliano, 1980). Thus, blushing phobics seem to be 
captured in a vicious circle. Given the possibly detrimental effects of enhanced SFA, teaching blushing phobics to focus attention on the pertinent aspects of the situation (the 'task'), instead of focusing inward on feelings, thoughts and symptoms, might well be helpful in treating anxiety (Bögels et al., 1997).

Therefore, we developed an attention training for fear of blushing, Task Concentration Training (TCT). TCT consists of three phases: (1) getting insight into attentional processes and the effects of focusing attention on the self; (2) focusing attention outward in non-threatening, and (3) in threatening situations. Thus attention training aims to make patients aware of what is really going on around them and, as a consequence, to re-evaluate their thoughts about the feared situations. Moreover, as SFA appears incompatible with task focus, attending to the (social) task may be considered as an active coping technique. Several exploratory case-studies (Bögels et al., 1997; Mulkens, Bögels, \& De Jong, 1999) have revealed promising results.

The aim of the present study was to investigate the effectiveness of TCT compared to Exposure in Vivo (EXP): an existing treatment of which the effects on social phobia are well-established (e.g. Taylor, 1996). Another reason for choosing EXP as a comparison treatment is the shared component in both treatments of the hierarchical practising of social situations. Therefore, such a comparison allows to evaluate whether adding attention training enhances the efficacy of exposure only.

We investigated the effects of TCT and EXP on self-report measures of erythrophobia, as well as on actual blushing behaviour. Furthermore, TCT was expected to specifically influence blushing phobics' negative cognitions, by providing the opportunity to experience disconfirming information (cf. Bögels et al., 1997; Clark \& Wells, 1995). To investigate the relative efficacy of TCT, erythrophobics were treated individually with either EXP or TCT. Half of the Ss served as a waiting-list control group, waiting 6 weeks before receiving treatment. Before and after treatment (or waiting-list), we assessed patients' fear of blushing and negative cognitions, and carried out a behavioural test, during which actual blushing (i.e. blood pooling in the cheek) and self-reported blushing intensity were recorded. The inclusion of both objective (i.e. physiology) and subjective indices of blushing allows to differentiate between fearful preoccupation and actual facial colouration (cf. Mulkens, De Jong, \& Bögels, 1997; Mulkens, De Jong, Dobbelaar, \& Bögels, 1999b).

\section{Method}

\section{Patients}

Patients were included in the study when they met the following criteria: a primary diagnosis of social phobia (DSM-IV), with fear of blushing in social situations as the prominent fear, no (cognitive-) behavioural treatment for erythrophobia in the past 2 years, no use of medication for fear of blushing. Patients were recruited by means of advertisements, in which people who suffered from fear of blushing were offered treatment. 
Patients were first screened over the telephone, after which 40 individuals were invited for an intake session. They were interviewed by means of a structured clinical interview for DSM-III-R disorders (the SCID; Spitzer \& Williams, 1986). Furthermore, they were asked to fill out the subscale 'fear of blushing' of the Blushing, Trembling, and Sweating Questionnaire (BTS-Q; Bögels \& Reith, 1999) on which they had to score above a certain cut-off point: at least $1.5 S D$ s higher than the mean score obtained by students (Bögels, Alberts, \& De Jong, 1996), implying that men had to score at least 38.6 and women 51.2 (range $0-100$ ).

Nine of the 40 individuals undergoing the intake did not enter treatment: 4 appeared to be not rightly classified, 4 did not accept treatment because of practical reasons, and 1 did not show up anymore. All remaining 31 patients $(7 \mathrm{men})$ had a primary diagnosis of social phobia, with fear of blushing as the predominant complaint. At intake, mean 'fear of blushing' scores were 65.7 (SD 12.8) and 77.0 (SD 14.5) for women and men, respectively.

\section{Experimental design and procedure}

All patients were screened by the first author and SCID-interviews were conducted by a trained psychologist. After the intake session, the first assessment (pretest I) took place, after which half of the patients started the treatment, being randomly assigned to EXP or TCT. The other half started treatment after a 6-week waiting-list period, at the end of which a second assessment took place (pretest II). Then, these latter patients were also randomly assigned to one of the two treatments. Of the 31 patients who started treatment, 5 patients dropped out (16\%): 3 from TCT, 2 from EXP. Eventually, 12 patients finished the EXP treatment, and 14 finished the TCT treatment. Patients were assessed on behavioural tests, on questionnaires, and on diary recordings at pretest I, pretest II, and post-test. After a six-week follow-up period (FU I), and after 1 year (FU II), they completed the questionnaires again.

\section{Treatment}

\section{Therapists}

Five female students who had almost finished their studies in Mental Health Sciences at Maastricht University and had passed a clinical training functioned as therapists. They received an intensive three-day training in the treatment procedures, provided by the first and second author. All therapists attended weekly supervision sessions.

\section{General aspects}

Both treatments consisted of 6 weekly one-hour sessions. Both treatments followed an identical structure: in session 1 the rationale was explained, in session 2 general exercises were done, in session 3 a hierarchy of fearful situations was constructed, and in the following 3 sessions the items from the hierarchy were practised within and between sessions, by means of role plays and in vivo exercises. Both rationales emphasized that the aim of treatment was to become less afraid of blushing, and not to eliminate blushing. Patients were instructed to practise extensively between the sessions (at least 5 out of 7 
days), using homework diaries. Both treatments were kept pure; that is, no skills training or cognitive restructuring took place.

\section{Exposure in Vivo}

The EXP treatment was based on the latest insights into active exposure components, that is, refraining from subtle avoidance strategies (like averting the eyes or the body when blushing, wearing make-up) and dropping safety behaviours (Wells et al., 1995). It was explained that by prolonged, graded, and frequent exposure to feared situations, without applying (subtle) avoidance strategies, the fear of blushing would eventually diminish. Standardized unusual exposure exercises were done in session 2, built up hierarchically: from sitting silently for 2 minutes without having eye-contact (sitting back-to-back), to eventually sitting face-to-face, having eye-contact without saying anything for 2 minutes. Patients rated their anxiety (range $=0-100$ ) before and at the end, and their highest fear during the exercise. These exercises were repeated, until fear decreased substantially. Homework assignments between sessions 2 and 3-4 were to make diary registrations of situations in which patients had fear of blushing (i.e. kind of situation, whether they had encountered or avoided it, whether they blushed, how they felt and with which intensity, and what the consequence of avoidance had been), and to do unusual things that had nothing to do with fear of blushing, like wearing 2 different socks, or reading a 'wrong' magazine in the presence of other people. This was to demonstrate that behaving differently causes tension, but habituates. In the third session, an individual fearhierarchy was constructed, which was practised between and within sessions throughout the remaining treatment.

Task Concentration Training

In the rationale of TCT, the role of SFA in the maintenance of fear of blushing was emphasized. The effects of SFA were demonstrated by an exercise: patients were asked to tell the therapist a short story about their latest holidays, thereby focusing all attention on the self: on thoughts, feelings, the way they thought they came across to the therapist, etc. Then, the detrimental effects of SFA were discussed, and connected to their daily social difficulties (Bögels et al., 1997). The aim of the treatment would be to learn to direct more attention to the task at hand instead of focusing on the self, so that the vicious circle of SFA and fear of blushing would be broken and fear of blushing would decrease. In the second session, concentration exercises were done in order to demonstrate the beneficial effects of task-focused attention. These were listening exercises, built up hierarchically (see Bögels et al., 1997 for details). Homework assignments between sessions 2 and 3-4 were to make diary registrations of the direction of attention in blushing-fearful situations, and to do general, non-threatening concentration exercises. For example, walking through a quiet forest and focusing attention alternately on the different sensorial aspects of the environment, watching the news very concentratedly and summarizing it afterwards, etc. In the third session, an individual fear-hierarchy was constructed, which was practised between and within sessions throughout the remaining treatment. The aim was to practice directing attention to the task in these situations. 
Assessment

Questionnaires

The following questionnaires were completed:

The Social Phobia and Anxiety Inventory (SPAI; Turner, Beidel, Dancu, \& Stanley, 1989; Dutch translation: Scholing, Bögels, \& Velzen, 1995). The social phobia subscale, measuring aspects of generalized social phobia, was used for descriptive purposes. Patients rated each item on a 7-point scale, rescaled from 0 ('never') to 6 ('always') (range 0-192). The internal consistency is very high (.99; Bögels \& Reith, 1999).

The Blushing Propensity Scale (BPS; Leary \& Meadows, 1991; Dutch version: Bögels et al., 1996). The Dutch BPS consists of 19 circumscribed social situations for each of which the subject has to indicate how often she feels herself blushing. Answers range from 0 ("I never feel myself blushing in that situation") to 4 ("I always feel myself blushing in that situation"). The internal consistency of the Dutch BPS is high (.92; Bögels et al., 1996), as is its test-retest reliability (.93; Mulkens et al., 1997).

The Blushing, Trembling, and Sweating Questionnaire (BTS-Q; Bögels \& Reith, 1999). In this study, we only used the part concerning blushing. The subscale 'fear of blushing' measures, by VASs, to what degree patients are afraid to blush and experience blushing as a problem (range $=0-100$ ). The subscale 'bodily reactions while blushing' indicates to what extent certain bodily reactions are experienced during blushing (range $=0-4$ ). The subscale 'blushing consequences' indicates to what extent the patient, when blushing, is hindered by disturbances in mental processes, such as black-outs or problems in concentrating (range $=0-4$ ). The subscale 'blushing cognitions' consists of positive and negative cognitions about blushing and its social consequences, which are given a proportional score of $0 \%$ ("I do not believe it at all") to $100 \%$ ("I'm totally convinced") (range=0-100). The subscale 'avoidance of blushing' measures the extent to which strategies are used to avoid or hide blushing (range=0-4). The last subscale of the BTS-Q asks patients to estimate how often they blushed in the past week. The homogeneity of the BTS-Q is satisfactory for all subscales (ranging from .77 to .98). Furthermore, the BTS-Q has good discriminant validity; it is able to discriminate not only social phobics from controls, but also social phobics with fear of bodily symptoms like blushing from social phobics without such fears (Bögels \& Reith, 1999).

The Self-Focused Attention scale (SFA; Bögels et al., 1996). This is a newly developed scale to measure the focus of self-attention. It consists of 11 items: 6 items refer to self-attention focused on one's arousal (SFA-arousal) (range=0-24), and 5 items concern self-attention directed to one's interpersonal behaviour (SFA-performance) (range $=0-20)$. The internal consistency is high for both subscales (.86 and .78, respectively; Bögels et al., 1996).

Idiosyncratic dysfunctional beliefs

Four main idiosyncratic dysfunctional beliefs (Causal Catastrophic Misinterpretations: $\mathrm{CCMs}$ ) of each patient with regard to their blushing were assessed during the intake. An example of a CCM is: "When I blush, I look stupid". Before and after each treatment session, patients rated the beliefs on VASs (range 0-100). 
Diary measures

Patients were instructed to record their blushing, anxiety, and associated behaviour systematically on self-monitoring diaries in the week prior to the start of the treatment or waiting period and in the last week of the treatment or waiting period. Every day, patients answered questions concerning the extent to which they had had fear of blushing (range 0-4), the intensity of this fear (ranging from $0=$ 'not at all' to $100=$ 'very much'), the extent to which they had conducted (subtle) avoidance behaviour and safety strategies (range 0-4), and which strategies they used to become less anxious (0-4).

\section{Behavioural and physiological assessment}

The behavioural assessment consisted of a conversation with 2 stooges (interaction test), and a short speech before an audience of 4 people (performance test), taken in a fixed order, during which physiological responses were recorded. To measure changes in blood flow in the cheek, a photoplethysmograph probe was attached to the left cheek and a temperature probe to the right cheek of the subject. Skin conductance electrodes were placed on the medial phalanges of the middle finger and ring finger of Ss' non-dominant hand. Cheek colouration was recorded from a HP model 15230A plethysmograph transducer that was modified in such a way that it was dc coupled rather than ac coupled. The probe operates in the infrared spectrum. Cheek temperature was assessed by means of a temperature dependent resistor (PT100) that was dc coupled. Skin conductance level was recorded from two Beckman $\mathrm{Ag}-\mathrm{AgCl}$ electrodes (8 mm diameter), placed on the medial phalanges of the middle finger and ring finger of subject's non-dominant hand, using the method of constant voltage $(0.5 \mathrm{~V})$. The electrodes were filled with an isotonic paste and connected to a Beckman Skin Conductance Coupler (type 9844). All physiological signals were sampled with a frequency of $1000 \mathrm{~Hz}$ by a Compaq 486 (33 MHz) computer.

When all equipment had been attached, the research assistant left the room and asked the patient to sit and relax for a short while ( 2.5 minutes), during which a baseline recording was made. After that, the patient filled out a short self-report, consisting of two VASs ('How anxious were you in the past 2.5 minutes?' and 'How much did you blush during the past 2.5 minutes?').

Then, patients were informed that they were expected to have a conversation with 2 people (a man and a woman) during 5 minutes (cf. Öst, Jerremalm, \& Johansson, 1981) and that these 2 stooges would make notes to judge their interaction behaviour. After the conversation, patients filled out the self-report again. Physiological responses were recorded during another period of 2.5 minutes, in order to measure physiological recovery from the conversation.

After a 20-minute break (recovery period), patients did the second test. After a 2.5-minute baseline measurement and the completion of the 2 self-report VASs, the test was explained. The patient was told to give a 3-minute speech in front of an audience of 4 people, after 2 minutes'preparation time. The subject of the speech could be freely chosen. The audience would judge the patient's skills. After the test, the patient completed the self-report, whereas the physiology was recorded for 2.5 more minutes (recovery). 
Treatment credibility and integrity

Treatment credibility was firstly assessed after the rationale was explained. Patients filled out a 3-item questionnaire: (1) how logical does this form of treatment seem to be for you?; (2) how confident are you that this treatment will help you overcome your fear of blushing?; and (3) to what extent would you advise this treatment to a friend with similar problems? on a scale, from 1 ('not at all') to 9 ('extremely'). Treatment credibility was again assessed at post-test, at FU I, and FU II.

Treatment integrity was assessed by audiotaping all treatment sessions. The first author listened to 10-minute excerpts of tapes chosen at random and compared the content to the treatment manual. Feedback about the audiotaped sessions was given during supervision, in order to maximize the purity of the treatments. To determine whether the training had led to the predicted strategic behaviour, patients indicated in diaries (see diary measures) what strategies they used to become less anxious: relaxation, thinking less catastrophically, concentrating on the task at hand (i.e. TCT), or staying in the situation until the anxiety diminished (i.e. EXP).

\section{Data reduction}

In this study, two broad questions were addressed, each divided into more specific questions: (1) what is the effect of treatment vs waiting-list on (a) fear of blushing and cognitive change, and (b) actual blushing and self-reported blushing and anxiety during behavioural tests, and (2) are there differential treatment effects of TCT vs EXP on (a) fear of blushing and cognitive change, and (b) actual blushing and self-reported blushing and anxiety during behavioural tests? Both (a) questions will be addressed by using the self-report questionnaires and the CCMs, whereas physiological variables and selfreports of the behavioural tests will serve to address the (b) questions.

To minimalize the risk of Type I errors, dependent variables were divided into two groups: outcome and descriptive variables. Only the first set of variables was used to test the hypotheses. To measure changes in 'fear of blushing', we used 2 outcome variables: the BTS-Q subscale 'fear of blushing' and a newly composed measure, built up from the Blushing Propensity Scale (BPS) and the BTS-Q subscales 'bodily reactions while blushing', 'blushing consequences', and 'avoidance of blushing'. This composite variable is called 'blushing responsiveness and consequences'. To measure cognitive change, the BTS-Q subscale 'negative cognitions' and the CCMs were used. To this end, mean CCM scores at the start and at the end of waiting and treatment, respectively, were computed. The other variables (diaries ${ }^{9}$, SPAI, SFA-arousal, SFA-performance, BTS-Qblushing frequency, and BTS-Q-positive cognitions) were used for descriptive purposes
only.

With regard to the (b) questions (effects on actual blushing), we used the cheek colouration data from the behavioural tests. These data were analyzed as follows: every

\footnotetext{
'The descriptive diary data were reduced by calculating a composite measure, constructed of two correlated $(r=.50, p=.005)$ variables: 'Fear of blushing' (the item 'the extent of fear of blushing' multiplied by 'the intensity of this fear', resulting in a range of $0-400$ ) and 'avoidance' (built up out of diary items that all
measured aspects of avoidance (range 0-4)).
} 
30 seconds the level was selected, resulting in 10 values during the conversation, and 6 values during the presentation. Mean values were calculated for each period. We also collected cheek temperature and skin conductance data. However, the results obtained were highly similar and thus only the results for the cheek colouration data are presented, whereas the results of cheek temperature and skin conductance level are presented in a footnote.

To investigate changes in self-reported blushing and anxiety, self-report data during the behavioural tests were used. Because these data violated the assumption of normality, transformations were performed, using the following formula: nvar $=\ln ((\operatorname{var}+1) /(101-\mathrm{var}))$.

\section{Statistical analyses}

Of the 31 Ss who originally started treatment, 4 (in the 'treatment at once' condition) were eliminated from the final data analysis due to a failure to complete treatment. One subject (in the 'waiting-list' condition) completed most of the waiting-list measurements (that is, CCMs were available, and the data of the behavioural assessment) but dropped out during treatment. This case was included in the analyses of the 'waiting-list' versus 'treatment at once' effects. Two patients (both waiting-list controls) refused to do one or more behavioural tests because they felt too anxious to carry them out. At FU II, 21 patients returned their questionnaires: 9 in the EXP condition, and 12 in the TCT condition. Only patients who completed both post-test and FU II assessments, were included in the comparison analyses of pre-test versus 1-year follow-up, and post-test versus 1-year follow-up.

Waiting-list effects vs treatment effects and differential treatment effects were tested with Multivariate Analyses of Variance (MANOVAs) with one between groups factor (Group: waiting vs treatment, or Condition: EXP vs TCT), using difference scores between relevant time assessments.

To determine clinically significant change, the number of patients who improved significantly in both treatments were compared by means of a Chi-square. When norms of a functional population are available, Jacobson and Truax (1991) advise using the point that lies half-way between the mean of the functional and dysfunctional population. Cutoff scores of 45.7 and 43.5 were established for men and women, respectively (using the means of the present dysfunctional population, and a functional population from Bögels and Reith, 1999 (i.e. 14.5 for men, and 21.3 for women)). Effect sizes of changes in fear of blushing were computed as an indication of treatment effects (Cohen, 1988).

\section{Results}

\section{Dropouts versus completers}

Five patients dropped out during treatment, because of lack of confidence in the treatment, time constraints, improvement, fear, or a combination of these reasons. A striking demographic feature was the difference between dropouts and completers in the 
mean duration of their complaint, being only 4.6 (SD 3.1) years for dropouts, and 13.5 (SD 10.1) years for completers. Shorter duration might imply less distress and, therefore, sooner dropping out. Still, dropouts had higher initial 'fear of blushing' scores $(75.1 ; S D$ 15.6) than completers $(62.1 ; S D 16.3)$.

\section{Waiting-list versus treatment at once}

Results regarding outcome are summarized in Tables 1 and 2, descriptive results are shown in Table 3.

\section{(la) Effects on fear of blushing}

The MANOVA revealed a significant effect of treatment above waiting-list, $F$ hot $(2,23)=4.5, p<.05$. Univariate $\mathrm{F}$-tests showed that this effect was mainly due to the variable 'blushing responsiveness and consequences' $(F(1,24)=9.4, p=.005)$, and to a lesser extent to the variable BTS-Q 'fear of blushing' $(F(1,24)=3.7, p=.07)$. Thus, it can be concluded that a six-week treatment produces better results than waiting-list (see also Table 1).

(1a) Effects on negative cognitions.

The MANOVA yielded no significant effect of treatment above waiting-list, Fhot $(2,23)=1.7$. However, there was an overall significant decrease in negative cognitions, $F$ hot $(2,24)=11.5, p<.001$ (see also Table 1).

Table 1: Effects of waiting (WL) versus treatment (NWL) on outcome measures (mean and SD)

\begin{tabular}{lccc} 
Variable & Pretest I & $\begin{array}{c}\text { Pretest II/ } \\
\text { Post-test }\end{array}$ \\
\hline BTS-Q-Fear of blushing & WL $(n=14)$ & $63.11(19.18)$ & $56.44(20.18)$ \\
& NWL $(n=12)$ & $60.74(12.78)$ & $42.64(20.28)$ \\
Blushing responsiveness and consequences & & \\
WL $(n=14)$ & $2.24(.41)$ & $2.22(.40)$ \\
NWL $(n=12)$ & $1.96(.42)$ & $1.56(.55)$ \\
BTS-Q-Negative cognitions & & $50.87(09.98)$ \\
& WL $(n=14)$ & $58.00(09.81)$ & $35.21(21.69)$ \\
NWL $(n=12)$ & $48.63(20.47)$ & \\
CCMs & & & $73.07(12.86)$ \\
& WL $(n=15)$ & $83.55(9.75)$ & $49.25(25.07)$ \\
\hline
\end{tabular}

(1b) Effects on actual blushing

Plethysmograph values at different occasions are summarized in Table 2. The MANOVA revealed no significant difference between treatment and waiting, Fhot $(2,20)=.23 .^{10}$

\footnotetext{
${ }^{10}$ The MANOVAs with regard to cheek temperature and skin conductance level revealed no significant main effect of Group $(F(2,20)=77$, and $F(2,19)=1,87, p=18$, respectively). The values at different occasions are summarized in Table 2.
} 
Furthermore, there was no significant overall decrease in actual blushing, Fhot $(2,21)=1.8, p>1$.

(1b) Effects on self-reported blushing and anxiety

In Table 2, values of self-reported blushing and anxiety on different occasions are presented. The MANOVA with regard to self-reported blushing did not reveal a difference between treated patients and waiting-list patients, $F$ hot $(2,23)=15$, nor did the second behavioural test $(F \operatorname{hot}(2,25)=11.1, p<.001$, and $F$ hot $(2,25)=15.9, p<.001$, respectively).

Table 2: Effects of waiting (WL) versus treatment (NWL) on three physiological measures, self-reports of blushing, and self-reports of anxiety during conversation, and presentation (mean and SD)

\begin{tabular}{|c|c|c|c|}
\hline \multirow[b]{2}{*}{ Variables } & & \multicolumn{2}{|c|}{ Conversation } \\
\hline & & Pretest I & Pretest II / Post-test \\
\hline Cheek colouration (V) & $\begin{array}{l}\text { WL }(n=14) \\
\text { NWL }(n=9)\end{array}$ & $\begin{array}{l}4.25(2.29) \\
3.06(1.75)\end{array}$ & $\begin{array}{l}3.32(1.98) \\
1.22(2.80)\end{array}$ \\
\hline Cheek temperature $\left({ }^{\circ} \mathrm{C}\right)$ & $\begin{array}{l}\text { WL }(n=14) \\
\text { NWL }(n=9)\end{array}$ & $\begin{array}{l}3.23(.20) \\
3.14(.15)\end{array}$ & $\begin{array}{l}3.20(.14) \\
3.18(.19)\end{array}$ \\
\hline $\mathrm{SCL}^{*}(\mu \mathrm{mho})$ & $\begin{array}{l}\text { WL }(n=12) \\
\text { NWL }(n=10)\end{array}$ & $\begin{array}{l}1.88(.26) \\
1.58(.47)\end{array}$ & $\begin{array}{l}1.64(.67) \\
1.72(.66)\end{array}$ \\
\hline $\begin{array}{l}\text { Self-reported blushing } \\
\text { (transformed)\# }\end{array}$ & $\begin{array}{l}\text { WL }(n=14) \\
\text { NWL }(n=12)\end{array}$ & $\begin{array}{c}.42(1.19) \\
-1.05(1.93)\end{array}$ & $\begin{array}{l}-.64(1.58) \\
-2.23(1.62)\end{array}$ \\
\hline $\begin{array}{l}\text { Self-reported anxiety } \\
\text { (transformed)\# }\end{array}$ & $\begin{array}{l}\text { WL }(n=14) \\
\text { NWL }(n=12)\end{array}$ & $\begin{array}{l}.45(1.67) \\
-.33(1.32)\end{array}$ & $\begin{array}{l}-.57(1.94) \\
-1.48(1.61)\end{array}$ \\
\hline & & \multicolumn{2}{|c|}{ Presentation } \\
\hline Cheek colouration (V) & $\begin{array}{l}\text { WL }(n=14) \\
\text { NWL }(n=9)\end{array}$ & $\begin{array}{l}3.10(2.46) \\
2.87(2.26)\end{array}$ & $\begin{array}{l}2.70(1.70) \\
2.00(1.68)\end{array}$ \\
\hline Cheek temperature $\left({ }^{\circ} \mathrm{C}\right)$ & $\begin{array}{l}\text { WL }(n=14) \\
\text { NWL }(n=9)\end{array}$ & $\begin{array}{l}3.24(.18) \\
3.21(.19)\end{array}$ & $\begin{array}{l}3.24(.17) \\
3.21(.19)\end{array}$ \\
\hline $\mathrm{SCL}^{*}(\mu \mathrm{mho})$ & $\begin{array}{l}\text { WL }(n=12) \\
\text { NWL }(n=10)\end{array}$ & $\begin{array}{l}1.77(.29) \\
1.54(.32)\end{array}$ & $\begin{array}{l}1.60(.73) \\
1.56(.61)\end{array}$ \\
\hline $\begin{array}{l}\text { Self-reported blushing } \\
\text { (transformed)\# }\end{array}$ & $\begin{array}{l}\text { WL }(n=14) \\
\text { NWL }(n=12)\end{array}$ & $\begin{array}{l}-.47(1.62) \\
-.59(2.12)\end{array}$ & $\begin{array}{l}-.92(1.57) \\
-1.37(1.94)\end{array}$ \\
\hline $\begin{array}{l}\text { Self-reported anxiety } \\
\text { (transformed)\# }\end{array}$ & $\begin{array}{l}\text { WL }(n=14) \\
\text { NWL }(n=12)\end{array}$ & $\begin{array}{l}.68(1.31) \\
.36(.84)\end{array}$ & $\begin{array}{l}-.27(1.66) \\
-.48(1.20)\end{array}$ \\
\hline
\end{tabular}


For informatory purposes solely, results with respect to the descriptive measures are summarized in Table 3.

Table 3: Effects of waiting (WL) versus treatment (NWL) on descriptive measures (mean and SD).

\begin{tabular}{|c|c|c|}
\hline Variable & Pretest I & $\begin{array}{c}\text { Pretest II / } \\
\text { Post-test }\end{array}$ \\
\hline \multicolumn{3}{|l|}{ SPAI-Social phobia } \\
\hline WL $(n=14)$ & $97.39(21.24)$ & $88.78(30.12)$ \\
\hline NWL $(n=12)$ & $80.25(19.55)$ & $71.33(28.68)$ \\
\hline \multicolumn{3}{|l|}{ SFA-Arousal } \\
\hline WL $(n=14)$ & $9.5(4.01)$ & $8.57(4.38)$ \\
\hline NWL $(n=12)$ & $7.75(6.47)$ & $6.33(6.32)$ \\
\hline \multicolumn{3}{|l|}{ SFA-Performance } \\
\hline WL $(n=14)$ & $10.07(3.63)$ & $9.71(3.81)$ \\
\hline NWL $(n=12)$ & $8.83(5.22)$ & $7.08(5.25)$ \\
\hline \multicolumn{3}{|c|}{ Diary-Composite fear and avoidance* } \\
\hline WL $(n=14)$ & $.81(.36)$ & $.64(.40)$ \\
\hline NWL $(n=11)$ & $.67(.36)$ & $.48(.24)$ \\
\hline \multicolumn{3}{|l|}{ BTS-Q-Positive cognitions } \\
\hline WL $(n=14)$ & $34.25(19.76)$ & $32.54(17.23)$ \\
\hline NWL $(n=12)$ & $28.04(16.85)$ & $40.04(15.87)$ \\
\hline \multicolumn{3}{|c|}{ BTS-Q-Blushing frequency past week } \\
\hline$W L(n=14)$ & $12.93(5.33)$ & $10.15(7.78)$ \\
\hline NWL $(n=11)$ & $13.25(15.95)$ & $5.17(5.34)$ \\
\hline
\end{tabular}

* Means and SDs per day, calculated over the past week

\section{Differential treatment effects}

Results on outcome and descriptive variables are summarized in Tables 4, 5, and 6.

\section{Credibility of treatment rationale and treatment integrity}

There was no difference between the two treatments concerning credibility of the treatment rationale on any given moment: pre-test $(t(24)=-0.5$ (means being $6.43(S D$ 1.29) for EXP and $6.64(S D .95)$ for TCT), post-test $(t(24)=-0.3$ (means $6.42(S D 1.38)$ and $6.64(S D 1.95)$ for EXP and TCT, respectively), FU I $(t(24)=0.4$ (means $6.64(S D$ $1.43)$ and 6.38 (SD 1.90) for EXP and TCT, respectively), and FU II $(t(19)=0.5$ (means $6.30(S D 1.58$ ) and 6.25 (SD 2.26) for EXP and TCT, respectively).

Inspection of the patients' diaries revealed that EXP patients indicated that they did not practice any of the strategies more frequently after treatment. Patients in the TCT 
group, however, practised 'concentrating on the task at hand' significantly more often after treatment, $t(13)=4.2, p<.001$ (means being 1.3 and 2.4 before and after treatment, respectively), whereas there were no differences with respect to the other strategies.

\section{(2a) Effects on fear of blushing}

There was a borderline significant treatment effect of TCT above EXP at post-test (Fhot $(2,23)=3.2, p=.06)$. At FU I, this effect had disappeared $(F$ hot $(2,23)=.2)$. When pretest was compared to FU II, no differential effects were present, either $(F$ hot $(2,18)=.2)$. A comparison of post-test with $\mathrm{FU}$ II indicates that treated patients in both conditions improved further $(F$ hot $(2,19)=6.8, p<.01)$ (see also Table 4$)$.

(2a) Effects on cognitions.

A MANOVA yielded no significant difference with regard to cognitive change between the two treatments at post-test, $F$ hot $(2,23)=1.9, p>1$. However, at FU I, there was a significant difference in favour of TCT, Fhot $(2,23)=4.2, p<.05$. This effect was mainly due to the variable 'BTS-Q negative cognitions' $(F(1,24)=5.0, p<.05)$, compared to the variable 'CCMs' $(F(1,24)=.07, n s)$. At $F U$ II, this differential effect was gone ( $F$ hot $(2,18)=1.8, p>1$. $)$. A comparison between post-test and FU II yielded a tendency for an overall further improvement $(F$ hot $(2,19)=3.2, p=.06$ ) (see also Table 4).

Table 4: Effects of EXP versus TCT on outcome measures (mean and SD) on four test occasions

\begin{tabular}{lccccc}
\hline Variable & & pre-test & post-test & FU I & FU II \\
\hline BTS-Q-Fear of blushing & & & & \\
EXP $(n=12)$ & $51.26(16.49)$ & $42.82(20.72)$ & $30.60(18.73)$ & $28.17(19.49)$ \\
TCT $(n=14)$ & $64.56(15.37)$ & $45.79(21.20)$ & $40.18(20.50)$ & $34.17(24.48)$ \\
Blushing responsiveness and & & & & \\
consequences & & & & \\
& EXP $(n=12)$ & $2.16(.39)$ & $1.74(.57)$ & $1.71(.63)$ & $1.73(.26)$ \\
& TCT $(n=14)$ & $2.05(.46)$ & $1.74(.64)$ & $1.60(.55)$ & $1.51(.65)$ \\
BTS-Q-Negative cognitions & & & & \\
& EXP $(n=12)$ & $43.25(15.32)$ & $33.69(18.23)$ & $33.67(18.78)$ & $31.41(16.94)$ \\
& TCT $(n=14)$ & $55.48(13.54)$ & $36.95(20.35)$ & $32.30(19.19)$ & $26.67(17.78)$ \\
CCMs & & & & \\
& EXP $(n=12)$ & $73.77(8.99)$ & $48.46(20.39)$ & $38.83(25.79)$ & $48.00(28.56)$ \\
& TCT $(n=14)$ & $73.61(16.11)$ & $49.09(28.05)$ & $39.21(24.82)$ & $36.15(24.99)$ \\
\hline
\end{tabular}

${ }^{2} \mathrm{~N}=9(\mathrm{EXP}) / \mathrm{N}=12(\mathrm{TCT})$ at $\mathrm{FU} \mathrm{II}$ 
(2b) Effects on actual blushing

Plethysmograph values at different occasions are summarized in Table 5. The MANOVA revealed no difference between TCT and EXP, Fhot $(2,17)=.6 .^{11}$

(2b) Effects on self-reported blushing and anxiety

In Table 5, self-reported blushing and anxiety on different occasions are presented. The MANOVA revealed no significant difference between TCT and EXP on self-reported blushing $(F$ hot $(2,21)=1.8)$, nor on anxiety $(F$ hot $(2,21)=2.1, p>.1)$.

Table 5: Effects of EXP versus TCT on three physiological measures, self-reports of blushing, and selfreports of anxiety during conversation, and presentation (mean and SD)

\begin{tabular}{|c|c|c|c|}
\hline \multirow[b]{2}{*}{ Variables } & & \multicolumn{2}{|c|}{ Conversation } \\
\hline & & pre-test & post-test \\
\hline Cheek colouration (V) & $\begin{array}{l}\operatorname{EXP}(n=8) \\
\operatorname{TCT}(n=11)\end{array}$ & $\begin{array}{l}2.70(1.45) \\
2.74(1.56)\end{array}$ & $\begin{array}{l}1.32(3.46) \\
2.52(1.40)\end{array}$ \\
\hline Cheek temperature $\left({ }^{\circ} \mathrm{C}\right)$ & $\begin{array}{l}\operatorname{EXP}(n=9) \\
\operatorname{TCT}(n=11)\end{array}$ & $\begin{array}{l}3.17(.13) \\
3.15(.16)\end{array}$ & $\begin{array}{l}3.15(.15) \\
3.17(.18)\end{array}$ \\
\hline $\mathrm{SCL}^{*}(\mu \mathrm{mho})$ & $\begin{array}{l}\operatorname{EXP}(n=10) \\
\operatorname{TCT}(n=10)\end{array}$ & $\begin{array}{l}1.60(.40) \\
1.53(.72)\end{array}$ & $\begin{array}{l}1.61(.62) \\
1.39(.66)\end{array}$ \\
\hline $\begin{array}{l}\text { Self-reported blushing } \\
\text { (transformed)\# }\end{array}$ & $\begin{array}{l}\operatorname{EXP}(n=12) \\
\operatorname{TCT}(n=12)\end{array}$ & $\begin{array}{l}-.61(1.46) \\
-1.08(2.01)\end{array}$ & $\begin{array}{l}-1.28(1.61) \\
-2.07(1.65)\end{array}$ \\
\hline \multirow[t]{2}{*}{$\begin{array}{l}\text { Self-reported anxiety } \\
\text { (transformed)\# }\end{array}$} & $\begin{array}{l}\operatorname{EXP}(n=12) \\
\operatorname{TCT}(n=12)\end{array}$ & $\begin{array}{l}-.68(1.86) \\
-.44(1.59)\end{array}$ & $\begin{array}{l}-.85(1.74) \\
-1.97(1.63)\end{array}$ \\
\hline & & \multicolumn{2}{|c|}{ Presentation } \\
\hline Cheek colouration (V) & $\begin{array}{l}\operatorname{EXP}(n=8) \\
\operatorname{TCT}(n=11)\end{array}$ & $\begin{array}{l}2.87(2.26) \\
2.34(1.80)\end{array}$ & $\begin{array}{l}1.98(.63) \\
2.10(1.56)\end{array}$ \\
\hline Cheek temperature $\left({ }^{\circ} \mathrm{C}\right)$ & $\begin{array}{l}\operatorname{EXP}(n=9) \\
\operatorname{TCT}(n=11)\end{array}$ & $\begin{array}{l}3.19(.13) \\
3.22(.20)\end{array}$ & $\begin{array}{l}3.18(.14) \\
3.21(.18)\end{array}$ \\
\hline $\mathrm{SCL}^{*}(\mu \mathrm{mho})$ & $\begin{array}{l}\operatorname{EXP}(n=10) \\
\operatorname{TCT}(n=10)\end{array}$ & $\begin{array}{l}1.50(.51) \\
1.52(.57)\end{array}$ & $\begin{array}{l}1.35(.68) \\
1.32(.62)\end{array}$ \\
\hline $\begin{array}{l}\text { Self-reported blushing } \\
\text { (transformed)\# }\end{array}$ & $\begin{array}{l}\operatorname{EXP}(n=12) \\
\operatorname{TCT}(n=12)\end{array}$ & $\begin{array}{l}-.96(1.50) \\
-.69(1.88)\end{array}$ & $\begin{array}{l}-.93(1.33) \\
-1.60(2.04)\end{array}$ \\
\hline $\begin{array}{l}\text { Self-reported anxiety } \\
\text { (transformed)\# }\end{array}$ & $\begin{array}{l}\operatorname{EXP}(n=12) \\
\operatorname{TCT}(n=12)\end{array}$ & $\begin{array}{l}-.28(1.64) \\
.20(1.14)\end{array}$ & $\begin{array}{l}-.55(1.70) \\
-.36(1.26)\end{array}$ \\
\hline
\end{tabular}

"The MANOVAs with regard to cheek temperature and skin conductance level revealed no significan main effect of Group $(F$ hot $(2,18)=17$, and $F$ hot $(2,17)=.24$, respectively). The values at different occasions are summarized in Table 5 . 
For descriptive and informative purposes only, we also included the data from the other questionnaires that were filled out by patients (see Table 6). Interestingly, the BTS-Q self-reported blushing frequency decreases substantially in both groups over time.

Table 6: Descriptive statistics on descriptive variables of questionnaires (mean and SD) of patients who completed treatment in the EXP vs TCT condition

\begin{tabular}{|c|c|c|c|c|}
\hline Variable & pre-test & post-test & FU I & $\mathrm{FU} \Pi^{2}$ \\
\hline \multicolumn{5}{|l|}{ SPAI-Social phobia } \\
\hline $\operatorname{EXP}(n=12)$ & $76.49(25.30)$ & $70.27(28.15)$ & $65.36(27.72)$ & $66.36(23.45)$ \\
\hline TCT $(n=14)$ & $92.00(24.61)$ & $83.10(30.61)$ & $75.25(27.08)$ & $70.76(30.33)$ \\
\hline \multicolumn{5}{|l|}{ SFA-Arousal } \\
\hline $\operatorname{EXP}(n=12)$ & $7.58(5.99)$ & $4.58(4.68)$ & $6.42(5.09)$ & $3.56(3.40)$ \\
\hline $\operatorname{TCT}(n=14)$ & $8.71(4.89)$ & $8.21(6.64)$ & $7.07(5.92)$ & $3.75(3.08)$ \\
\hline \multicolumn{5}{|l|}{ SFA-Performance } \\
\hline $\operatorname{EXP}(n=12)$ & $8.92(4.60)$ & $6.75(5.10)$ & $7.50(4.95)$ & $8.56(6.04)$ \\
\hline TCT $(n=14)$ & $9.64(4.45)$ & $8.71(5.47)$ & $9.21(4.49)$ & $6.75(5.05)$ \\
\hline \multicolumn{5}{|l|}{$\begin{array}{l}\text { Diary-Composite fear and } \\
\text { avoidance* }\end{array}$} \\
\hline $\operatorname{EXP}(n=11)$ & $.53(.38)$ & $.36(.26)$ & No follow-up & No follow-up \\
\hline TCT $(n=14)$ & $.75(.35)$ & $.44(.27)$ & & \\
\hline \multicolumn{5}{|l|}{ BTS-Q-Positive cognitions } \\
\hline $\operatorname{EXP}(n=12)$ & $34.25(14.55)$ & $34.42(14.03)$ & $35.58(20.41)$ & $44.83(21.72)$ \\
\hline TCT $(n=14)$ & $27.21(18.54)$ & $44.29(17.92)$ & $47.86(20.87)$ & $57.08(26.12)$ \\
\hline \multicolumn{5}{|l|}{$\begin{array}{l}\text { BTS-Q-Blushing frequency } \\
\text { past week }\end{array}$} \\
\hline $\operatorname{EXP}(n=12)$ & $11.33(15.59)$ & $5.17(5.11)$ & $2.42(2.39)$ & $3.33(4.50)$ \\
\hline TCT $(n=14)$ & $11.92(8.69)$ & $4.00(2.99)$ & $4.29(7.57)$ & $3.92(5.12)$ \\
\hline
\end{tabular}

*Means and $S D$ s per day, calculated over the past week

* $\mathrm{N}=9(\mathrm{EXP}) / \mathrm{N}=12$ (TCT) at FU II.

Clinically significant change and effect sizes

Percentages of patients who demonstrated clinically significant change on the BTS-Q 'fear of blushing' in both treatments are depicted in Table 7. No differences were found between the two treatments on post-test $\left(\chi^{2}(1)=1\right)$, FU I $\left(\chi^{2}(1)=1.7, p>.1\right)$, and FU II, $\left(\chi^{2}(1)=2.4, p>\right.$.1). Effect sizes, however, were large at all occasions only for TCT. 
Table 7: Percentage of patients showing clinically significant change and effect sizes of both treatment conditions at post-test, FUI, and FU II

\begin{tabular}{ccccccccc}
\hline & \multicolumn{3}{c}{ Perc. clin. sign. change } & & \multicolumn{3}{c}{ Effect size } \\
\cline { 2 - 3 } & post-test & FU I & FU II & & post-test & FU I & FU II \\
\hline Fear of blushing & & & & & & & \\
TCT & $43 \%$ & $50 \%$ & $58 \%$ & & 1.14 & 1.4 & 1.48 \\
EXP & $42 \%$ & $75 \%$ & $89 \%$ & & 0.51 & 1.19 & 1.2 \\
\hline
\end{tabular}

\section{Discussion}

The main purposes of the present study were to examine the relative efficacy of behavioural treatment for fear of blushing above waiting-list, and to examine potential differential treatment effects of EXP and TCT, on fear of blushing, cognitive change, actual blushing and self-reported blushing and anxiety. The major results can be summarized as follows: (1) There was a significant effect of treatment above waiting with respect to fear of blushing, whereas patients in the waiting-list and treatment condition made equal cognitive improvement. (2) TCT tended to produce better results with respect to fear of blushing than EXP at post-test, and at 6-weeks follow-up, TCT produced significantly better cognitive change than EXP. (3) At 1-year follow-up, treatment effects continued, whereas differential effects had disappeared. (4) The reduction in fear of blushing was not parallelled by a reduction in actual blushing during the behavioural assessments.

\section{Treatment success}

Compared to waiting, treatment was significantly more successful in reducing the blushing phobics' complaints. Thus, despite the short duration of the treatment, apparent improvements with regard to fear of blushing could be demonstrated. Besides, note that our patients' severity of complaints measured up with that of clinical Ss (see Bögels \& Reith, 1999). Patients with complaints of this severity usually receive longer treatment than the six sessions, provided in the present study. Note also that the patients who were assigned to the waiting-list group seemed to improve somewhat as well, which may have reduced the sensitivity to detect treatment effects in the present study. This improvement in the waiting-list group may well be due to waiting-list patients' optimism with regard to the forthcoming training. Also, the detailed intake, the keeping of a diary, the completion of questionnaires, and the behavioural tests, may have served as exposure assignments and as an attention placebo on the one hand, and have caused patients to put into perspective the severity of their complaints, on the other. Taken together, we feel that the significant improvements are promising. 
TCT versus EXP

At post-test, TCT tended to produce more favourable results with regard to fear of blushing. The larger effect sizes of TCT in contrast to EXP support this finding. However, at FU I, differential effects at this variable have disappeared. This indicates that TCT might act somewhat faster in dispelling fear of blushing in the short-term, but that these initial differences converge in the end. In contrast, the percentage of clinically significant change is somewhat smaller for TCT than for EXP. Yet, since patients in the EXP condition started treatment with smaller pre-test scores, it was easier for them to reach the point that was set for clinically significant change.

At FU I, cognitive change appeared to be significantly greater for TCT. Note also the descriptive results, suggesting that the credibility of BTS-Q positive cognitions had increased, especially for TCT. This implies that TCT is somewhat better in stimulating cognitive change than EXP. By giving patients the opportunity to experience disconfirming information, through becoming aware of their objective environment, TCT seems to promote cognitive change. Also, TCT inhibits patients to rely on their internal sensations rather than on external information to evaluate how they come across (Clark $\&$ Wells, 1995). The finding that cognitive change during TCT takes place, independent of specific cognitive restructuring, has an important practical implication; that is, TCT is a treatment technique that can be acquired by therapists relatively easily, compared to cognitive therapy (Bögels et al., 1997), which might lead TCT to become the treatment of choice.

The absence of firm differential effects with respect to fear of blushing might be due to the fact that both treatment methods bear resemblances to each other. That is, both treatments imply the use of a hierarchy to practice difficult situations, and prescribe insession and between session exercises in which exposure to feared situations takes place. Because the EXP was maximalized regarding the dropping of safety behaviours (Wells et al., 1995), and TCT was set up to focus attention outward, it might be that patients in both groups were able to pick up disconfirming information with regard to their dysfunctional schemas about blushing. Furthermore, inspection of the descriptive data on SFA, directed at arousal, seems to indicate that this type of attention decreases in both treatments. Nevertheless, TCT's tendency to produce better results regarding fear of blushing is, given the small patient numbers in this study, worth mentioning. Yet, studies with greater patient numbers are needed to draw more firm conclusions concerning the relative efficacy of TCT.

\section{Changes in actual blushing}

Treatment did not affect actual blushing during the behavioural tests, neither as measured physiologically nor as indexed by self-reports. Several explanations could account for this result. Firstly, the absence of differences between treated and non-treated individuals with respect to actual blushing leads us to question the physiological response pattern of normal control Ss. It would be interesting to establish whether the physiological responses of non-fearful controls differ from the physiological responses of patients with fear of blushing. If not, there would be not much room for improvement with respect to 
the patients' blush responses, after all. Secondly, the two behavioural tests might have been too distinct from situations in patients' daily life, making changes in actual blushing as a result of treatment hard to detect. Thirdly, the absence of differences in actual blushing between treated patients and waiting-list controls might be due to the relatively short length of the treatments.

No differential treatment effects in actual blushing could be detected at post-test. However, since no treatment effects were demonstrated with respect to actual blushing, at all, it is questionable whether differential effects for type of treatment could be investigated. Yet, it seems that fear of blushing could be satisfactorily reduced, independent of a reduction in actual blushing. Moreover, the significant overall decrease of self-reported blushing at the second behavioural test (for waiting-list and treatment at once), and the substantial decrease in the BTS-Q 'blushing frequency' subscale in both treated groups at post-test, further supports the notion that actual blushing and subjective blushing are not necessarily parallelled. Thus fear of blushing seems to reflect a fearful preoccupation, irrespective of actual facial colouration.

In sum, TCT seems to be an equivalent and potentially more ameliorative alternative to EXP as a treatment for fear of blushing. The present study shows some evidence suggesting that TCT has more favourable effects. It remains to be investigated whether TCT is an effective treatment for social phobics with other somatic fears (like trembling and sweating), and for social phobics with non-somatic fears. 


\section{General discussion}

The objective of this thesis was to investigate several issues concerning fear of blushing. After offering a general introduction about blushing and fear and blushing, potential etiological and maintaining factors of fear of blushing were examined empirically, while starting from a heuristic model. Furthermore, a treatment method, based on this model, was judged on its merits.

We formulated six research questions. The first two questions concerned the biological aspects of blushing. That is, blushing propensity as a potential vulnerability factor in the development of fear of blushing. Therefore, we compared 'so-called' blushers and non-blushers on the basis of an objectively measured, physiological response. The third question concerned the part of the model that considered learning history as a potential etiological factor for fear of blushing. The fourth question regarded beliefs and cognitions about blushing in nonphobic individuals, in order to put negative beliefs of blushing phobics into perspective. The fifth and sixth question concerned the treatment of fear of blushing; A newly developed treatment method, that was designed to reduce self-focused attention in blushing phobics, was tested for its effectiveness.

In Sections 4.1 through 4.6, the respective conclusions for each separate study were presented in detail, already. In the present chapter, the main findings will be discussed by theme, referring to the initial research questions, and considering the implications towards the model. Meanwhile, attempts are made to integrate the results. Finally, some directions for future research will be formulated.

\subsection{No evidence for differences in objective blushing}

The first two experiments showed that people who consider themselves high or low in blushing propensity, or who are high or low in fear of blushing, do not differ significantly on physiological measures of blushing. That is, changes in facial blood pooling, as measured photoplethysmographically, as well as changes in facial temperature, were very similar for both low and high groups. Besides, in the first experiment, independent raters judged both groups as equal with respect to blushing behaviour. Conversely, self-reports with respect to blushing intensity were significantly different between high and low scoring groups, as were the self-reports with respect to fear of blushing during the experiments.

These results give rise to some critical reflections. Firstly, the findings cast doubt on people's ability to reliably assess their blush intensity. Apparently, (high fearful) individuals base judgements of their own blush intensity on other cues than either cheek temperature or cheek colouration, as measured in the present experiments. In addition, 
these findings question the validity of assessment instruments like the Blushing Propensity Scale (BPS; Leary \& Meadows, 1991; Dutch translation: Bögels, Alberts, \& De Jong, 1996). As the self-reported fear of blushing during the experiment was also higher for the high BPS participants, it appears that the BPS represents a fearfulness towards blushing rather than blushing propensity per se. All in all, no evidence emerged to indicate that blushing propensity is an important factor for developing fear of blushing.

The differential self-reports in the absence of a differential physiological blush response may indicate that (1) high fearful/ BPS participants overestimate their blush response, (2) low fearful/ BPS participants underestimate their blush intensity, or (3) both. Raters' judgements might provide valuable additional information to settle this matter. However, although we had raters judge the blush intensity in Experiment 1, the relatively low inter rater reliability and the validity of these data should be considered. That is, raters' agreement was marginal in both the first $(r=.43)$ and the second study $(.43$ and .56 for the two social stressors, respectively). With respect to the validity, raters might have been biased by signs of embarrassment other than blushing and/or "blushaccompanying' behaviour (like casting down the eyes, acting nervously). To further investigate which of the above three possibilities is the most appropriate explanation, raters might be instructed more accurately and strictly on how to assess blushing. They should be trained to obtain maximum inter rater agreement. Perhaps the rating should take place at more instants during the observation instead of only one rating as an overall impression.

Taken together, it seems that a vulnerability to blush relatively easily does not contribute substantially to fear of blushing (cf. the proposed model in Chapter 2). It should be noted, however, that we do not intend to suggest that individual differences in blushing propensity do not exist. Yet, on the basis of the results from our two experiments it seems justified to conclude that people's blush ratings are not particularly reliable. Thus people who, objectively, blush more readily than other people, may well be other people than those who think that they blush relatively easily. Relatedly, although no differences in the physiological blush threshold/ blush responsiveness could be detected between individuals who are high and low in BPS/ fear of blushing given a particular social stressor, it can not be ruled out, on the basis of the present studies, that the high scoring groups more often pass this threshold: That is, there might be more other situations in which high scoring individuals blush and low scoring individuals do not blush, due to their interpretation of the situation/ behaviour/ environment (perhaps, they interpret an (ambiguous) situation more often as embarrassing/ shameful). Thus, despite similar physiological make-up, one group might blush objectively more often than the other. However, whenever this is the case, this is merely based on psychological differences (other rules/ values/ cognitions: fearful preoccupation), rather than on physiological differences.

What, then, leads people to think that they are blushing? We expected that it would be warmth. That is, cheek temperature might serve as an interoceptive signal for blushing. However, as for facial colouration, cheek temperature did neither discriminate 
between individuals high and low in blushing propensity, nor between individuals high and low in fear of blushing. In fact, cheek colouration and cheek temperature showed the same pattern of results, although the temperature responses were much slower. The latter characteristic can be explained by the fact that the skin is a bad heat conductor (Guyton \& Hall, 1996). In line with previous research, there was no straightforward association between participants' skin colouration and their skin temperature (cf. Shearn, Bergman, Hill, Abel, \& Hinds, 1990; Shearn, Bergman, Hill, Abel, \& Hinds, 1992). One explanation might be that people strongly vary with respect to the heat conduction of their skin as a result of differences in skin composition. Most important for the current context, high and low scoring individuals reacted similarly at the physiological level, but not at a subjective level. This leads us to believe that the first group has a lower detection threshold for feeling a blush, or they might be fearfully preoccupied with blushing. These two possibilities are not mutually exclusive: a fearful preoccupation might facilitate the detection of physiological responses (cf. Kroeze, van den Hout, Haenen, \& Schmidt, 1996). A fearful preoccupation might lead blushing phobics to selectively attend to interoceptive signals or other cues/ social situations that might predict a blush response, and/or may lead to an overrepresentation of 'blush events' in memory. Consequently, by paying more attention to potential blush events and bodily cues connected with blushing, blushing phobics' fear will not extinguish. Alternatively, low fearful individuals might have a higher threshold for detecting a blush, or they might even deny it.

Some critical notes are in order with respect to these two experiments. In our experiments, we choose to use the photoplethysmograph as a 'golden standard' to measure actual blushing, and not, for example, raters' observations. Yet, in earlier studies, the plethysmograph has proven to be a reliable and valid method to measure the actual blush response (e.g. Shearn et al., 1990, 1992). That is, cheek colouration responses were significantly greater during stimulation intended to produce blushing than during comparison stimulation, and only video displays of the individual's face that coincided with maximal cheek colouration during stimulation intended to produce blushing were judged reliably as blushing. Furthermore, our plethysmographic device was able to establish 'blood pooling', which is, objectively spoken, the blush response. Some variation with external redness may be possible, though, due to people's differential skin properties (e.g. thickness, level of pigmentation, colour). The latter might cause the actual blush response to differ somewhat from the observable redness as observed by raters. Still, raters' observations may be biased by the presence of alternative 'blush-accompanying behaviours' (see above). Taking these obstacles into account, objective indices of blushing seem to be preferred, as yet.

Taken together, the results of the first two experiments show that self-reports about blushing deviate from physiological indices of blushing, and point into the direction that high blushing-fearful individuals have a fearful preoccupation towards (the visibility of) blushing. It is worth noting that our results concord with the earlier findings of McEwan and Devins (1983). They compared three groups on measures of observableness and behavioural signs of anxiety, as rated by the individuals themselves as by peers. One group consisted of high socially anxious individuals who scored high 
on self-reported intensity of somatic symptoms (e.g. palpitations, trembling). The second group consisted of low socially anxious individuals who scored low on self-reported intensity of somatic symptoms, and the third group were high socially anxious individuals with low somatic scores. It appeared that only the first group's self-rated anxiety was significantly greater than peer-rated anxiety, and that these individuals also reported that they displayed significantly more behavioural signs of anxiety than were noticed by their peers. The authors conclude that the social anxious individuals' concerns - that symptoms of anxiety are salient to others - may derive from the subjective experience of elevated somatic concomitants of anxiety. Our results are also in line with Drummond's (1997) finding that vascular responses were similar in groups of low and high frequent blushers. Taken together, the empirical evidence converges to the conclusion that blushing propensity may have an ideational basis.

\subsection{Learning experiences and fear of blushing}

The two studies, described in Section 4.3, revealed that high blushing-fearful individuals reported more negative learning experiences than their non-phobic counterparts. This was the case for both studies, the first being a questionnaire investigation and the second being an interview. However, the percentages of reported negative learning experiences were much higher in the written investigation than in the oral interview. Despite methodological issues that might explain these differences, the general tendency remained that high fearful individuals reported to have encountered more negative learning experiences, conditioning experiences being at the top.

Retrospective research with respect to the origins of fears and phobias has been criticised for two reasons (Taylor, Deane, \& Podd, 1999). Firstly, results may have been biased in favour of traditional conditioning etiologies due to the methodology employed, in particular the use of the Phobic Origins Questionnaire (Öst, Jerremalm, \& Johansson, 1981). Secondly, the issue of memory distortions as a source of bias when people construct reasons for their fears has been raised (Menzies \& Clarke, 1994; Menzies, Kirkby, \& Harris, 1998; Merckelbach, De Jong, Muris, \& Van den Hout, 1996). The POQ has been criticized because of its classification of any traumatic event as classical conditioning. The original POQ consists of only two questions concerning classical conditioning, to be answered with either "yes" or "no":

1) 'When you think back on your phobia and try to remember how it started; can you then remind yourself that the fear started with any specific event or situation where you experienced strong discomfort and/or anxiety?'

2) 'Do you think that the start of your fear is possible to trace back to any specific event or situation where you have been frightened or hurt?'

Simply answering "yes" to these questions was taken as evidence of a Pavlovian onset, whereas neither question seeks to identify the essential ingredients of a Pavlovian conditioning procedure (Menzies \& Clarke, 1994). Classical conditioning of fear implies that a former neutral stimulus (e.g. blushing) is paired with a stimulus that already elicits 
fear or pain (e.g. being bullied). The answers to the two POQ conditioning questions do not provide evidence that such a pairing has taken place.

In our first POQ study, we have attempted to adapt the original POQ, rephrasing the conditioning questions in such a way that a clear pairing between blushing and a negative experience could be detected (e.g. "Have you ever experienced a nasty or painful situation because you were blushing"?). In our second POQ study, we asked participants to report the specific memory they had about that experience (details with respect to time, persons present et cetera were required for a memory to be regarded as specific). When individuals were not able to report such a specific memory, conditioning experiences were not scored. Specific interrogating was also done for the two other learning categories (vicarious learning and informational learning). With the above adjustments, we tried to overcome as much as possible the two major criticisms with respect to the POQ. Still, the results are only of relative value, since it remains unclear whether individuals have post hoc attributed their fear to an incident they happen to remember. (Reversely, people might just not be able anymore to 'remember' a certain situation.) Moreover, blushing-fearful individuals might have a better memory for painful situations concerning blushing because of their current preoccupation with the subject. Furthermore, to address the second criticism mentioned above, Taylor et al. (1999) examined the test-retest reliability of retrospective accounts, and established that these were quite unstable over time. Thus, the retrospective nature of studies investigating the origins of fears and phobias remains an obstacle to draw solid conclusions.

The results of our study can be interpreted in at least two ways which are not necessarily mutually exclusive. First, high blushing-fearful individuals may have encountered more negative learning experiences than did their non-fearful counterparts. Second, this may not be the case, suggesting that our results may well fit into a cognitive model of fear. That is, attentional factors may cause individuals to selectively attend to, negatively interpret, and selectively remember negative events. With respect to the first possibility, blushing-fearful individuals might indeed have encountered more negative learning experiences (like bullying) because they blushed more frequently. However, they might as well be bullied with blushing because of something else. That is, someone might have been accused of blushing (whereas he was not blushing yet) because of something else, which he might find awful (for example because of social anxiety or because of his ideas and opinions), which might then lead to actual blushing. As such, a vicious circle is started. The second possibility implies that high blushing-fearful individuals merely have a bias (in attention, interpretation, and/or memory) towards these instants. Yet, some individuals who now suffer from fear of blushing might, due to low self-esteem and/or dysfunctional interpretations of (the consequences of) certain situations, have experienced any given situation in their past faster and/or more often as blush-inducing, and might indeed have blushed; Although they are not characterized by a lower blush threshold or an overresponsive blush-system.

Taken together, although our results, at first sight, suggest that high blushing fearful individuals might have been exposed to more negative learning experiences than low blushing-fearful individuals, the difficulties that emerge when drawing conclusions 
based on retrospective material should be taken into consideration. In any case, when investigating retrospective material, our results lead to the recommendation for the use of strict formulations as to when experiences should be classified as negative learning experiences, and especially when classified as aversive conditioning events. Besides, prospective studies instead of retrospective studies are recommended in order to gain reliable and valid data concerning the actual learning history of blushing-fearful individuals. On the other hand, it might as well be concluded that it makes no difference whether high and low blushing-fearful individuals are rightly classified as to whether they indeed have encountered more or less negative learning experiences. Eventually, individual UCS-representations are the matters that really count, leading individuals to suffer and perhaps seek treatment (e.g. Davey, 1997).

\subsection{Normal individuals have predominantly negative beliefs about blushing}

Section 4.4 indicates that unselected individuals' ideas about blushing are of a predominantly negative nature. This pertains to situations in which they are the blushing actors, as well as to situations in which they observe other people blushing. Remarkably, both men and women consider blushing as less negative when the actor is someone of the opposite sex, as opposed to someone of the same sex.

Thus, negative beliefs about blushing are not specific for people with fear of blushing. In contrast to, for example, normal individuals' versus panic disordered patients' beliefs about bodily sensations, the present results suggest that blushing phobics' beliefs about blushing are not so obviously irrational. What, then, distinguishes normal people from blushing phobics? Given the results of the previous chapter (no actual physiological differences, overestimation of the strength of the blush response in high fearful individuals), blushing phobics might more often think that they are blushing than low fearful individuals do. Clearly such a belief is highly dysfunctional.

Although our study provides evidence to indicate that the belief 'blushing has negative consequences' is objectively correct, it might well be that blushing phobics exaggerate the catastrophic consequences of blushing. In addition, they might underestimate their skills to handle such a catastrophic situation. Indeed, an important assumption held by social phobics, is that it is unacceptable to show signs of insecurity. Whenever blushing is regarded as such a sign, it might become problematic. This hypothesis is supported by the results of Bögels and Reith (1999), indicating that blushing phobics' credibility ratings of negative consequences of blushing are significantly higher than the ratings of nonphobic control individuals. Section 4.6 also shows that the credibility of negative beliefs, such as "When I blush, I will lose face", decreases significantly after treatment. These results suggest that some beliefs, held by blushing phobics, (e.g. "I blush more than other people") might be irrational, and other beliefs (e.g. "Blushing has negative consequences") might be, in fact, correct.

Meanwhile, it should be acknowledged that we did not assess the specific content of the beliefs nor their intensity. Therefore, it can not be ruled out on the basis of the 
present data that blushing phobics' beliefs about blushing are of a qualitatively different nature than non-fearful individuals' beliefs, and/or of a much more negative valence. Besides, in case fearful individuals' and non-fearful individuals' beliefs would, indeed, have a comparable content, fearful individuals' beliefs might tap a dysfunctional scheme (putting someone to inconvenience), whereas normal individuals' beliefs might tap a more functional cognitive scheme (enabling them to put these beliefs into perspective). It is unclear whether the beliefs tapped by this study should be labeled as '(core) beliefs', and/or 'automatic thoughts' and we do not know how negative they are. It might well be that blushing phobics hold very negative beliefs about blushing (e.g. "I'm worthless because of my blushing"), which are far more difficult to challenge than beliefs of the type ("It's silly to blush now").

The present findings may have consequences for cognitive treatment. Firstly, cognitive treatment should focus on the overestimation of blushing. Secondly, its aim should be to focus on the specific cognitive scheme when intervening, and merely turn very negative beliefs into less negative beliefs (i.e. to refine specific beliefs). That is, given that blushing is generally seen as negative, it would be unfruitful to make patients believe that this is not the case, but treatment might help to put into perspective the gravity of catastrophic consequences, given that people think negatively about blushing.

\subsection{Fear of blushing can be successfully treated with Task Concentration Training}

In Sections 4.5 and 4.6, a new treatment technique, called Task Concentration Training, was introduced, tested, and evaluated. Section 4.5 describes a single-case study in which attention is switched each week, in order to investigate the effect of self-directed (exposure-like, not avoiding to feel anxious) versus outward-directed (task-oriented) attention. All in all, this case study seemed successful, leading to important changes in fear of blushing, negative cognitions, and avoidance behaviour. However, the largest anxiety decreases took place in the exposure weeks. Yet, the patient appeared to have used TCT strategies, then, as well. In a larger treatment outcome study, comparing TCT versus Exposure in Vivo, TCT and exposure both turned out to be effective treatment strategies for fear of blushing. In the short-term, TCT tended to be somewhat more effective than EXP in decreasing fear of blushing; at 6-weeks follow-up, TCT was significantly better in decreasing negative cognitions regarding blushing. At 1-year follow-up, these differences can still be observed (see Table 4 in Section 4.6), although they no longer attained statistical significance. This is probably due the fact that, at 1-year follow-up, less individuals were included into the analyses (only those who completed both pre-test and 1-year follow-up assessments). Neither treatment caused a decrease in actual blushing as measured during behavioural assessments. Thus, improvements in fear of blushing do not necessarily have to be accompanied by decreases in actual blushing. This, again, is in line with the idea that blushing reflects a fearful preoccupation, irrespective of facial colouration. The fact that actual blushing was not affected by 
treatment may be explained in several ways: First, the physiological responses of fearful individuals could be of a comparable level to those of non-fearful individuals, which would provide not much room for improvement with regard to patients' responses. Second, the behavioural assessments might have been too distinct from patients' daily situations, making changes as a result of treatment hard to detect. Third, actual blushing might not have changed (yet), because the period between the two measurement occasions was too short.

The results of this study should be regarded in the light of the small sample size. That is, a sample of 31 individuals minus 6 dropouts is rather small, which might have resulted in insufficient power to detect meaningful differences. Still, considering the small sample size and the short duration of treatment, the results of TCT tending to produce somewhat more effect - especially its superiority in decreasing negative cognitions about blushing - than Exposure in Vivo, are quite worth mentioning. In light of the proposed model in Chapter 2, it may be hypothesized that strategies which aim to reduce self-focused attention, diminish fear of blushing via a cognitive pathway. Although TCT also made use of exposure-like assignments and these might have contributed also to the eventual effect, the addition of attention training might have a surplus value, since TCT did somewhat better on cognitions. In the long run (after 1 year), the effects seem to last, although firm inferences cannot be made given the further dropout rate. All in all, the results of this study concord with the model's hypotheses, although studies with larger sample sizes are needed to more definitely establish whether TCT, indeed, is a suitable substitution or addition to regular Exposure in Vivo treatment and cognitive therapy.

\subsection{The model revisited}

In this thesis, some of the factors that are believed to contribute to the etiology of fear of blushing and to the maintenance of this disorder, have been investigated (see Figure 5.1). On the basis of the available results from the present studies it may be tentatively concluded that there is no evidence for a biological vulnerability in the etiology of fear of blushing. Furthermore, it seems to be rather difficult for individuals to estimate their own blush intensity in the laboratory. That is, self-reports about blushing diverged significantly between individuals high and low in blushing propensity and in fear of blushing, whereas physiological parameters were equal among both high and low scoring groups. Next, it remains difficult to establish whether learning experiences fulfill an important role in the acquisition of fear of blushing. Given the retrospective nature of the data, the higher percentages of negative learning experiences provided by high fearful individuals might still be based on cognitive biases with regard to pathways to phobias. We also detected that normal, unselected individuals hold primarily negative beliefs about blushing. However, it remains to be investigated whether the content of these types of beliefs is similar for blushing-fearful and non-fearful individuals. Furthermore, it seemed that blushing phobics overestimate their blushing, and exaggerate the catastrophic consequences of their blushing. 


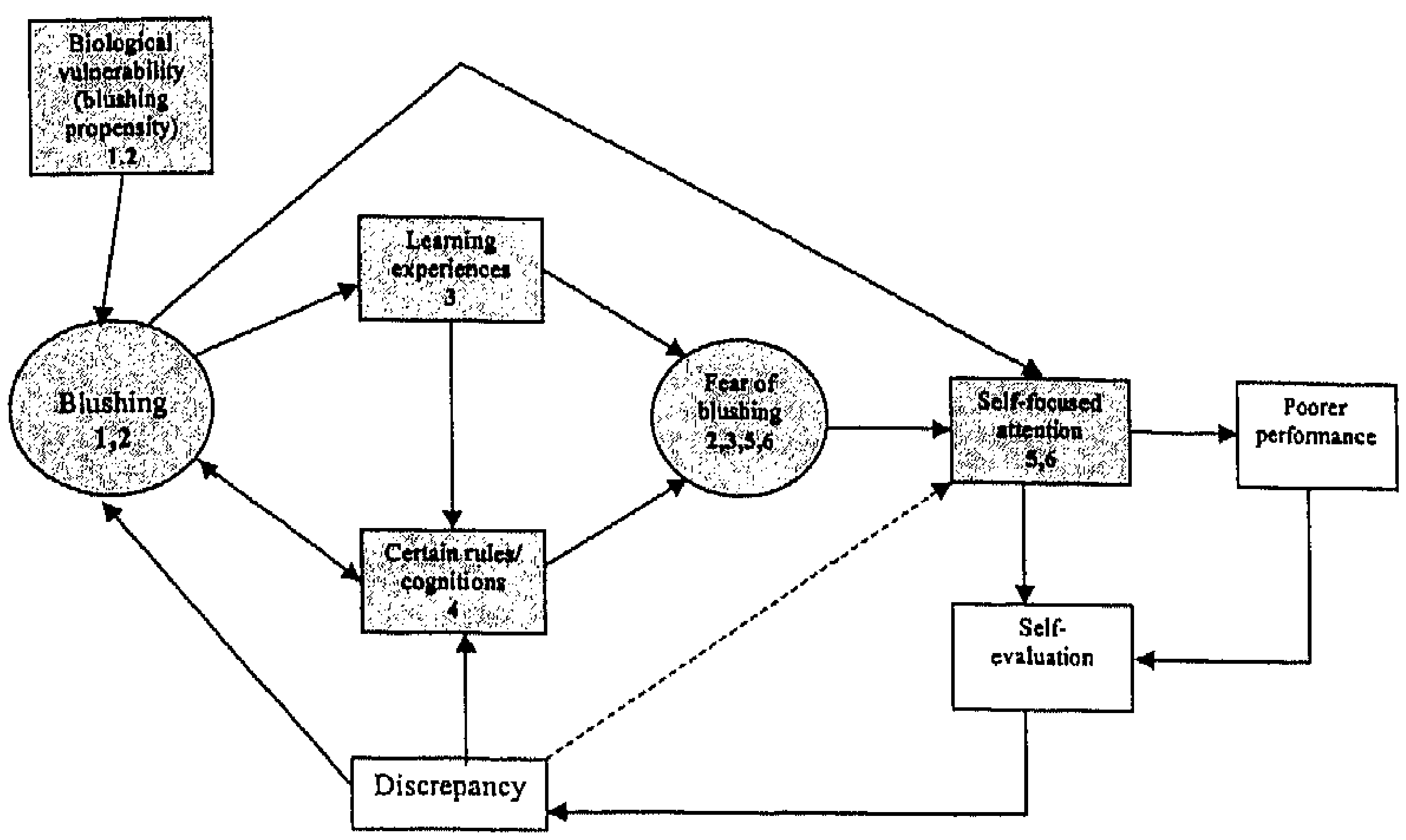

Figure 5.1: Elements of the model that were investigated in the present thesis

The right part of the model states that, once an individual has fear of blushing, he or she is inclined to direct more attention to the self (including blushing), in anticipation with and/or during social situations. This is supposed to lead to (social) mistakes which might aggravate this process. In addition, self-focused attention is assumed to elicit a process of self-evaluation which, via a discrepancy between observed and desired self, and cognitions about the self, maintains the fear. The idea that social phobics take an observer perspective during social situations (our model's 'self-focused attention') was also theorized by, for example, Clark and Wells (1995) and Rapee and Heimberg (1997). It was empirically sustained by Wells, Clark, and Ahmad (1998) who found social phobics to view themselves significantly more often as if from an external point of view. Recent research by Woody (1996), however, does not support the notion of impaired social performance during heightened self-focused attention (our model's 'poorer performance'), whereas Panayiotou and Vrana (1998) found evidence for a limitedcapacity central processor. A limited capacity central processor implies that, when attention is focussed in a particular direction, or on a particular task, less capacity can be devoted to another task, and consequently performance on the other task will suffer. Panayiotou and Vrana (1998) found that self-focus led to larger startle probe responses among socially anxious individuals, and self-focus combined with evaluation led to poorer recall performance among all individuals. The finding of decreased performance, occurring under evaluative conditions, is a result consistent with the literature showing that self-focus impairs performance only when paired with other variables such as 
evaluation anxiety (Hope, Gansler, \& Heimberg, 1989). Self-focus, furthermore, increases access to self-relevant thought content (Hope, Gansler, \& Heimberg, 1989). Our model assumes that, during social situations, the blushing-fearful individual feels evaluated and focuses attention on the self and presumably also on his/her blush behaviour. Meanwhile, the individual's ideas about blushing are of such a nature that blushing is regarded as negative and unacceptable, which leads to more fear eventually. Next, these ideas and the fearful preoccupation are likely to result in the individual thinking more often that he/she is blushing, thereby creating a vicious circle.

Taken together, the available empirical evidence supports a cognitive explanation of fear of blushing. In other words, a so-called fearful preoccupation might well play a role in the acquisition as well as in the maintenance of fear of blushing. A slightly revised model may be presented (see Figure 5.2), which has been outlined above, already. What remains unclear, yet, is how individuals acquire a fearful preoccupation with blushing. It might be that, like other cognitive assumptions, a fearful preoccupation is obtained by upbringing, traumatic events and thus learning history. Nevertheless, this can not be firmly stated by the results of these studies. Further research is needed to further clarify this issue.

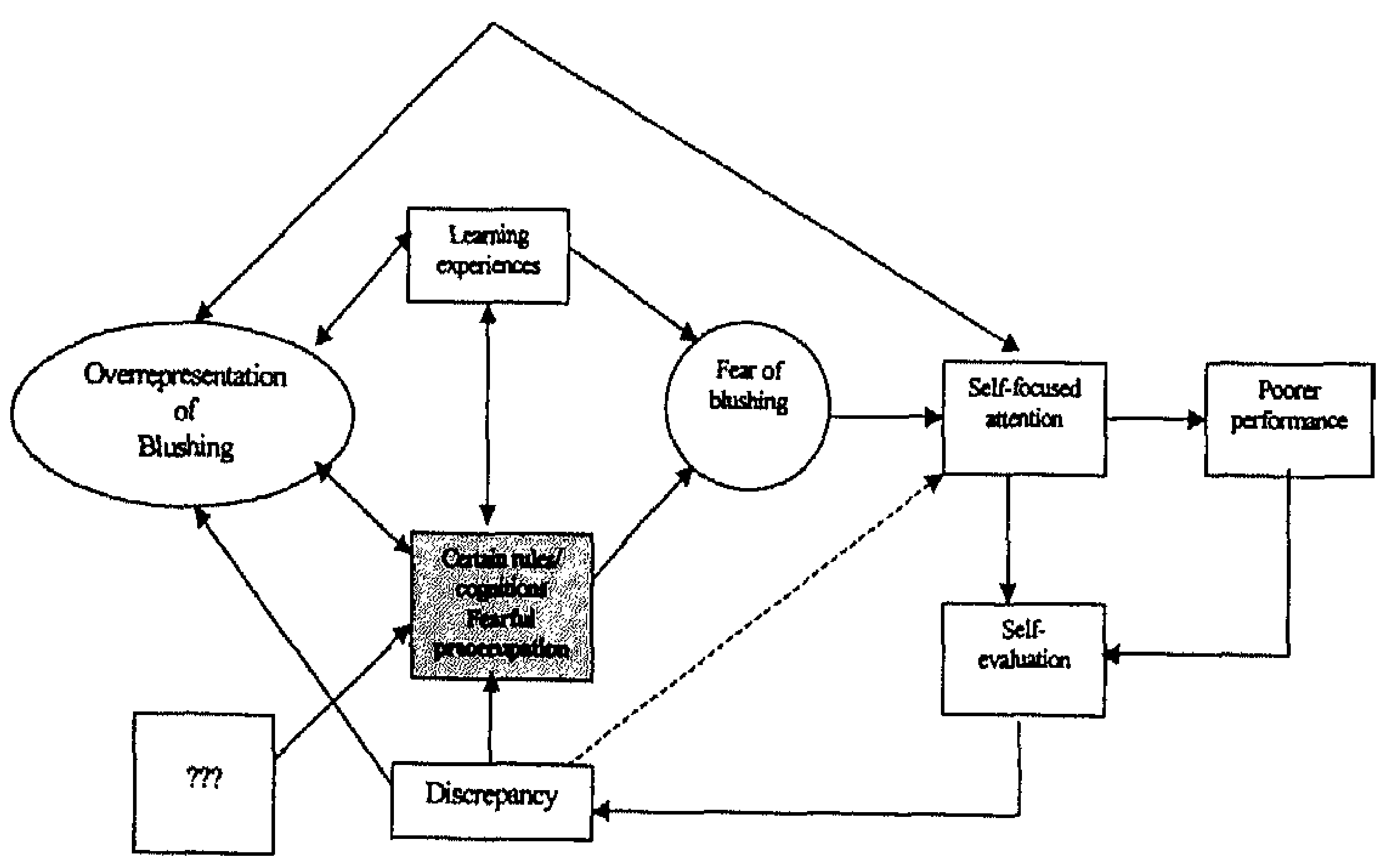

Figure 5.2: Schematic representation of the presumed factors that cause and maintain fear of blushing.

\subsection{Directions for future research}

The model presented in this thesis is based on several suppositions, which are not all investigated. Thus, conclusions based on the present results are limited to the investigated area. Still, the present results suggest that a fearful preoccupation is an 
important factor in the acquisition and maintenance of fear of blushing. What remains to be investigated in this respect is how people obtain such a fearful preoccupation. Future research might further investigate this issue, for example with prospective studies, include potentially predicting variables, such as the personality characteristics neuroticism and extraversion (cf. Townsley Stemberger, Turner, Beidel, \& Calhoun, 1995), the temperament of behavioural inhibition (BI; Kagan, Snidman, \& Arcus, 1992) which is currently viewed as an important early marker of proneness to the develoment of anxiety disorders, including social phobia (cf. Rosenbaum, Biederman, Hirsfeld, Bolduc, \& Chaloff, 1991; Rosenbaum, Biederman, Pollock, \& Hirshfeld, 1994), parental rearing practices, traumatic experiences et cetera. Although this is much more cost- and time-intensive, it allows more definite conclusions than the present retrospective studies. Another way to tackle the difficulties caused by retrospective data, is to ask about traumatic events from informants (e.g. the parents, close friends) who knew the phobics at the time of onset of their blushing fear. Still, these individuals might be subject to the same biases as mentioned above.

With respect to beliefs about blushing, we investigated normal people's beliefs about blushing. Future research might engage also low and high blushing-fearful individuals' beliefs about blushing. Such a procedure allows to investigate potential differences in the valence and the content of particular beliefs. In order to have all beliefs rated as positive, negative, or neutral, individuals might be asked to rate their own beliefs, or, alternatively, a panel of men and women might set a so-called 'golden standard' for all reported beliefs, so that answers of high and low fearful individuals may be reliably compared.

Treatment studies concerning fear of blushing should be conducted with larger patient groups, to avoid null-findings due to power problems. Having larger patient groups, it will also be less difficult to compare both treatment groups separately against a waiting-list control condition, instead of having to compare the pooled treatment conditions against a waiting-list control group. Furthermore, it might be interesting to find out whether attentional instructions alone are as effective as attentional instructions plus the application in threatening situations. Such a design allows to investigate whether task-focusing techniques alone provide similar results as when employed in combination with exposure techniques. That is, it might well be that exposure to feared situations is unnecessary to result in satisfactory treatment outcome. A few case studies (Wells, 1990; Wells, White, and Carter, 1997), investigating the effect of attentional instructions alone, seemed promising for panic disorder. Still, effect studies with larger patient groups need to be executed to further investigate this question. In case the influencing of attentional processes alone would be sufficient to decrease phobic fear, this would support our hypothesis that attentional processes are important factors in the maintenance of fear of blushing. To corroborate these suggestions, experimental studies might further investigate the effect of self-focused attention on fear of blushing. That is, self-focusing instructions in non-fearful individuals should result in higher levels of fear and selfreported blush intensity, whereas in high fearful individuals, external focus instructions should result in lower levels of fear and subjective blush intensity, provided that their 
ideas about blushing are negatively enough. Finally, since distorted cognitions seem to play such a central role in the acquisition and maintenance of fear of blushing, it might be interesting to compare TCT directly to cognitive treatment for fear of blushing, to investigate the most effective strategy for changing negative beliefs in fear of blushing. 


\section{References}

Allgulander, C. (1999). Paroxetine in social anxiety disorder: A randomized placebocontrolled study. Acta Psychiatrica Scandinavica, 100, 193-198.

American Psychiatric Association (1980). Diagnostic and Statistical Manual of Mental Disorders, Third Edition. Washington, DC: American Psychiatric Association.

American Psychiatric Association (1987). Diagnostic and Statistical Manual of Mental Disorders, Third Edition, Revised. Washington, DC: American Psychiatric Association.

American Psychiatric Association (1994). Diagnostic and Statistical Manual of Mental Disorders, Fourth Edition. Washington, DC: American Psychiatric Association.

Amies, P. L., Gelder, M. G., \& Shaw, P. M. (1983). Social phobia: A comparative clinical study. British Journal of Psychiatry, 142, 174-179.

Argyle, M. \& Williams, M. (1969). Observer or observed? A reversible perspective in person perception. Sociometry, 32, 396-412.

Baldwin, D., Bobes, J., Stein, D. J., Scharwächter, I., \& Faure, M. (1999). Paroxetine in social phobia/social anxiety disorder: Randomized, double-blind, placebocontrolled study. British Journal of Psychiatry, 175, 120-126.

Baumeister, R. F., Hamilton, J. C., \& Tice, D. M. (1985). Public versus private expectancy of success: Confidence booster or performance pressure? Journal of Personality and Social Psychology, 48, 1447-1457.

Bechterew, W. (1897a). Neue Beobachtungen über die "Erröthungsangst". Neurologisches Zentralblatt, 16, 985-989.

Bechterew, W. (1897b). Über das Erröthen des Gesichts als besondere pathologische Form. Neurologisches Zentralblatt, 16, 326-327.

Bechterew, W. (1897c). Die Erröthungsangst als eine besondere Form von krankhafter Störung. Neurologisches Zentralblatt, 16, 386-391.

Bechterew, W. (1897d). Mittheilung an der Herausgeber. Neurologisches Zentralblatt, 16,720 .

Beck, A. T., Emery, G., \& Greenberg, R. (1985). Anxiety disorders and phobias: A cognitive perspective. New York: Basic Books.

Beidel, D. C., Turner, S. M., \& Dancu, C. V. (1985). Physiological, cognitive and behavioral aspects of social anxiety. Behaviour Research and Therapy, 23, 109. 117.

Benedek, T. (1925). Notes from the analysis of a case of erythrophobia. International Journal of Psychoanalysis, 6, 430-439.

Bij1, R. V., Van Zessen, G., \& Ravelli, A. (1997). Psychiatrische morbiditeit onder volwassenen in Nederland: het NEMESIS-onderzoek. II. Prevalentie van psychiatrische stoornissen. Nederlands Tijdschrift voor Geneeskunde, 141, 24532460. 
Bögels, S. M. (1994). Cognitive therapy versus applied social skills training for fear of blushing, trembling and sweating. Paper presented at the 24th congress of the European Association of Behavioural and Cognitive Therapies, Corfu, Greece.

Bögels, S. M. (1997). Cognitieve gedragstherapie bij sociale fobie: Nieuwe ontwikkelingen in de theorie en behandeling. Directieve Therapie, 17, 39-56.

Bögels, S. M., Alberts, M., \& De Jong, P. J. (1996). Self-consciousness, self-focused attention, blushing propensity and fear of blushing. Personality and Individual Differences, 21, 573-581.

Bögels, S. M. \& Mulkens, S. (1997). Protocollaire behandeling van patiënten met een sociale fobie: Taakconcentratietraining en cognitieve therapie. In G. P. J. Keijsers, A. van Minnen, \& C. A. L. Hoogduin (Eds.), Protocollaire behandelingen in de ambulante geestelijke gezondheidszorg (pp. 127-157). Houten/Diegem: Bohn Stafleu Van Loghum.

Bögels, S. M., Mulkens, S., \& De Jong, P. J. (1995). Overmatig zelfbewustzijn en taakconcentratie: een nieuw model voor de behandeling van bloosangst. Gedragstherapie, 28, 153-174.

Bögels, S. M., Mulkens, S., \& De Jong, P. J. (1997). Task concentration training and fear of blushing. Clinical Psychology and Psychotherapy, 4, 251-258.

Bögels, S. M. \& Reith, W. (1998). Validity of two questionnaires to assess social fears: the Dutch Social Phobia and Anxiety Inventory and the Fear of Blushing, Trembling, and Sweating Questionnaire. Unpublished data.

Bögels, S. M. \& Reith, W. (1999). Validity of two questionnaires to assess social fears: the Dutch Social Phobia and Anxiety Inventory and the Fear of Blushing, Trembling, and Sweating Questionnaire. Journal of Psychopathology and Behavioral Assessment, 21, 51-66.

Bögels, S. M. \& Scholing, A. (1995). Behandeling van angst om te blozen, trillen of zweten. Tijdschrift voor Psychotherapie, 21, 248-267.

Boucher, M. (1890). Une forme particulière d'obsession héréditaire. Vortrag, gehalten auf dem ersten Psychiatercongress in Rouen, 1890. Le Progrès Médical, XII, 133.

Brown, B. R. \& Garland, H. (1971). The effects of incompetency, audience acquaintanceship, and anticipated evaluative feedback on face-saving behavior. Journal of Experimental Social Psychology, 7, 490-502.

Bruch, M. A. (1989). Familial and developmental antecedents of social phobia: issues and findings. Clinical Psychology Review, 9, 37-47.

Bruch, M. A. \& Heimberg, R. G. (1994). Differences in perceptions of parental and personal characteristics between generalized and nongeneralized social phobics. Journal of Anxiety Disorders, 8, 155-168.

Burgess, T. H. (1839). The physiology or mechanism of blushing. London: John
Churchill.

Burgio, K. L., Merluzzi, T. V., \& Pryor, J. B. (1986). Effects of performance expectancy
and self-focused attention and self-focused attention on social interaction. Journal of Personality and Social 
Buss, A. H. (1980). Self-consciousness and social anxiety. San Francisco: W.H. Freeman.

Buss, A. H., Iscoe, I., \& Buss, E. H. (1979). The development of embarrassment. Journal of Psychology, 103, 227-230.

Butler, G. (1985). Exposure as a treatment for social phobia: Some instructive difficulties. Behaviour Research and Therapy, 23, 651-657.

Butler, G., Cullington, A., Munby, M., Amies, P., \& Gelder, M. (1984). Exposure and anxiety management in the treatment of social phobia. Journal of Consulting and Clinical Psychology, 52, 642-650.

Cacioppo, J. T., Glass, C. R., \& Merluzzi, T. V. (1979). Self-statements and selfevaluations: A cognitive-response analysis of heterosocial anxiety. Cognitive Therapy and Research, 3, 249-262.

Cacioppo, J. T. \& Petty, R. E. (1981). Social psychological procedures for cognitive response assessment: The thought-listing technique. In T. V. Merluzzi, C. R. Glass, \& M. Genest (Eds.), Cognitive assessment. New York/ London: Guilford Press.

Casper, J. L. (1846). Denkwürdigkeiten zur medicinischen Statistik und Staatsarzneikunde für Criminalisten und Ärzte. Berlin: Duncker \& Humblot.

Caspi, A., Elder, G. H., \& Bem, D. J. (1988). Moving away from the world: Life-course patterns of shy children. Developmental Psychology, 24, 824-831.

Castelfranchi, C. \& Poggi, I. (1990). Blushing as a discourse: was Darwin wrong? In W. R. Crozier (Ed.), Shyness and embarrassment: perspectives from social psychology (pp. 230-251). New York: Cambridge University Press.

Chambless, D. L. \& Hope, D. A. (1996). Cognitive approaches to the psychopathology and treatment of social phobia. In P. M. Salkovskis (Ed.), Frontiers of cognitive therapy (pp. 345-382). New York, London: The Guilford Press.

Clark, D. M. (1989). Anxiety states: Panic and generalized anxiety. In K. Hawton, P. M. Salkovskis, J. Kirk, \& D. M. Clark (Eds.), Cognitive behaviour therapy for psychiatric problems: A practical guide (pp. 52-96). Oxford: Oxford University Press.

Clark, D. M. \& Wells, A. (1995). A cognitive model of social phobia. In R. G. Heimberg, M. R. Liebowitz, D. A. Hope, \& F. R. Schneier (Eds.), Social phobia: Diagnosis, assessment, and treatment. New York, London: The Guilford Press.

Cohen, J. (1988). Statistical power analysis for the behavioral sciences. Hillsdale, NJ: Lawrence Erlbaum Associates.

Crissey, J. T. \& Parish, L. C. (1993). The red face: Historical considerations. Clinics in Dermatology, 11, 197-201.

Cupach, W. R. \& Metts, S. (1990). Remedial processes in embarrassing predicaments. In J. Anderson (Ed.), Communication Yearbook (Vol. 13, pp. 323-352). Newbury Park, CA: Sage.

Cutlip, W. D. \& Leary, M. R. (1993). Anatomic and physiological bases of social blushing: Speculations from neurology and psychology. Behavioural Neurology, $6,181-185$. 
Daly, J. A., Vangelisti, A. L., \& Lawrence, S. G. (1989). Self-focused attention and public speaking anxiety. Personality and Individual Differences, 10, 903-913.

Davey, G. C. L. (1997). Phobias: A handbook of theory, research and treatment. Chichester: John Wiley and Sons.

Darwin, C. (1965). The expression of emotions in man and animals. Chicago: The University of Chicago Press. (Original work published in 1872).

Davidson, J. R. T. (1998). Pharmacotherapy of social anxiety disorder. Journal of Clinical Psychiatry, 59, 47-53.

De Jong, P. J. (1998a). Een rood hoofd als excuus. Blozen beschouwd vanuit functioneel perspectief. Nederlands Tijdschrift voor de Psychologie, 53, 117-125.

De Jong, P. J. (1998b). Excused by a red face: Evidence for remedial effects of social blushing. Unpublished manuscript.

De Jong, P. J. (1999). Communicative and remedial effects of social blushing. Journal of Nonverbal Behavior, 23, 197-217.

Den Boer, J. A., Van Vliet, I. M., \& Westenberg, H. G. (1995). Recent developments in the psychopharmacology of social phobia. European Archives of Psychiatry and Clinical Neuroscience, 244, 309-316.

Dodge, C. S., Hope, D. A., Heimberg, R. G., \& Becker, R. E. (1988). Evaluation of the Social Interaction Self-Statement Test with a social phobic population. Cognitive Therapy and Research, 12, 211-222.

Donohue, B. C., Van Hasselt, V. B., \& Hersen, M. (1994). Behavioral assessment and treatment of social phobia: An evaluative review. Behavior Modification, 18, 262288.

Dosužkov, T. (1965). Deux observations d'éreuthophobie. L'Évolution Psychiatrique, $34,427-448$.

Drott, C., Claes, G., Olsson-Rex, L., Dalman, P., Fahlen, T., \& Gothberg, G. (1998). Successful treatment of facial blushing by endoscopic transthoracic sympathicotomy. British Journal of Dermatology, 138, 639-643.

Drummond, P. D. (1997). The effect of adrenergic blockade on blushing and facial flushing. Psychophysiology, 34, 163-168.

Drummond, P. D. (in press). A caution about surgical treatment for facial blushing. British Journal of Dermatology.

Duval, S. \& Wicklund, R. A. (1973). Effects of objective self-awareness on attributions of causality. Journal of Experimental Social Psychology, 9, 17-31.

Edelmann, R. J. (1985). Dealing with embarrassing events: Socially anxious and nonsocially anxious groups compared. British Journal of Clinical Psychology, 24, 281-288.

Edelmann, R. J. (1987). The psychology of embarrassment. Chichester: John Wiley and Sons.

Edelmann, R. J. (1990a). Embarrassment and blushing: A component-process model, some initial descriptive and cross-cultural data. In R. Crozier (Ed.), Shyness and embarrassment: Perspectives from social psychology (pp. 363). New York: Cambridge University Press. 
Edelmann, R. J. (1990b). Coping with blushing. London: Sheldon Press.

Edelmann, R. J. (1990c). Chronic blushing, self-consciousness, and social anxiety. Journal of Psychopathology and Behavioral Assessment, 12, 119-127.

Edelmann, R. J., Asendorpf, J., Contarello, A., Zammuner, V., Georgas, J., \& Villanueva, C. (1989). Self-reported expression of embarrassment in five European cultures. Journal of Cross Cultural Psychology, 20, 357-371.

Eisenberg, N., Fabes, R. A., Miller, P. A., Fultz, J., Shell, R., Mathy, R. M., \& Reno, R. R. (1989). Relation of sympathy and personal distress to prosocial behavior: a multimethod study. Journal of Personality and Social Psychology, 57, 55-66.

Emmelkamp, P. M. G., Bouman, T., \& Scholing, A. (1995). Angst, fobieën en dwang: diagnostiek en behandeling. Houten/ Diegem: Bohn Stafleu Van Loghum.

Emmelkamp, P. M. G., Mersch, P. P., Vissia, E., \& Van der Helm, M. (1985). Social phobia: A comparative evaluation of cognitive and behavioral interventions. Behaviour Research and Therapy, 23, 365-369.

Essau, C. A., Conradt, J., \& Petermann, F. (1999). Frequency and comorbidity of social phobia and social fears in adolescents. Behaviour Research and Therapy, 37, 831843.

Eysenck, H. J. (1982). Personality, genetics, and behavior. New York: Praeger.

Falloon, I. R., Lloyd, G. G., \& Harpin, R. E. (1981). The treatment of social phobia. Real-life rehearsal with nonprofessional therapists. Journal of Nervous and Mental Disease, 169, 180-184.

Feldman, S. S. (1962). Blushing, fear of blushing, and shame. Journal of the American Psychoanalytic Association, 10, 368-385.

Fenichel, O. (1945). The psycho-analytic theory of neurosis. New York: Norton.

Fenigstein, A. (1979). Self-consciousness, self-attention, and social interaction. Journal of Personality and Social Psychology, 37, 75-86.

Fenigstein, A. \& Carver, C. S. (1978). Self-focusing effects of heartbeat feedback. Journal of Personality and Social Psychology, 47, 75-86.

Feske, U. \& Chambless, D. L. (1995). Cognitive behavioral versus exposure only treatment for social phobia: A meta-analysis. Behavior Therapy, 26, 695-720.

Foa, E. B., Franklin, M. E., Perry, K. J., \& Herbert, J. D. (1996). Cognitive biases in generalized social phobia. Journal of Abnormal Psychology, 105, 433-439.

Friedländer, A. (1900). Zur klinischen Stellung der sogen. Erythrophobie. Neurologisches Zentralblatt, 19, 848-850, 950-957.

Frijda, N. H. (1985). The emotions. Cambridge: Cambridge University Press.

Fyer, A. J., Mannuzza, S., Chapman, T. F., Liebowitz, M. R., \& Klein, D. F. (1993). A direct interview family study of social phobia. Archives of General Psychiatry, 50, 286-293.

Garland, H. \& Brown, B. R. (1972). Face-saving as affected by subjects' sex, audiences' sex, and audience expertise. Sociometry, 35, 280-289.

Gelernter, C. S., Uhde, T. W., Cimbolic, P., Arnkoff, D. B., Vittone, B. J., Tancer, M. E., \& Bartko, J. J. (1991). Cognitive-behavioral and pharmacological treatments of social phobia: A controlled study. Archives of General Psychiatry, 48, 938945. 
Ginsburg, J. \& O'Reilly, B. (1987). Are blushes the same as flushes? Clinical Science, 72 (Suppl. 16, 65P, Abstract No. 184), 65.

Glass, C. R., Merluzzi, T. V., Biever, J. L., \& Larsen, K. H. (1982). Cognitive assessment of social anxiety: Development and validation of a self-statement questionnaire. Cognitive Therapy and Research, 6, 37-55.

Goffman, E. (1955). On face-work: an analysis of ritual elements in social interaction. Psychiatry: Journal for the study of interpersonal processes, 18, 213-231.

Gould, R. A., Buckminster, S., Pollack, M. H., Otto, M. W., \& Yap, L. (1997). Cognitive-behavioral and pharmacological treatment for social phobia: A metaanalysis. Clinical Psychology: Science and Practice, 4, 291-306.

Gould, R. A., Otto, M. W., \& Pollack, M. H. (1995). A meta-analysis of treatment outcome for panic disorder. Clinical Psychology Review, 15, 818-844.

Guyton, A. C. \& Hall, J. E. (1996). Textbook of medical physiology. Philadelphia: W.B. Saunders Company.

Halberstadt, A. G. \& Green, L. R. (1993). Social attention and placation theories of blushing. Motivation and Emotion, 17, 53-64.

Hartman, L. M. (1983). A metacognitive model of social anxiety: Implications for treatment. Clinical Psychology Review, 3, 435-456.

Hayward, P. \& Wardle, J. (1997). The use of medication in the treatment of phobias. In G. C. L. Davey (Ed.), Phobias: A handbook of theory, research and treatment. Chichester: John Wiley \& Sons.

Heimberg, R. G., Dodge, C. S., Hope, D. A., Kennedy, C. R., Zollo, L. J., \& Becker, R. E. (1990). Cognitive behavioral group treatment for social phobia: Comparison with a credible placebo control. Cognitive Therapy and Research, 14, 1-23.

Heimberg, R. G., Liebowitz, M. R., Hope, D. A., Schneier, F. R., Holt, C. R., Welkowitz, L. A., Juster, H. R., Campeas, R., Bruch, M. A., Cloitre, M., Fallon, B., \& Klein, D. F. (1998). Cognitive behavioral group therapy vs phenelzine therapy for social phobia: 12-week outcome. Archives of General Psychiatry, 55, 1133-1141.

Herbert, J. D., Hope, D. A., \& Bellack, A. S. (1992). Validity of the distinction between generalized social phobia and avoidant personality disorder. Journal of Abnormal Psychology, 101, 332-339.

Hoche, A. (1897). Mittheilung an den herausgeber. Neurologisches Zentralblatt, 16, 528.

Hofmann, S. G., Newman, M. G., Ehlers, A., \& Roth, W. T. (1995). Psychophysiological differences between subgroups of social phobia. Journal of Abnormal Psychology, 104, 224-231.

Hope, D. A., Gansler, D. A., \& Heimberg, R. G. (1989). Attentional focus and causal attributions in social phobia: Implications from social psychology. Clinical Psychology Review, 9, 49-60.

Hope, D. A., Heimberg, R. G., \& Bruch, M. A. (1995). Dismantling cognitive-behavioral group therapy for social phobia. Behaviour Research and Therapy, 33, 637-650.

Hull, J. G. (1981). A self-awareness model of the causes and effects of alcohol consumption. Journal of Abnormal Psychology, 90, 586-600. 
Ingram, R. E. (1990). Self-focused attention in clinical disorders: Review and a conceptual model. Psychological Bulletin, 107, 156-176.

Jacobson, N. S. \& Truax, P. (1991). Clinical significance: A statistical approach to defining meaningful change in psyhotherapy research. Journal of Consulting and Clinical Psychology, 59, 12-19.

Janet, P. \& Raymond, F. (1903). Les obsessions et la psychasthénie. (Vol. 2). Paris: Alcan.

Jawad, F. (1982). Facial vasodilation - blushing. Journal of the Pakistan Medical Association, 32, 54-55.

Julius, A. J. \& Van Mourik, J. C. (1985). Transaxillaire thoracale sympathectomie ter behandeling van primaire hyperhidrosis en rubeosis. Nederlands Tijdschrift voor Geneeskunde, 129, 1042-1045.

Kagan, J., Snidman, N., \& Arcus, D. M. (1992). Initial reactions to unfamiliarity. Current Directions in Psychological Science, 1, 171-174.

Karch, F. E. (1971). Blushing. Psychoanalytic Review, 58, 37-50.

Kasahara, Y. \& Sakamoto, K. (1971). Ereuthophobia and allied conditions: a contribution toward the psychopathological and crosscultural study of a borderline state. In S. Arieti (Ed.), The world biennal of psychiatry and psychotherapy (Vol. 1, pp. 292-311). New York: Basic Books.

Keltner, D. (1995). Signs of appeasement: evidence for the distinct displays of embarrassmen, amusement, and shame. Journal of Personality and Social Psychology, 68, 441-454.

Keltner, D. \& Bonanno, G. A. (1997). A study of laughter and dissociation: distinct correlates of laughter and smiling during bereavement. Journal of Personality and Social Psychology, 73, 687-702.

Keltner, D. \& Buswell, B. N. (1996). Evidence for the distinctness of embarrassment, shame, and guilt: a study of recalled antecedents and facial expressions of emotion. Cognition and Emotion, 10, 155-171.

Keltner, D., Young, R. C., \& Buswell, B. N. (1997). Appeasement in human emotion, social practice, and personality. Aggressive Behavior, 23, 359-374.

Kendler, K. S., Neale, M. C., Kessler, R. C., Heath, A. C., \& Eaves, L. J. (1992). The genetic epidemiology of phobias in women: The interrelationship of agoraphobia, social phobia, situational phobia, and simple phobia. Archives of General Psychiatry, 49, 273-281.

Kessler, R. C., McGonagle, K., Zhao, S., Nelson, C., Hughes, M., Eschlemann, S., Wittchen, H.-U., \& Kendler, K. S. (1994). Lifetime and 12-month prevalence of DSM-III-R psychiatric disorders in the United States: Results from the National Comorbidity Survey. Archives of General Psychiatry, 51, 8-19.

Kessler, R. C., Stein, M. B., \& Berglund, P. (1998). Social phobia subtypes in the National Comorbidity Survey. American Journal of Psychiatry, 155, 613-619.

Kroeze, S., Van den Hout, M., Haenen, M.-A., \& Schmidt, A. (1996). Symptom reporting and interoceptive attention in panic patients. Perceptual and Motor Skills, 82, 1019-1026. 
Kushner, M. G., Sher, K. J., \& Beitman, B. D. (1990). The relation between alcohol problems and the anxiety disorders. American Jounal of Psychiatry, 147, 685-95.

Lader, M. H. (1967). Palmar conductance measures in anxiety and phobic states. Journal of Psychosomatic Research, 11, 271-281.

Lader, M. H. \& Mathews, A. M. (1968). A physiological model of phobic anxiety and desensitization. Behaviour Research and Therapy, 6, 411-421.

Leary, M. R. (1983). A brief version of the Fear of Negative Evaluation Scale. Personality and Social Psychology Bulletin, 9, 371-375.

Leary, M. R., Britt, T. W., Cutlip, W. D., \& Templeton, J. L. (1992). Social blushing. Psychological Bulletin, 112, 446-460.

Leary, M. R. \& Meadows, S. (1991). Predictors, elicitors, and concomitants of social blushing. Journal of Personality and Social Psychology, 60, 254-262.

Leitenberg, H. (1973). The use of single-case methodology in psychotherapy research. Journal of Abnormal Psychology, 82, 87-101.

Levin, A. P., Schneier, F. R., \& Liebowitz, M. R. (1989). Social phobia: Biology and pharmacology. Clinical Psychology Review, 9, 129-140.

Lewinsohn, P. M., Hoberman, H., Teri, L., \& Hautzinger, M. (1985). An integrative theory of depression. In S. Reiss \& R. Bootzin (Eds.), Theoretical issues in behavior therapy (pp. 331-359). New York: Academic Press.

Liebowitz, M. R., Schneier, F. R., Campeas, R., Hollander, E., Hatterer, J., Fyer, A., Gorman, J., Papp, L., Davies, S., Gully, R., \& Klein, D. F. (1992). Phenelzine vs atenolol in social phobia: A placebo-controlled comparison. Archives of General Psychiatry, 49, 290-300.

Lindsay-Hartz, J. (1984). Contrasting experiences of shame and guilt. American Behavioral Scientist, 27, 689-704.

Lydiard, R. B. \& Falsetti, S. A. (1995). Treatment options for social phobia. Psychiatric Annals, 25, 570-576.

Magee, W. J., Eaton, W. W., Wittchen, H. U., McGonagle, K. A., \& Kessler, R. C. (1996). Agoraphobia, simple phobia, and social phobia in the national comorbidity survey. Archives of General Psychiatry, 53, 159-168.

Mancini, C. \& Van Ameringen, M. (1996). Paroxetine in social phobia. Journal of Clinical Psychiatry, 57, 519-522.

Mannuzza, S., Fyer, A. J., Liebowitz, M. R., \& Klein, D. F. (1990). Delineating the boundaries of social phobia: Its relationship to panic disorder and agoraphobia. Journal of Anxiety Disorders, 4, 41-59. Marks, I. M. (1986). Genetics of fear and anxiety disorders. British Journal of
Psychiatry, 149, 406-418.

Marks, I. M. (1987). Fears, phobias, and rituals: panic, anxiety, and their disorders. Oxford: Oxford University Press.

Marks, I. M. \& Gelder, M. G. (1966). Different ages of onset in varieties of phobia. American Journal of Psychiatry, 123, 218-221.

Marks, I. M. \& Mathews, A. M. (1979). Brief standard self-rating for phobic patients. Behaviour Research and Therapy, 17, 263-267. 
Mattick, R. P. \& Peters, L. (1988). Treatment of severe social phobia: Effects of guided exposure with and without cognitive restructuring. Journal of Consulting and Clinical Psychology, 56, 251-260.

Mattick, R. P., Peters, L., \& Clarke, J. C. (1989). Exposure and cognitive restructuring for social phobia: A controlled study. Behavior Therapy, 20, 3-23.

McEwan, K. L. \& Devins, G. M. (1983). Is increased arousal in social anxiety noticed by others? Journal of Abnormal Psychology, 92, 417-421.

Meichenbaum, D., Henshaw, D., \& Himel, N. (1982). Coping with stress as a problemsolving process. In H. W. Krohne \& L. Laux (Eds.), Achievement, stress, and anxiety (pp. 127-142). Washington: Hemisphere Publishing Corporation.

Mellander, S., Andersson, P. O., Afzelius, L. E., \& Hellstrand, P. (1982). Neural betaadrenergic dilatation of the facial vein in man. Possible mechanism in emotional blushing. Acta Physiologica Scandinavica, 114, 393-399.

Menzies, R. G. \& Clarke, J. C. (1994). Retrospective studies of the origins of phobias: a review. Anxiety, Stress, and Coping, 7, 305-318.

Menzies, R. G., Kirkby, K., \& Harris, L. M. (1998). The convergent validity of the Phobic Origin Questionnaire (POQ): A review of the evidence. Behaviour Research and Therapy, 36, 1081-1089.

Merckelbach, H., Arntz, A., Arrindell, W. A., \& De Jong, P. J. (1992). Pathways to spider phobia. Behaviour Research and Therapy, 30, 543-546.

Merckelbach, H., De Jong, P. J., Muris, P., \& Van den Hout, M. A. (1996). The etiology of specific phobias: a review. Clinical Psychology Review, 16, 337-361.

Mersch, P. P. (1995). The treatment of social phobia: the differential effectiveness of exposure in vivo and an integration of exposure in vivo, rational emotive therapy and social skills training. Behaviour Research and Therapy, 33, 259-269.

Miller, J. P. (1965). The psychology of blushing. International Journal of PsychoAnalysis, 46, 188-199.

Miller, R. S. (1986). Embarrassment: Causes and Consequences. In W. H. Jones, J. M. Cheek, S. R. Briggs (Eds.), Shyness: Perspectives on research and treatment (pp. 295-311). New York: Plenum Press.

Miller, R. S. (1992). The nature and severity of self-reported embarrassing consequences. Personality and Social Psychology Bulletin, 18, 190-198.

Mineka, S. \& Zinbarg, R. (1995). Conditioning and ethological models of social phobia. In R. G. Heimberg, M. R. Liebowitz, D. A. Hope, \& F. R. Schneier (Eds.), Sacial phobia: Diagnosis, assessment, and treatment. New York, London: The Guilford Press.

Mitchell, A. (1905). About dreaming, laughing and blushing. Edinburgh and London: William Green and Sons.

Montejo, J. \& Liebowitz, M. R. (1994). Social phobia: Anxiety disorder comorbidity. Bulletin of the Menninger Clinic, 58 (Suppl. A), 21-42.

Mowrer, O. H. (1939). Stimulus response theory of anxiety. Psychology Review, 46, 553565. 
Mulkens, S., Bögels, S. M., \& De Jong, P. J. (1999a). Attentional focus and fear of blushing: A case study. Behavioural and Cognitive Psychotherapy, 27, 153-164.

Mulkens, S., Bögels, S. M., De Jong, P. J., \& Louwers, J. (1998). Fear of blushing: Effects of task concentration training versus exposure in vivo on fear and physiology. Submitted for publication.

Mulkens, S., De Jong, P. J., \& Bögels, S. M. (1997). High blushing propensity: Fearful preoccupation or facial coloration? Personality and Individual Differences, 22, 817-824.

Mulkens, S., De Jong, P. J., Dobbelaar, A., \& Bögels, S. M. (1999b). Fear of blushing: Fearful preoccupation irrespective of facial coloration. Behaviour Research and Therapy, 37, 1119-1128.

Mulley, G. P. (1978). Flushing. Journal of the Royal College of Physicians of London, I2, 359-364.

Newman, M. G., Hofmann, S. G., Trabert, W., Roth, W. T., \& Taylor, C. B. (1994). Does behavioral treatment of social phobia lead to cognitive changes? Behavior Therapy, 25, 503-517.

Noyes, R. Jr., Moroz, G., Davidson, J. R. T., Liebowitz, M. R., Davidson, A., Siegel, J., Bell, J., Cain, J. W., Curlik, S. M., Kent, T. A., Lydiard, R. B., Mallinger, A. G., Pollack, M. H., Rapaport, M., Rasmussen, S. A., Hedges, D., Schweizer, E., \& Uhlenhuth, E. H. (1997). Moclobemide in social phobia: A controlled doseresponse trial. Journal of Clinical Psychopharmacology, 17, 247-254.

Öst, L. G. \& Hugdahl, K. (1981). Acquisition of phobias and anxiety response patterns in clinical patients. Behaviour Research and Therapy, 19, 439-447.

Öst, L. G., Jerremalm, A., \& Johansson, J. (1981). Individual response patterns and the effects of different behavioral methods in the treatment of social phobia. Behaviour Research and Therapy, 19, 1-16.

Owen, H. \& Lanning, W. (1982). The effects of three treatment methods upon anxiety and inappropriate attentional style among high school athletes. International Journal of Sport Psychology, 13, 154-162.

Panayiotou, G. \& Vrana, S. R. (1998). Effect of self-focused attention on the startle reflex, heart rate, and memory performance among socially anxious and nonanxious individuals. Psychophysiology, 35, 328-336.

Parker, G. (1979). Reported parental characteristics of agoraphobics and social phobics. British Journal of Psychiatry, 135, 555-560.

Perugi, G., Simonini, E., Savino, M., Mengali, F., Cassano, G. B., \& Akiskal, H. S. (1990). Primary and secondary social phobia: Psychopathologic and familial differentiations. Comprehensive Psychiatry, 31, 245-252. Pitres, A. \& Régis, E. (1897). L'obsession de la rougeur (éreuthophobie). Archives de
Neurologie, 3, 1-26.

Pollentier, S. (1992). Wie aus der Erythrophobie eine soziale Phobie wurde: Eine Ubersicht der klinisch-diagnostischen Problematik. Nervenarzt, 63, 28-33. Rachman, S. (1977). The conditioning theory of fear-acquisition: A critical examination.
Behaviour Research and Therapy, 15, 375-387. 
Rapee, R. M. (1995). Descriptive psychopathology of social phobia. In R. G. Heimberg, M. R. Liebowitz, D. A. Hope, \& F. R. Schneier (Eds.), Social phobia: Diagnosis, assessment, and treatment (pp. 41-66). New York, London: The Guilford Press.

Rapee, R. M. \& Heimberg, R. G. (1997). A cognitive-behavioral model of anxiety in social phobia. Behaviour Research and Therapy, 35, 741-756.

Rapee, R. M. \& Lim, L. (1992). Discrepancy between self- and observer ratings of performance in social phobics. Journal of Abnormal Psychology, 101, 728-731.

Reich, J. \& Yates, W. (1988). Family history of psychiatric disorders in social phobia. Comprehensive Psychiatry, 29, 72-75.

Ribordy, S. C., Tracy, R. J., \& Bernotas, T. D. (1981). The effects of an attentional training procedure on the performance of high and low test-anxious children. Cognitive Therapy and Research, 5, 19-28.

Ringold, A. L. (1994). Paroxetine efficacy in social phobia [letter; comment]. Journal of Clinical Psychiatry, 55, 363-364.

Rosenbaum, J. F., Biederman, J., Hirshfeld, D. R., Bolduc, E. A., \& Chaloff, J. (1991). Behavioral inhibition in children: A possible precursor to panic disorder and social phobia. Journal of Clinical Psychiatry, 52 (Suppl. 11), 5-9.

Rosenbaum, J. F., Biederman, J., Pollock, R. A., \& Hirshfeld, D. R. (1994). The etiology of social phobia. Journal of Clinical Psychiatry, 55, 10-16.

Ruiter, C., de, Rijken, H., Garssen, B., van Schaik, A., \& Kraaimaat, F. (1989). Comorbidity among the anxiety disorders. Journal of Anxiety Disorders, 3, 57-68.

Ryan, T. J. (1973). Structure, pattern and shape of the blood vessels of the skin. In A. Jarrett (Ed.), The physiology and pathophysiology of the skin: The nerves and blood vessels (Vol. 2, ). New York: Academic Press.

Sanderson, W. C., DiNardo, P. A., Rapee, R. M., \& Barlow, D. H. (1990). Syndrome comorbidity in patients diagnosed with a DSM-III-R anxiety disorder. Journal of Abnormal Psychology, 99, 308-312.

Sarason, I. G. (1975). Anxiety and self-preoccupation. In I. G. Sarason \& C. D. Spielberger (Eds.), Stress and anxiety (Vol. 2, pp. 129-151). New York: Hemisphere.

Scheier, M. F. \& Carver, C. S. (1977). Self-focused attention and the experience of emotion: Attraction, repulsion, elation, and depression. Journal of Personality and Social Psychology, 35, 625-636.

Scheier, M. F., Carver, C. S., \& Matthews, K. A. (1983). Attentional factors in the perception of bodily states. In J. T. Cacioppo \& R. E. Petty (Eds.), Social psychophysiology: A sourcebook. New York: Guilford Press.

Schlenker, B. R. \& Leary, M. R. (1982). Social anxiety and self-presentation: A conceptualization and model. Psychological Bulletin, 92, 641-669.

Schneier, F. R., Chin, S. J., Hollander, E., \& Liebowitz, M. R. (1992a). Fluoxetine in social phobia [letter]. Journal of Clinical Psychopharmacology, 12, 62-64.

Schneier, F. R., Goetz, D., Campeas, R., Fallon, B., Marshall, R., \& Liebowitz, M. R. (1998). Placebo-controlled trial of moclobemide in social phobia. British Journal of Psychiatry, 172, 70-77. 
Schneier, F. R., Johnson, J., Hornig, C. D., Liebowitz, M. R., \& Weissman, M. M. (1992b). Social phobia: Comorbidity and morbidity in an epidemiologic sample. Archives of General Psychiatry, 49, 282-288.

Schneier, F. R., Martin, L. Y., Liebowitz, M. R., Gorman, J. M., \& Fyer, A. J. (1989). Alcohol abuse in social phobia. Journal of Anxiety Disorders, 3, 15-23.

Schnenk, J. M. (1967). Blushing and unconscious hostility. Diseases of the Nervous System, $28,679$.

Scholing, A. (1993). Social phobia: Cognitive and behavioural treatment. Doctoral dissertation, Rijksuniversiteit Groningen.

Scholing, A., Bögels, S. M., \& Van Velzen, C. (1995). The Dutch Social Phobia and Anxiety Inventory (SPAI). Authorized translation.

Scholing, A. \& Emmelkamp, P. M. (1990). Social Phobia: Nature and treatment. In H. Leitenberg (Ed.), Handbook of social and evaluation anxiety (pp. 269-324). New York: Plenum Press.

Scholing, A. \& Emmelkamp, P. M. (1993a). Cognitive and behavioural treatments of fear of blushing, sweating or trembling. Behaviour Research and Therapy, 31, $155-170$.

Scholing, A. \& Emmelkamp, P. M. (1993b). Exposure with and without cognitive therapy for generalized social phobia: Effects of individual and group treatment. Behaviour Research and Therapy, 31, 667-681.

Semin, G. R. \& Manstead, A. S. R. (1982). The social implications of embarrassment displays and restitution behaviour. European Journal of Social Psychology, 12, 367-377.

Shearn, D., Bergman, E., Hill, K., Abel, A., \& Hinds, L. (1990). Facial coloration and temperature responses in blushing. Psychophysiology, 27, 687-693.

Shearn, D., Bergman, E., Hill, K., Abel, A., \& Hinds, L. (1992). Blushing as a function of audience size. Psychophysiology, 29, 431-436.

Shields, S. A., Mallory, M. E., \& Simon, A. (1990). The experience and symptoms of blushing as a function of age and reported frequency of blushing. Journal of Nonverbal Behavior, 14, 171-187.

Singer, R. N., Cauraugh, J. H., Murphey, M., Chen, D., \& Lidor, R. (1991a). Attentional control, distractors, and motor performance. Human Performance, 4, 55-69.

Singer, R. N., Cauraugh, J. H., Tennant, L. K., Murphey, M., Chen, D., \& Lidor, R. (1991b). Attention and distractors: Considerations for enhancing sport performances. International Journal of Sport Psychology, 22, 95-114.

Smith, T. W., Ingram, R. E., \& Brehm, S. S. (1983). Social anxiety, anxious selfpreoccupation, and recall of self-relevant information. Journal of Personality and Social Psychology, 44, 1276-1283.

Spitzer, R. L. \& Williams, J. B. W. (1986). Structured clinical interview for DSM-III-R (SCID). New York: New York State Psychiatric Institute, Biometrics Research.

Stein, M. B., Liebowitz, M. R., Lydiard, R. B., Pitts, C. D., Bushnell, W., \& Gergel, I. (1998). Paroxetine treatment of generalized social phobia (social anxiety disorder): A randomized controlled trial. Journal of the American Medical Association, 280, 708-713. 
Stopa, L. \& Clark, D. M. (1993). Cognitive processes in social phobia. Behaviour Research and Therapy, 31, 255-267.

Stopa, L. \& Clark, D. M. (2000). Social phobia and interpretation of social events. Behaviour Research and Therapy, 38, 273-283.

Taylor, J. E., Deane, F. P., \& Podd, J. V. (1999). Stability of driving fear acquisition pathways over one year. Behaviour Research and Therapy, 37, 927-939.

Taylor, S. (1996). Meta-analysis of cognitive-behavioral treatment for social phobia. Journal of Behavior Therapy and Experimental Psychiatry, 27, 1-9.

Telaranta, T. (1998). Treatment of social phobia by endoscopic thoracic sympathicotomy. European Journal of Surgery, Suppl. 580, 27-32.

Templeton, J. L. \& Leary, M. L. (1991). The blush-inducing effect of stares: Evaluation apprehension or visual threat? Paper presented at the meeting of the Southeastern Psychological Association, New Orleans.

The International Multicenter Clinical Trial Group on Moclobemide in Social Phobia (1997). Moclobemide in social phobia: a double-blind, placebo-controlled clinical study. European Archives of Psychiatry and Clinical Neuroscience, 247, 71-80.

Townsley Stemberger, R., Turner, S. L., Beidel, D. C., \& Calhoun, K. S. (1995). Social phobia: An analysis of possible developmental factors. Journal of Abnormal Psychology, 104, 526-531.

Turner, S. M. \& Beidel, D. C. (1989). Social phobia: Clinical syndrome, diagnosis, and comorbidity. Clinical Psychology Review, 9, 3-18.

Turner, S. M., Beidel, D. C., Dancu, C. V., \& Keys, D. J. (1986a). Psychopathology of social phobia and comparison to avoidant personality disorder. Journal of Abnormal Psychology, 95, 389-394.

Turner, S. M., Beidel, D. C., Dancu, C. V., \& Stanley, M. A. (1989). An empirically derived inventory to measure social fears and anxiety: The Social Phobia and Anxiety Inventory. Psychological Assessment: A Journal of Consulting and Clinical Psychology, 1, 35-40.

Turner, S. M., Beidel, D. C., \& Larkin, K. T. (1986b). Situational determinants of social anxiety in clinic and nonclinic samples: Physiological and cognitive correlates. Journal of Consulting and Clinical Psychology, 54, 523-527.

Turner, S. M., Beidel, D. C., \& Townsley, R. M. (1990). Social phobia: Relationship to shyness. Behaviour Research and Therapy, 28, 497-505.

Van Ameringen, M., Mancini, C., \& Streiner, D. (1994). Sertraline in social phobia. Journal of Affective Disorders, 31, 141-145.

Vandereycken, W. \& Pollentier, S. (1986). Erytrofobie of de angst om te blozen - een literatuuroverzicht. Directieve therapie, 6, 36-55.

Versiani, M., Nardi, A. E., Mundim, F. D., Alves, A. B., Liebowitz, M. R., \& Amrein, R. (1992). Pharmacotherapy of social phobia. A controlled study with moclobemide and phenelzine. British Journal of Psychiatry, 161, 353-360.

Von Stockert, F. (1929). Klinik und Ätiologie der Kontaktneurosen. Klinische Wochenschrift, 8, 76-79.

Wegner, D. M. \& Giuliano, T. (1980). Arousal-induced attention to self. Journal of Personality and Social Psychology, 38, 719-726. 
Wells, A. (1990). Panic disorder in association with relaxation induced anxiety: An attentional training approach to treatment. Behavior Therapy, 21, 273-280.

Wells, A., Clark, D. M., \& Ahmad, S. (1998). How do I look with my minds eye: Perspective taking in social phobic imagery. Behaviour Research and Therapy, 36, 631-634.

Wells, A., Clark, D. M., Salkovskis, P., Ludgate, J., Hackmann, A., \& Gelder, M. (1995). Social phobia: The role of in-situation safety behaviors in maintaining anxiety and negative beliefs. Behavior Therapy, 26, 153-161.

Wells, A. \& Matthews, G. (1994). Attention and emotion: A clinical perspective. Hove: Lawrence Erlbaum Associates.

Wells, A., White, J., \& Carter, K. (1997). Attention training: Effects on anxiety and beliefs in panic and social phobia. Clinical Psychology and Psychotherapy, 4, 226-232.

Wicklund, R. A. (1975). Objective self-awareness. In L. Berkowitz (Ed.), Advances in experimental social psychology (Vol. 8, pp. 233-275). New York: Academic Press.

Wilkin, J. K. (1988). Why is flushing limited to a mostly facial cutaneous distribution? Journal of the American Academy of Dermatology, 19, 309-313.

Wilkin, J. K. (1993). The red face: Flushing disorders. Clinics in Dermatology, 11, 211 223.

Wine, J. D. (1971). Test anxiety and direction of attention. Psychological Bulletin, 76, 92-104.

Wine, J. D. (1980). Cognitive-attentional theory of test anxiety. In I. Sarason (Ed.), Test anxiety: Theory, research, and application. Hillsdale, NJ: Erlbaum.

Wittmoser, R. (1985). Treatment of sweating and blushing by endoscopic surgery. Acta Neurochirurgica Wien, 74, 153-154.

Woody, S. R. (1996). Effects of focus of attention on anxiety levels and social performance of individuals with social phobia. Journal of Abnormal Psychology, $105,61-69$. 


\section{Summary}

Social phobia is a serious anxiety disorder. Those suffering from it are characterized by a marked and persistent fear of one or more social or performance situations in which they are exposed to unfamiliar people or to possible scrutiny by others. The individual fears that he or she will act in a way (or show anxiety symptoms) that will be humiliating or embarrassing. The feared social or performance situations are mostly avoided or else endured with a feeling of intense anxiety or distress. The fear and avoidance significantly interfere with the person's normal routine, occupational (academic) functioning, or social activities or relationships, or there is a marked distress about having the phobia.

The majority of social phobics are troubled by all sorts of bodily symptoms while anticipating and/or enduring social situations, such as palpitations, blushing, trembling, and sweating. However, the fear of negative evaluation, that characterizes social phobia, may also relate specifically to these bodily symptoms. That is, the patient may be afraid of being negatively evaluated because of his/her blushing. In that case, we speak of erythrophobia or fear of blushing. If a person does not blush, he/she will not be suffering from social phobia. At least, that is what most blushing phobics believe. Fear of blushing is the subject of this dissertation.

First some remarks about blushing, the bodily symptom that is the central feature in fear of blushing. Blushing refers to the spontaneous reddening or darkening of the face, the ears, the neck, and the upper chest that occurs in response to perceived social scrutiny or evaluation. It occurs when the small blood vessels of this so-called 'blush-region' dilate, increasing the blood volume in this area. Why blushing typically occurs in this blush region and not elsewhere in the body, is probably due to a combination of factors, such as visibility on site - as blood vessels in the face lie nearer to the surface than elsewhere in the body - and the supposed differential composition of the vascular system in the face and that elsewhere in the body. The conditions under which people tend to blush are somewhat clearer: they may involve threats to the public identity, compliments and other forms of positive attention, scrutiny or staring looks, and accusations of blushing.

Furthermore, theories have been formulated about why people blush. The conditions under which people tend to blush might tell us more about the reasons for blushing. That is, blushing seems to occur especially when people feel that they are in the centre of attention and are concerned with what has happened. Blushing as a communicative function would have remedial effects in this case. From this point of view, blushing should vary along the extent to which one is aware of an incident and the extent to which one lives up to certain social rules. In a model, the factors that might lead to blushing, are brought together (see Chapter 1).

Chapter 2 further examines social phobia and fear of blushing. Among other things, attention is given to the history of the diagnosis, to epidemiologic characteristics, comorbidity, and consequences of the disorder. Several theories aim to explain the 
etiology and the maintenance of fear of blushing. It seems plausible that a biological vulnerability to blush relatively easily/intensely plays a role in the development of fear of blushing. However, the experience of negative learning experiences with regard to blushing, the holding of dysfunctional thoughts (cognitions) about blushing, and the tendency to direct the attention to oneself and to the blushing in social situations do not seem unimportant. In a heuristic model, all these potential causal and maintaining factors are assembled and connected. The model assumes that fear of blushing stems from holding dysfunctional cognitions about blushing and social situations and/or having experienced negative learning experiences with regard to blushing. Besides, a biological vulnerability to blush relatively easily/intensely might facilitate having negative learning experiences (e.g. there might be a greater chance of being bullied because of one's blushing). Once a person has developed fear of blushing, this fear might be maintained by the person's tendency to direct his/her attention towards the self (and the potential blushing), which causes self-evaluation ("Am I coming across the way I want to/ should?"). In case the person (thinks that he/she) is not coming across in the desired way, and when there are certain beliefs about how one should behave (e.g. "I ought not blush in this situation"), the fear will be maintained. Four research questions refer to the above issues (see Chapter 3 ).

Concerning the treatment of fear of blushing, several - more or less effective alternatives can be chosen. These consist of biological methods (surgical techniques and psychopharmacological treatment), and cognitive-behavioural methods. Given the room for improvement of therapeutical methods, and considering the suggestions in the heuristic model, application of attention techniques seems to be an appropriate addition or alternative for the existing treatments. Consequently, a new treatment method, called Task Concentration Training (TCT) has been developed. This technique is based on blushing phobics' supposed tendency to direct their attention too much to themselves during social interactions. The aim is to teach blushing phobics to redirect their attention externally and to the task more often. Two research questions refer to treatment issues (see Chapter 3).

Section 4.1 describes an experiment, examining the matter that a high blushing propensity might be a vulnerability factor for the development of fear of blushing. Indeed, self-reported blushing propensity and fear of blushing are strongly associated. However, it is unclear how accurate self-reports about blushing are. For this experiment, subjects who scored high or low on a questionnaire that aims to measure blushing propensity, were invited to the laboratory twice. In the first session, they sang a song ('Lang zal 'ie/ze leven') which was taken on video; in the second session they were shown the video fragment in the presence of two male confederates while blushing was objectively measured by means of a photoplethysmograph. Obviously, subjects were ignorant about the fact that they were going to watch their own video recording. Besides the 'sing' video, they were shown a baseline video (a steady test card) and a general arousal-inducing video
(the shower murder scene from Hitchcock's $P_{s y c h o}$ ). It appeared that subjects, high and
low in blushing propensity, did not differ with respes low in blushing propensity, did not differ with respect to physiological indices of blushing, whereas they did with regard to their self-reported blush intensity: high scoring subjects indicated that they had blushed more intensely than the low scoring group. This lead to the conclusion that people with high blushing propensity overestimate their blush intensity, and that self-reports about blushing are perhaps not accurate. 
Section 4.2 describes an experiment which further explores the theme in Section 4.1, that high blushing propensity might be a vulnerability factor for developing fear of blushing. In the study in Section 4.1, subjects high or low in blushing propensity were asked to participate. Although there is a strong association between self-reported blush intensity and fear of blushing, there is no perfect correlation. Therefore, in Section 4.2, individuals high and low in fear of blushing were subjected to similar tests as described in Section 4.1. Additionally, a mild social stressor was added (watching the test card in the presence of two male confederates), to rule out the possibility that an absence of differential physiological reactions would be due to a ceiling effect in blushing reactions. The results of this study were, however, comparable with those in the first study: no differences between the groups with respect to physiological indices of blushing, but significant differences regarding self-reports. Again, this lead to the suggestion that blushing fearful individuals overestimate their blush intensity. These findings suggest that people have difficulties to reliably estimate their blushing intensity, and, furthermore, they dispute the validity of instruments such as the Blushing Propensity Scale (BPS). Since the high scoring individuals in both experiments also scored higher on a measure of fear of blushing, it is suggested that fear of blushing is based on a fearful preoccupation, rather than on differences in objective blushing intensity.

Section 4.3 describes two studies investigating the learning history of individuals high and low in fear of blushing. In the first study, high and low blushing fearful students filled out a questionnaire, inquiring into conditioning experiences, vicarious learming, and informational learning in connection with blushing. For example, individuals were asked whether they had ever had a nasty experience because of blushing, whether they had ever observed in family members or close friends that they were afraid to blush, and whether they had ever heard/seen/ read negative things about blushing in the media. Individuals completed these questions with 'yes' or 'no'. In the second study, blushing fearful individuals who had applied for treatment and a matched control group, were interviewed using the same questionnaire. In this study, however, there were strict rules concerning the classification of a certain incident as a conditioning experience, vicarious learning experience, and informational learning experience. That is, individuals were asked to report a specific memory with regard to each type of learning experience. In both studies, individuals high in fear of blushing more often reported negative learning experiences in connection with blushing than individuals low in fear of blushing. However, these percentages were remarkably lower in the second (interview) study. Although there seems to be evidence for the role of negative learning experiences in the development of fear of blushing, warnings are given with respect to the retrospective character of both studies. Possibly, high fearful individuals are more biased in their attention, interpretation, and memory of negative events in connection with blushing, because now they are troubled by it. Moreover, the use of strict instruments (interview in which specific experiences should be reported) is preferred above the potential less valid 'yes'/'no' questionnaire system.

Section 4.4 discusses the part of the heuristic model relating to negative cognitions. Individuals with fear of blushing have negative thoughts about blushing. However, since nobody actually enjoys blushing, it seemed interesting to investigate non-fearful 
individuals' ideas about blushing. Therefore, 'normal' individuals (men and women) were asked to write down their thoughts about blushing. These thoughts concerned situations in which they saw a man blushing, in which they saw a woman blushing, and in which they blushed themselves. In addition, they were asked what they thought other people (men and women) would think about them when they themselves blushed. It appeared that normal individuals reported predominantly negative thoughts about blushing, in other people as well as in themselves. Remarkably, both men and women judged blushing less negatively when the actor was someone of the opposite sex than when it was someone of their own sex. Although normals, apparently, also have negative thoughts about blushing (like blushing fearfuls do), they might still differ from blushing phobics with regard to other characteristics. That is, blushing phobics might overestimate the frequency and/or the intensity of their blushing, and the (social) consequences of their blushing, and underestimate themselves and their possibilities. The implications of these findings for cognitive therapy are discussed in Section 4.4.

Sections 4.5 and 4.6 address the assumption that blushing phobics direct too much attention to themselves in social situations. A treatment (Task Concentration Training, TCT) has been developed, which aims at teaching blushing phobics to redirect their attention; more toward the task and the environment, and less toward themselves and potential blushing. In two studies, the effects of TCT on fear of blushing were investigated. Section 4.5 describes a case study in which the patient is instructed to direct the attention outward and inward, alternately (per week). Section 4.6 describes a treatment study in which six sessions of TCT are compared to six sessions of Exposure in Vivo. In this treatment study, self-reports about fear of blushing were used, as well as objective indices of blushing before and after the treatment (as established during two behavioural tests). Follow-up measurements took place after six weeks and after one year. Half of the patients served as a waiting-list control group. The results indicated that both treatments were effective, but that TCT was somewhat more effective in the long term with regard to decreasing negative cognitions about blushing. Furthermore, it appeared that there was no decrease in actual blushing after treatment. This might implicate that six weeks are too short a period to decrease blushing, that because of the nature of the behavioural tests, these might invariably elicit/ provoke blushing, but also that actual blushing was not as bad as expected before the treatment, which implies that there is not much room for improvement. Nevertheless, TCT might be a welcome addition to the existing behaviouralcognitive repertoire.

In the model, some changes have taken place, based on the reported investigations. However, it should be noted that, since not all components of the model have been investigated, these are merely suggestions, as yet. In the new model, 'a fearful preoccupation' has a more prominent place, beside the role cognitions play with regard to blushing. There seems to be no physiological difference between blushing phobics and non-phobics. The earlier component 'blushing' might preferably be named 'overrepresentation of blushing'. 


\section{Samenvatting}

Sociale fobie is een ernstige angstklacht. Degene die lijdt aan deze stoornis is voortdurend bang in één of meerdere situaties waarin hij/zij sociaal moet functioneren of iets moet presteren en waarbij hij/zij blootgesteld wordt aan onbekenden of een mogelijke kritische beoordeling door andere mensen. De betrokkene is bang dat hij/zij zich op een manier zal gedragen (of angstverschijnselen zal tonen) die vernederend of beschamend is. Meestal gaat de angst gepaard met vermijding van deze sociale situaties of worden deze doorstaan met intense angst. De angst en vermijding belemmeren in belangrijke mate de normale dagelijkse routine, het beroepsmatig functioneren (of studie of school), of sociale activiteiten of relaties met anderen, of er is een duidelijk lijden vanwege het hebben van de fobie.

De meeste sociaal-fobici hebben last van allerlei lichamelijke verschijnselen in afwachting van en/of tijdens sociale situaties, zoals hartkloppingen, blozen, trillen en zweten. Echter, de angst voor negatieve beoordeling, die kenmerkend is voor sociale fobie, kan ook voornamelijk betrekking hebben op deze lichamelijke reacties. Dat wil zeggen, de angst om te blozen kan het onderwerp zijn (geworden) van de sociale fobie; men is bang negatief beoordeeld te worden vanwege blozen. We spreken dan van bloosangst. Als iemand geen last zou hebben van blozen, zou hij/zij geen last hebben van sociale fobie. Althans, dat is wat de meeste mensen met bloosangst menen. Bloosangst is het onderwerp van dit proefschrift.

Maar eerst iets over blozen, het lichamelijke verschijnsel waar het om draait bij bloosangst. Met blozen wordt bedoeld het spontaan rood worden van het gezicht, de oren, de nek en de borst als reactie op het ervaren van een kritische blik of sociale evaluatie. Blozen treedt op wanneer de kleine bloedvaten in dit 'bloosgebied' zich verwijden, waardoor zich hier meer bloed ophoopt. Waarom blozen nou juist in de bloosregio plaatsvindt en niet elders in het lichaam, is waarschijnlijk het gevolg van een combinatie van factoren. Zoals zichtbaarheid ter plekke, onder meer omdat bloedvaatjes in het gezicht dichter aan de oppervlakte liggen dan bloedvaatjes elders in het lichaam, en het veronderstelde verschil in samenstelling van het vaatstelsel in het gezicht en dat elders in het lichaam. Iets duidelijker zijn de omstandigheden waaronder mensen plegen te blozen: bedreiging van de publieke identiteit, complimenten en andere vormen van positieve aandacht, kritisch bekeken of aangestaard worden, en beschuldigd worden van blozen. Voorts zijn er theorieën over het waarom van blozen. Het lijkt erop dat de omstandigheden waaronder mensen zoal blozen ons meer kunnen vertellen over de redenen van blozen. Dat wil zeggen, blozen lijkt vooral voor te komen in situaties waarin mensen zich in het centrum van de aandacht voelen staan en begaan zijn met wat er gebeurd is. Blozen als communicatieve functie zou dan een remediërende werking hebben. Blozen zou in deze optiek moeten variëren met de mate waarin men zich bewust 
is van een incident en met de mate waarin men er bepaalde sociale regels op na houdt. In een model worden deze factoren die zouden leiden tot het optreden van blozen, samengebracht (zie hoofdstuk 1).

Hoofdstuk 2 gaat vervolgens in op sociale fobie en de angst om te blozen. Onder meer is er aandacht voor de geschiedenis van de diagnose, voor epidemiologische kenmerken, comorbiditeit en gevolgen van de stoornis. Er zijn diverse theorieën die trachten de etiologie en instandhouding van bloosangst te verklaren. Zo lijkt het aannemelijk dat een eventuele biologische kwetsbaarheid om sneller/intenser te blozen een rol speelt bij de ontwikkeling van bloosangst. Maar ook het meemaken van negatieve leerervaringen met betrekking tot blozen, het er op na houden van disfunctionele gedachten (cognities) over blozen, en de neiging de aandacht steeds op zichzelf en het mogelijke blozen te richten in sociale situaties lijken niet onbelangrijk. In een heuristisch model zijn alle factoren die mogelijk van belang zijn voor het ontstaan en de instandhouding van bloosangst bij elkaar gebracht en met elkaar verbonden. Het model veronderstelt dat bloosangst voortkomt uit het hebben van disfunctionele opvattingen over blozen en sociale situaties en/of het hebben meegemaakt van aversieve gebeurtenissen met betrekking tot blozen. Een biologische kwetsbaarheid om makkelijk/ intens te blozen zou een faciliterende werking kunnen hebben op het meemaken van aversieve ervaringen met blozen (bijv. eerder met blozen gepest worden). Wanneer men eenmaal bang is om te blozen, zou deze angst in stand gehouden worden door de neiging van de betrokkene steeds de aandacht op zichzelf te richten (en het mogelijke blozen), hetgeen zorgt voor zelf-evaluatie ("Kom ik over zoals ik over wil/ moet komen?"). Wanneer men niet overkomt (of denkt over te komen) zoals men wenst, en men heeft bepaalde opvattingen over hoe men zou moeten overkomen (bijv. met betrekking tot blozen: "Ik hoor niet te blozen in deze situatie"), blijft de angst in stand. Een viertal onderzoeksvragen in Hoofdstuk 3 richt zich op bovenstaande kwesties.

Wat betreft de behandeling van bloosangst bestaat er een aantal strategieën, meer of minder effectief, die kunnen worden toegepast. Deze technieken behelzen biologische technieken (operatieve technieken en psychofarmaca) en cognitief-gedragstherapeutische technieken. Gezien de ruimte voor verbetering van technieken en gezien de suggesties in het heuristisch model, lijkt het toepassen van aandachtstechnieken een mogelijke aanvulling of een alternatief op de bestaande behandelmethoden. Een nieuwe behandeling, genaamd Taakconcentratietraining (TCT), is dan ook ontwikkeld. Deze techniek is gebaseerd op de veronderstelde neiging van bloosangstigen zich tijdens sociale interacties te veel op zichzelf te richten en stelt zich ten doel bloosangstigen te leren hun aandacht weer meer naar buiten en op de taak te richten. Een tweetal onderzoeksvragen in Hoofdstuk 3 focust op de effectiviteit van TCT als behandeling bij bloosangst (zie Hoofdstuk 3).

Sectie 4.1 beschrijft een experiment dat inhaakt op de kwestie dat een hoge bloosgeneigdheid een mogelijke kwetsbaarheidsfactor voor de ontwikkeling van bloosangst is. Inderdaad zijn zelfgerapporteerde bloosgeneigdheid en bloosangst sterk geassocieerd. Het is echter niet duidelijk hoe accuraat zelfrapportage over blozen is. Voor het experiment werden proefpersonen geselecteerd die hoog of laag scoorden op 
een vragenlijst die bloosgeneigdheid beoogt te meten. $\mathrm{Zij}$ werden tweemaal uitgenodigd: in de eerste sessie zongen zij een liedje ('Lang zal 'ie/ze leven'), in de tweede sessie werd hen dit fragment getoond in het bijzijn van twee mannelijke assistenten terwijl blozen objectief werd gemeten met een fotoplethysmograaf. Uiteraard wisten de proefpersonen niet dat zij hun eigen opname zouden terugzien. Naast het zangfilmpje werd ook een baseline video getoond (testbeeld) en een stukje film dat spanning zou opwekken in het algemeen (de douchemoordscène uit Hitchcocks Psycho). Het bleek dat de hoog en laag bloosgeneigde proefpersonen niet van elkaar verschilden wat betreft de fysiologische indices van blozen, maar wel in zelfgerapporteerde bloosintensiteit: de hoog scorende groep gaf aan sterker gebloosd te hebben dan de laag scorende groep. Dit gegeven leidde tot de conclusie dat hoog bloosgeneigde personen hun bloosintensiteit overschatten en dat zelfrapportage met betrekking tot blozen wellicht niet accuraat is.

Sectie 4.2 beschrijft een studie die voortborduurt op het thema in Sectie 4.1, namelijk dat een hoge bloosgeneigdheid een kwetsbaarheidsfactor zou kunnen zijn voor het ontwikkelen van bloosangst. In de eerste studie werden hoog bloosgeneigden uitgenodigd mee te werken. Hoewel een hoge zelfgerapporteerde bloosgeneigdheid sterk correleert met bloosangst, bestaat er geen perfecte samenhang. Daarom werden voor het tweede experiment hoog en laag bloosangstige individuen onderworpen aan vergelijkbare tests als beschreven in Sectie 4.1; daarnaast werd er nog een mildere sociale stressor toegevoegd (het bekijken van testbeeld in de aanwezigheid van twee mannelijke assistenten), om uit te sluiten dat een mogelijke afwezigheid van verschillen in bloosintensiteit toe te schrijven zou zijn aan een plafondeffect wat betreft bloosreacties. De resultaten van deze studie waren echter vergelijkbaar met de resultaten van de eerste studie: geen verschillen tussen beide groepen wat betreft de fysiologische indices van blozen, wel op zelfrapportage. Wederom leidde dit tot de suggestie dat hoog bloosangstigen hun bloosintensiteit overschatten. Deze bevindingen suggereren dat mensen het moeilijk vinden om hun bloosintensiteit betrouwbaar in te schatten en trekken voorts de validiteit van instrumenten zoals de BPS (Blushing Propensity Scale) in twijfel. Aangezien de hoogscoorders in beide experimenten ook hoger scoorden op een maat voor bloosangst, wordt gesuggereerd dat bloosangst veeleer berust op een angstige preoccupatie dan op verschil in objectieve bloosintensiteit. Wellicht speelt de factor bloosgeneigdheid dan ook niet zo'n belangrijke rol in het ontstaan van bloosangst.

Sectie 4.3 beschrijft een tweetal studies waarin wordt nagegaan in hoeverre hoog en laag bloosangstigen negatieve leerervaringen met betrekking tot blozen hebben meegemaakt. In de eerste studie vulden hoog en laag bloosangstige studenten een vragenlijst in die betrekking heeft op conditionerende ervaringen, leren door observatie, en leren door informatieoverdracht. Zo werd er bijvoorbeeld gevraagd of men ooit een vervelende gebeurtenis vanwege blozen had meegemaakt, of men ooit bij familie of goede vrienden had geobserveerd dat zij bang waren om te blozen, en of men ooit negatieve zaken over blozen had gezien/gehoord/gelezen in de media. Men antwoordde door ja of nee in te vullen. In de tweede studie werd bij bloosangstige patiënten die zich aangemeld hadden voor een behandelstudie en aan een gematchte controlegroep deze vragenlijst als interview afgenomen. Hierbij golden echter strengere regels bij het 
classificeren van een bepaalde gebeurtenis als conditionerende ervaring, model-leren, en informatie-leren. De proefpersoon werd namelijk gevraagd een specifieke herinnering op te halen aan de betreffende soorten van leren. In beide studies rapporteerden hoog bloosangstigen vaker negatieve leerervaringen te hebben meegemaakt in relatie met blozen dan laag bloosangstigen. De percentages waren echter aanmerkelijk lager in de tweede (interview)studie. Hoewel er evidentie lijkt te zijn voor de rol van negatieve leerervaringen in het ontstaan van bloosangst, wordt ook gewaarschuwd voor het retrospectieve karakter van de beide studies. Mogelijk zijn hoog bloosangstigen meer bevooroordeeld in hun aandacht, interpretatie en herinnering van negatieve gebeurtenissen waarbij blozen een rol speelde, omdat ze nu - achteraf - hiermee een probleem hebben. Bovendien wordt het gebruik van strikte methodes (interview met specifieke ervaringen) geprefereerd boven het mogelijk minder valide 'ja/nee'vragenlijstsysteem.

Sectie 4.4 behandelt het gedeelte in het heuristisch model dat betrekking heeft op negatieve cognities. Bloosangstigen hebben negatieve gedachten over blozen. Echter, aangezien niemand het echt prettig vindt om te blozen, leek het interessant om te onderzoeken hoe niet-bloosangstigen tegen blozen aankijken. Daarom werd aan 'normale' individuen (mannen en vrouwen) gevraagd hun gedachten over blozen op te schrijven. Deze gedachten betroffen situaties waarin zij een man zagen blozen, een vrouw zagen blozen, en waarin ze zelf bloosden. Daarnaast werd hen gevraagd wat ze meenden dat anderen (mannen en vrouwen) over hen dachten wanneer zij zelf bloosden. Het bleek dat normalen vooral negatieve gedachten over blozen rapporteerden, zowel waar het blozen bij anderen betrof als bij zichzelf. Opmerkelijk was dat mannen en vrouwen blozen minder negatief vonden wanneer de blozer iemand van het andere geslacht was. Hoewel normalen blijkbaar ook negatief over blozen denken, kan het toch zo zijn dat zij zich van bloosangstigen onderscheiden met betrekking tot andere kenmerken. Bloosangstigen overschatten mogelijk de frequentie en/of de intensiteit van hun blozen, overschatten de (sociale) consequenties van hun blozen, en onderschatten hun eigen mogelijkheden. De implicaties van deze bevindingen voor cognitieve therapie worden in Sectie 4.4 besproken.

Secties 4.5 en 4.6 richten zich op de veronderstelling dat bloosangstigen hun aandacht te veel op zichzelf zouden richten in sociale situaties. Er is een behandeling ontwikkeld (Taakconcentratietraining, TCT) die beoogt bloosangstigen te leren hun aandacht weer meer op de taak en de omgeving te richten, en minder op zichzelf en het mogelijke blozen. In een tweetal studies is de effectiviteit van TCT bij bloosangst onderzocht. Sectie 4.5 behandelt een gevalsstudie waarbij de patiënt geïnstrueerd werd de aandacht afwisselend naar binnen en naar buiten te richten (afgewisseld per week). Sectie 4.6 beschrijft een behandelstudie waarbij 6 weken TCT met 6 weken Exposure in Vivo werd vergeleken bij bloosangstige patiënten. In deze behandelstudie werd, naast zelfrapportage over bloosangst, ook objectief blozen voor en na de behandeling gemeten gedurende een tweetal gedragstests. Er vonden follow-up-metingen van de vragenlijsten plaats na 6 weken en na 1 jaar. De helft van de patiënten diende als wachtlijstcontroleconditie. De resultaten wezen uit dat beide therapieën effectief waren, maar dat TCT op 
de langere termijn beter leek in het verminderen van negatieve cognities met betrekking tot blozen. Voorts kwam naar voren dat er geen vermindering optrad in het daadwerkelijke blozen na behandeling. Dit zou kunnen impliceren dat 6 weken een te korte tijd is om blozen te doen verminderen, dat de gedragstests onveranderlijk blozen zouden uitlokken vanwege de aard van de opdrachten, maar ook dat het daadwerkelijk blozen vóór de therapie al meeviel en er weinig ruimte voor verbetering was. TCT is mogelijk een welkome aanvulling op het bestaande cognitief-gedragstherapeutische repertoire.

In het model heeft een aantal wijzigingen plaatsgevonden op basis van de gerapporteerde onderzoeken. Daarbij moet echter worden aangetekend dat, aangezien niet alle componenten van het model onderzocht zijn, het vooralsnog gaat om suggesties. In het nieuwe model heeft een 'angstige preoccupatie' een prominente plaats ingenomen naast de rol van cognities met betrekking tot blozen. Een fysiologisch verschil tussen wel- en niet-bloosangstigen lijkt niet aan de orde. Bij de vroegere component 'blozen' lijkt het eerder om een 'overrepresentatie van blozen' te gaan. 


\section{Dankwoord}

Indien $u$ zich op enigerlei wijze verdiept heeft in het voorgaande, zal het $u$ niet verbazen dat veel mensen hebben bijgedragen aan de totstandkoming ervan. Een woord van dank is op zijn plaats.

Marcel van den Hout, promotor, slechts zo nu en dan vroeg ik je iets te lezen van mijn hand, omdat ik - zoals je terecht opmerkte - immers gezegend was met twee kanjers van co-promotoren. Toch had je steeds duidelijk en bruikbaar commentaar. Niettemin was ik ietwat huiverig voor je mening toen ik je plotsklaps mijn hele proefschrift in één keer kwam aanbieden. Je wijze helikopterblik maakte het mij echter mogelijk op het laatst nog enkele waardevolle verbeteringen aan te brengen.

Over naar deze kanjers van co-promotoren. De luxe van het hebben van twee begeleiders is minstens dat er altijd wel iemand beschikbaar is. Daarbij is het verrijkend om vanuit meerdere gezichtspunten naar een kwestie te kijken. Hetgeen meteen ook het enige nadeel is, aangezien de promovendus vervolgens een compromis moet verzinnen! Daarenboven is het extreem handig gebruik te kunnen maken van de expertise van alletwee de begeleiders.

Susan Bögels, jij was altijd het aanspreekpunt voor de klinische aangelegenheden en nog veel meer. Ik heb niet alleen als beginnend onderzoeker veel van je geleerd, maar ook als therapeut in opleiding bij de Riagg. Je gaf me steeds de indruk dat alles mogelijk was, ook wanneer ik hiervan nog niet overtuigd was. Jouw lichtvoetige en soms wat gehaaste "Dan doe je dit toch gewoon nog even zus of zo" deed me meer en meer concluderen dat 'even' een relatief begrip is. Maar dat 'even' ging ook mij gelukkig steeds beter af! Uiteindelijk ben ik een optimistischer mens geworden. Dank hiervoor!

Peter de Jong, jij was de supervraagbaak op het gebied van psychofysiologie en eigenlijk ook alles wat daar niets mee te maken had. Al in mijn studententijd keek ik tegen jou op; je wist op bijna alles een oplossing te verzinnen, klaarde een klus in minder dan geen tijd en deed dat dan met een grenzenloos enthousiasme. Je was een goede leermeester; altijd alert en immer kritisch. En steeds in voor nieuwe ideeën. Ik vond het geweldig dat je me mijn gang liet gaan met het aio-voorstel; de meeste studies zijn daar immers niet uit voortgekomen. Heel veel dank!

De studies in dit proefschrift waren zeker niet tot stand gekomen zonder de onontbeerlijke hulp van vele proefpersonen en cliënten. Lieve mensen, wat moesten jullie soms afschuwelijke dingen doen: een liedje zingen voor de camera (en dat dan ook nog terugzien in het bijzijn van starende assistenten), gesprekken houden met mensen die minimaal reageerden, en meer van zulke ellende. Dergelijke opdrachten waren zelfs voor de niet-bloosangstigen onder jullie heel spannend. Jullie waren ontzettend moedig! Ook jaarwerkstuk- en scriptiestudenten, therapeuten, en 'stooges' horen in dit rijtje thuis. Zonder jullie was het niet mogelijk geweest alle data te verzamelen. Mijn oprechte dank! 
Zonder statistische hulp had ik me waarschijnlijk maar slecht kunnen redden. Erik Schouten, je had altijd tijd (ook als je die niet had), en je lachte me nooit uit vanwege mijn gekke vragen. Vrijwel onmiddellijk begreep je waar ik het over had, hetgeen de drempel om langs te komen nog verder verlaagde. Mag ik je zo nu en dan nog eens storen met 'een vraagje'? Ook Theo van Aerts en Annie Raven ben ik dank verschuldigd voor de technische hulp, dan wel de hulp bij het invoeren van vrij veel cijfertjes.

Collega's van het Departement Met Steeds Een Andere Naam, in het bijzonder Guus Smeets en Iris Engelhard, bedankt voor de vele leuke (mail)momenten! Collega's tijdens de Riagg-tijd, bedankt voor jullie steun en gezelligheid. Alle nieuwe fijne collega's, met name Anita, Brigitte, Marieke en Remco, heel veel dank voor jullie geduld; ik kon me lange tijd niet ten volle op jullie projecten storten. Daar gaat snel verandering in komen!

Judith en Birgit, paranimfen, we hebben al heel wat lief en leed gedeeld. Ik vind het super dat jullie naast me willen staan tijdens het tot nu toe wellicht spannendste uur van mijn leven! Lieve ouders, gefeliciteerd met jullie $33^{e}$ trouwdag! Bedankt voor jullie steun aan en interesse in mijn bezigheden, ook al was het niet altijd duidelijk waar het nu weer over ging. Ik kon altijd merken dat jullie trots waren. Lieve broer Mark: mijn opstel is eindelijk af! Vind je het leuk geworden? Familie en vrienden, bedankt voor de nimmer aflatende belangstelling voor de vorderingen van mijn boekje. Lieve Amaury, bedankt voor het vele wachten, je lekkere maaltijden, je eindredactie en je leuke, her en der opgevangen opmerkingen die ik wél bij mijn cliënten gebruikte, maar slechts moeilijk op mezelf kon toepassen: "Wat is nou het ergste dat er kan gebeuren?" 


\section{Curriculum Vitae}

Sandra Mulkens werd op 17 September 1970 in Bunde geboren. In 1988 behaalde zij het diploma Gymnasium- $\alpha$ aan het College Sittard, waarna zij Gezondheidswetenschappen ging studeren aan de Universiteit Maastricht. In 1993 behaalde zij het doctoraal diploma van de afstudeerrichting Geestelijke Gezondheidkunde. Vervolgens was zij van 1994 tot 1998 aangesteld als Assistent in Opleiding (AiO) bij het Departement Medische, Klinische en Experimentele Psychologie van de Universiteit Maastricht, met een detachering naar de Riagg Maastricht. Deze aanstelling mondde uit in het schrijven van dit proefschrift. Parallel aan het AiO-schap startte zij in 1994 met de VGT-opleiding tot gedragstherapeut en in 1998 met de RINO-opleiding tot psychotherapeut. Inmiddels heeft zij het gewone lidmaatschap van de Vereniging voor Gedragstherapie behaald (juli 1999) en is zij geregistreerd Gezondheidszorgpsycholoog (augustus 1999). Na haar AiOaanstelling werd zij tijdelijk universitair docent bij bovengenoemd departement en werkte zij tijdelijk als gedragstherapeut bij de Riagg OZL te Heerlen. Sinds januari 2000 heeft zij een vaste aanstelling als psychotherapeut/ universitair docent bij de Capaciteitsgroep Experimentele Psychologie van de faculteit Psychologie, Universiteit Maastricht. Aldaar heeft zij therapie-, onderzoeks- en onderwijstaken. Het onderzoek en de therapeutische werkzaamheden concentreren zich op het gebied van verslaving en eetstoornissen. In 2001 kan zij zich als psychotherapeut laten registreren.

\section{Publicatielijst}

Mulkens, A.A.N., Bögels, S.M., \& De Jong, P.J. (1994). How irrational are blushing phobics' beliefs about blushing? Lezing, gehouden op het $24 \mathrm{e}$ Congress of the European Association for Behavioural and Cognitive Therapies, 6-10 september 1994, Corfu, Griekenland.

Mulkens, S. (1994). Selectieve aandacht en sociale angst: Een onderzoek met de gemodificeerde Stroop-taak. Lezing, gehouden op de Najaarsconferentie van de Vereniging voor Gedragstherapie, 3-4 november 1994, Dalfsen.

Mulkens, A.A.N., Bögels, S.M., \& De Jong, P.J. (1995). Attentional Training: A new therapy for fear of blushing. Poster, gepresenteerd op het World Congress of Behavioural and Cognitive Therapies, 10-15 juli 1995, Kopenhagen, Denemarken.

Bögels, S.M., Mulkens, S., \& De Jong, P.J. (1995). Overmatig zelfbewustzijn en taakconcentratie: een nieuw model voor de behandeling van bloosangst. Gedragstherapie, 28, 153-174. 
Mulkens, S. (1995). Waarom blozen mensen eigenlijk? De Psycholoog, 30, 490-495.

Mulkens, S. (1996). Een hoofd als een boei... Over het fenomeen blozen. Psychoskoop, 7, 28-35.

Mulkens, S., De Jong, P.J., \& Merckelbach, H. (1996). Disgust and spider phobia. Journal of Abnormal Psychology, 105, 464-468.

Bögels, S.M. \& Mulkens, S. (1997). Protocollaire behandeling van patiënten met een sociale fobie: Taakconcentratietraining en cognitieve therapie. In: Keijsers, G.P.J., van Minnen, A., \& Hoogduin, C.A.L. (Red.). Protocollaire behandelingen in de ambulante geestelijke gezondheidszorg (pp.127-157). Houten/ Diegem: Bohn Stafleu Van Loghum.

Bögels, S.M., Mulkens, S., \& De Jong, P.J. (1997). Task concentration training and fear of blushing. Clinical Psychology and Psychotherapy, 4, 251-258.

Mulkens, S., De Jong, P.J., \& Bögels, S.M. (1997). High blushing propensity: Fearful preoccupation or facial coloration? Personality and Individual differences, 22, 817-824.

Arrindell, W.A., Mulkens, S., Kok, J., \& Vollenbroek, J. (1999). Disgust sensitivity and the sex difference in fears to common indigenous animals. Behaviour Research and Therapy, 37, 273-280.

Mulkens, S., De Jong, P.J., Dobbelaar, A., \& Bögels, S.M. (1999). Fear of blushing: Fearful preoccupation irrespective of facial coloration. Behaviour Research and Therapy, 37, 1119-1128.

Mulkens, S., Bögels, S.M., \& De Jong, P.J. (1999). Attentional focus and fear of blushing: A case study. Behavioural and Cognitive Psychotherapy, 27, 153-164.

Mulkens, S., Bögels, S.M., \& De Jong, P.J. (1999). Learning history in fear of blushing. Behaviour Research and Therapy, 37, 1159-1167.

Mulkens, S., Bögels, S.M., De Jong, P.J., \& Louwers, J. (1998). Fear of blushing: Effects of task concentration training versus exposure in vivo on fear and physiology. Submitted for publication. 